Ocean Sci. Discuss., https://doi.org/10.5194/os-2017-54

Manuscript under review for journal Ocean Sci.

Discussion started: 1 August 2017

\title{
Definitive evidence of the Mediterranean Outflow heterogeneity. Part 3: at the Strait of Gibraltar exit
}

\author{
Claude Millot ${ }^{1}$, Mikhail Emelianov ${ }^{2}$ \\ ${ }^{1}$ Les Katikias, 83150 Bandol, France \\ $5 \quad{ }^{2}$ Institut de Ciències del Mar, CSIC, Pg. Marítim de la Barceloneta 37-49, 08003 Barcelona, Spain \\ Correspondence to: Claude Millot (ailesetiles@gmail.com)
}

Abstract. We have pursued, in Parts 1 and 2, the re-analysis of the 1985-1986 GIBEX CTD data we initiated in the mid 2000's with a focus on the Mediterranean Outflow (MO) heterogeneity. At the Strait entrance (Part 1), a

10 transect $\left(5^{\circ} 40^{\prime} \mathrm{W}\right)$ and a yo-yo time series $\left(5^{\circ} 43^{\prime} \mathrm{W}\right)$ show Mediterranean Waters (MWs) markedly stratified into relatively homogeneous layers where intense mixing processes occur, hence definitively showing that the MO there is composed of four-five different and essentially superimposed components. Within the Strait (Part 2), five north-south transects at both $5^{\circ} 50^{\prime} \mathrm{W}$ and $6^{\circ} 05^{\prime} \mathrm{W}$, together with another yo-yo time series $\left(6^{\circ} 05^{\prime} \mathrm{W}\right)$, show that the MO is markedly heterogeneous all along the Strait, but there on the horizontal, being composed of a set of

15 different components juxtaposed side by side. All temperature-salinity diagrams from these transects are straight mixing lines between the Atlantic Waters (AWs) and each of the MWs, most of them evidence bottom homogeneous layers, the lightest of the MWs is split and starts sinking as soon as the Camarinal sills in the northern side of the Strait while the densest MWs are in its southern side, the MO has an overall density range > $0.5 \mathrm{~kg} \cdot \mathrm{m}^{-3}$ and it is markedly meandering at $6^{\circ} 05^{\prime} \mathrm{W}$, and the AWs' variability is much larger than that of the

20 MWs, which prevents from accurately specifying the MO characteristics downstream.

Herein (Part 3) we re-analyze the whole CTD data set from the MO-2009 Experiment that was conducted at the Strait exit (near $6^{\circ} 20^{\prime} \mathrm{W}$ ) by the Institut de Ciències del Mar from Barcelona (Spain) in order to specify the downstream momentum and energy evolution of the MO and investigate the mechanisms leading to its structure. Even without the above-mentioned results and our previous hypotheses in mind, 418 CTD profiles combining regional surveys (over $30 \times 30 \mathrm{~km}^{2}$ ), repeated tow-yo transects (over $\sim 6 \mathrm{~km}$ ) performed with a relatively low sampling interval $(\sim 1 \mathrm{~km})$ in cross-MO and along-MO directions, and yo-yo time series, provide valuable information about the hydrological structure of the MO there. Four components, with the lightest (densest) in the north (south), clearly juxtaposed side by side and relatively isolated from each others, being often separated by marked interface layers, spread over a $\sim 0.7 \mathrm{~kg} \cdot \mathrm{m}^{-3}$ density range. Yo-yo time series confirm that short-term variability at a given place is essentially due to the $\mathrm{MO}$ meandering that allows evidencing locally two (up to three and even four) components, and density ranges up to $0.3 \mathrm{~kg} \cdot \mathrm{m}^{-3}$ within a couple of hours, which demonstrates that the MO heterogeneity is mainly due to the Sea functioning and the AWs-MWs mixing, its splitting does not needing any bathymetric effect. The fact that any of the four components can be missed with profiles $1 \mathrm{~km}$ apart accounts for their relatively small wideness and we claim that a single pair of tow and tow-yo (at a few-hundred $\mathrm{m}$ interval) cross-Strait transects performed near $6^{\circ} 20^{\prime} \mathrm{W}$ with basic instrumentation will provide definite information about the MO heterogeneity. 
Ocean Sci. Discuss., https://doi.org/10.5194/os-2017-54

Manuscript under review for journal Ocean Sci.

Discussion started: 1 August 2017

(c) Author(s) 2017. CC BY 4.0 License.

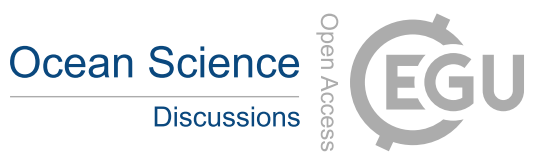

(c) (i)

Keywords: Strait of Gibraltar, Mediterranean Outflow, heterogeneity, Mediterranean Waters

40

\section{Contents}

1. Introduction

4

2. Materiel and methods

7

45 3. The data analysis

3.1. The cross-MO transect

3.2. The along-MO Transect-1

3.2.1. Legs 1,2

3.2.2. $\operatorname{Leg} 3$

$50 \quad$ 3.2.3. $\operatorname{Leg} 4$

3.2.4. $\operatorname{Leg} 5$

3.2.5. $\operatorname{Leg} 6$

3.2.6. $\operatorname{Leg} 7$

3.2.7. $\operatorname{Leg} 8$

26

27

$55 \quad 3.2 .8 . \operatorname{Leg} 9$

28

3.3. The along-MO Transect-2 29

3.3.1. Leg 1

30

3.3.2. $\operatorname{Leg} 2$

3.3.3. $\operatorname{Leg} 3$

60 3.3.4. $\operatorname{Leg} 4$

3.3.5. $\operatorname{Leg} 5$

34

3.3.6. Leg 6

3.3.7. $\operatorname{Leg} 7$

3.3.8. $\operatorname{Leg} 8$

65 3.4. Yo-yo time series at specific points

3.4.1. Central Point-1 41

3.4.2. Central Point-2 44

3.4.3. North-East Point-1

3.4.5. North-East Point-2 55

$\begin{array}{lll}70 & \text { 3.4.6. South-West Point } & 57\end{array}$

3.5. Regional surveys

3.5.1. Survey-1, Transect-1 and Survey-2, Transect-2 60

3.5.2. Survey-1, Transect-2 and Survey-2, Transect-3 62

75 3.5.3. Survey-1, Transect-3, Survey-2, Transect-2 and Survey 2, Transect-4 63

3.5.4. Survey-1, Transect-4 and Transect-5 65 
Ocean Sci. Discuss., https://doi.org/10.5194/os-2017-54

Manuscript under review for journal Ocean Sci.

Discussion started: 1 August 2017

(c) Author(s) 2017. CC BY 4.0 License.

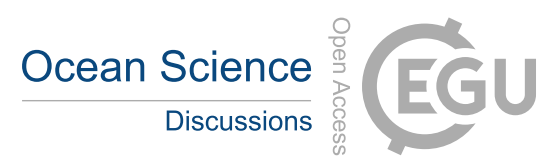

(c) (i)

4. Discussion

68

4.1 The overall sampling strategy

68

4.2 The regional surveys

$80 \quad 4.3$ The yo-yo time series

4.4 The along-MO transects

4.5 The cross-MO transects

4.6 Our own understanding of the Strait functioning

4.7 The density range of the $M O$

854.8 The 1980's vs. 2009 overall characteristics

5. Conclusion

Acknowledgments

References 
Ocean Sci. Discuss., https://doi.org/10.5194/os-2017-54

Manuscript under review for journal Ocean Sci.

Discussion started: 1 August 2017

(c) Author(s) 2017. CC BY 4.0 License.

\section{Introduction}

The debate about the Mediterranean Outflow (MO) heterogeneity has started (for CM) in the mid 1980's since, while working mainly in the interior of the Mediterranean Sea, we were participating in the scientific meetings organized in the framework of the Gibraltar Experiment (GIBEX). Indeed, while continuously progressing in the understanding and identification of the Mediterranean Waters (MWs) that are continuously formed in this or that sub-basin of both the eastern and the western basins of the Sea, we could not imagine that, first of all, only two of these MWs among all those we identified (e.g. CIESM group, 2001) were recognized at the Strait of Gibraltar entrance. And even though we have started, in the mid 2000's, focusing on the Strait (Millot et al., 2006) and providing arguments for a much marked heterogeneity of the MO from the Strait entrance to the Strait exit, most studies focusing on the Strait entrance have persisted, up to a few years ago, in considering that only one component of the EIW (the Eastern Intermediate Water) and the WDW (Western Deep Water) were constituting the MO. Nowadays, agreement has improved but Naranjo et al. (2015) still claim that "West of the sill (of Camarinal), ..., speaking of a unique Mediterranean Water seems more appropriate" while Garcia-Lafuente et al. (2017) claim that “... the severe mixing and dissipation that takes place ... downstream (from Camarinal) ... tends to form a rather mixed outflow ... in which the MWs are barely distinguishable". Such an assertion explains why most studies consider that the MO is basically homogeneous down to the Strait exit (Background Sect. 2 in Part 1).

110

As experimentalists, we have always considered that data alone only allow proposing hypotheses that would need theoretical simulations to be validated and definitively admitted. Now, after having focused, in a series of papers from Millot et al. (2006) to Millot (2014b), on the identification of this or that MW within the Strait, which is necessarily based on subjective considerations that have clearly not been convincing enough, we recently realized that arguments about mixing lines characteristics that are familiar to any sea experimentalist are available to definitively demonstrate the MO heterogeneity. We detail these arguments in Part 1 and analyze data sets available to everybody to show examples demonstrating the MO heterogeneity at both the Strait entrance (Part 1) and all along the Strait itself (Part 2), from both the 1985-1986 GIBEX and the 2004-2007 HYDROCHANGES data sets (Fig.1a). We could have continued using the GIBEX data (as we did in Millot 2009, 2014a) to focus on the Strait exit but we have been allowed to analyze the much more valuable CTD data set collected near $6^{\circ} 20^{\prime} \mathrm{W}$ (Fig. 1a) during the MO-2009 experiment, the analysis of which is proposed herein. 
Ocean Sci. Discuss., https://doi.org/10.5194/os-2017-54

Manuscript under review for journal Ocean Sci.

Discussion started: 1 August 2017

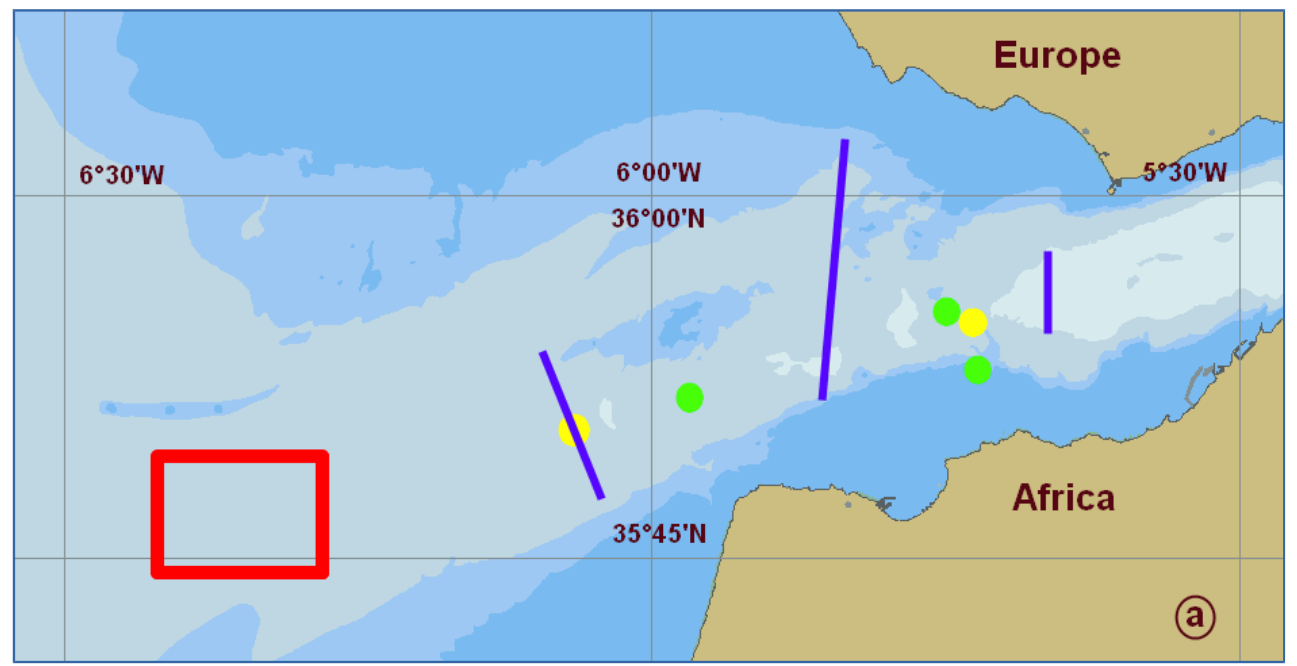

Figure 1a. The area covering the Strait entrance studied in Part 1(easternmost north-south CTD transect at $5^{\circ} 40^{\prime} \mathrm{W}$ in blue, yo-yo CTD time series at $5^{\circ} 43^{\prime} \mathrm{W}$ in yellow, CTDs moored at $5^{\circ} 45^{\prime} \mathrm{W}$ and $5^{\circ} 43.5^{\prime} \mathrm{W}$ in green), the Strait itself studied in Part 2 (CTD transects at $5^{\circ} 50^{\prime} \mathrm{W}$ and $6^{\circ} 05^{\prime} \mathrm{W}$ in blue, yo-yo CTD time series at $6^{\circ} 05^{\prime} \mathrm{W}$ in yellow, CTD moored at $5^{\circ} 58,5^{\prime} \mathrm{W}$ in green) and the Strait exit studied in Part 3 for the MO-2009 experiment area defined by the red rectangle which corresponds to Fig. 16 and 18 including the central zone detailed in Fig.1b.

We have presented the problem about the MO heterogeneity and have detailed both the assertions we deny and the features already evidenced that we think are reliable in Part 1 and 2. Thanks to a presentation of our analyzes split into three parts, we do not think necessary to present such basic knowledge again, so that an unaware reader might take advantage in reading the three parts in succession. Furthermore since we present, in Parts 1 to 3, extremely simple and actually straightforward analyzes that do not need any a priori knowledge about the Strait dynamics, we have wanted to be as objective and convincing as possible and we have decided to rely on the reader's objectivity to infer his/her own conclusions from the analyzes we propose. This is why we do not make reference to the results we previously obtained in both the Sea and the Strait, what will be synthesized together with our own general understanding of the Strait dynamics only in Sect. 4.

It is also our major aim of being as objective as possible that has led us to avoid associating this or that homogeneous layer or component of the MO evidenced here or there to this or that MW identified at the Strait entrance. There, we identified, in a purely objective way, five groups of given potential maximum densities $\left(\mathbf{S}_{\max }\right)$ corresponding to more or less wide ranges in potential temperature $(\mathrm{q})$ and salinity $(\mathrm{S})$. On the basis of our own knowledge, we associated them with given MWs and we colored them in either blue, violet, pink, red or orange, as we did in our previous papers. And to be as objective as possible, we then avoided dealing with MWs names and have been mainly dealing with colors for convenience, hence just saying that "the blue MW is the densest and the orange MW is the lightest of the MO components". Such a coloring was convenient in Part 1 
Ocean Sci. Discuss., https://doi.org/10.5194/os-2017-54

Manuscript under review for journal Ocean Sci.

Discussion started: 1 August 2017

(c) Author(s) 2017. CC BY 4.0 License.

essentially because the stratification of the MO upstream from the Camarinal sills is mainly on the vertical and

still relatively homogeneous MWs can be identified at the Strait entrance. Within the Strait (Part 2), mixing between the AWs and the MWs has markedly intensified, all q-S diagrams there are straight mixing lines and the MO heterogeneity is essentially on the horizontal so that linking $q-S-S_{q}$ sets upstream and downstream from the Camarinal sills cannot be purely objective. Coloring was not necessary in Part 2, and we just re-used it for convenience in the specific analysis of the yo-yo time series at $6^{\circ} 05^{\prime} \mathrm{W}$ and the possible links between q-S-S $\mathrm{q}$ sets collected upstream and downstream from the Camarinal sills.

Furthermore, i) the MO-2009 data at the Strait exit analyzed herein allow evidencing only four components, ii) dramatic changes in the MO characteristics have been evidenced during the past decades (Millot et al., 2006; illustrated herein), iii) no experiment has ever covered the whole Strait continuously with a sampling fine enough, so that no definitive link can be objectively made between the colors used in Parts 1, 2 and 3. The coloring used herein (blue, violet, red and orange) is thus entirely subjective and, in particular, we do not have adequate data to specify why five MWs were evidenced at the Strait entrance in the mid-1980's while only four can be evidenced at the Strait exit in the late 2000's, which could be a consequence of the dramatic changes illustrated in Sect. 4. In any event, on the basis of our own understanding of the Sea functioning (each of its two basins -E vs. W- producing a set of intermediate and deep -I vs. D- MWs), we expect retrieving at least four components in the MO composition. Now, we have also evidenced (Millot, 2013, 2014b) what we think is a major misunderstanding of the signature we all have associated -and that most of us continue associating- with some intermediate and even deep MWs so that, even though we personally color (in our mind) the WDW in blue, the EDW in violet, the EIW in red and the WIW in orange, the reader must forget about such an association and just imagine a colored $\mathrm{MO}$. 
Ocean Sci. Discuss., https://doi.org/10.5194/os-2017-54

Manuscript under review for journal Ocean Sci.

Discussion started: 1 August 2017

(c) Author(s) 2017. CC BY 4.0 License.

\section{Materiel and methods}

The MO-2009 experiment was conducted at the Strait exit to perform Strait dynamics studies while we (CM in particular) just aim at better understanding how the MWs we have followed all over the Sea from their zones of formation are escaping the Sea. As detailed in some of the MO-2009 papers (Gasser et al., 2011, 2017; Nash et al., 2012), the MO appears to be a strong, tidally modulated gravity current embedded with large amplitude oscillations and energetic turbulence while a significant fraction of energy dissipation, mixing and entrainment stress in gravity currents may occur in localized regions controlled by time-varying flow interactions with finescale topography. We do not know how much such small scale processes can modify the large scale structure of the MO we focus on and, even though these studies clearly rely on the relatively old papers of Baringer and Price $(1997 \mathrm{a}, \mathrm{b})$ that we criticized in Part 1, we do not know how important is for them the assumption of a MO that would be, at least from a hydrological point of view, either homogeneous or heterogeneous.

Hereafter, we analyze the MO-2009 CTD data set collected at the Strait exit (Fig.1a,b and 16) using several sampling strategies (regional surveys, cross-MO and along-MO transects, time series) as reported in Tab.1. Regional surveys were performed with classical individual profiles $\sim 5 \mathrm{~km}$ apart, transects were performed with a tow-yo strategy at a $\sim 1-\mathrm{km}$ interval and yo-yo time series were done as during GIBEX in Parts 1 and 2 . We examined all the 836 downcasts and upcasts and never found major differences so that we only consider the 418 downcasts that are thus given odd numbers. The CTD was complemented with a LADCP that, unfortunately for our purpose, was not operated systematically (only 257 profiles are available, often not in continuation) and, in particular, was not operated during all downcasts of the transects or the time series; we found only one event (Central Point-2 time series) during which a series of nine CTD downcasts evidencing especially interesting features were complemented with a series of eight LADCP profiles. 
Ocean Sci. Discuss., https://doi.org/10.5194/os-2017-54

Manuscript under review for journal Ocean Sci.

Discussion started: 1 August 2017

(C) Author(s) 2017. CC BY 4.0 License.

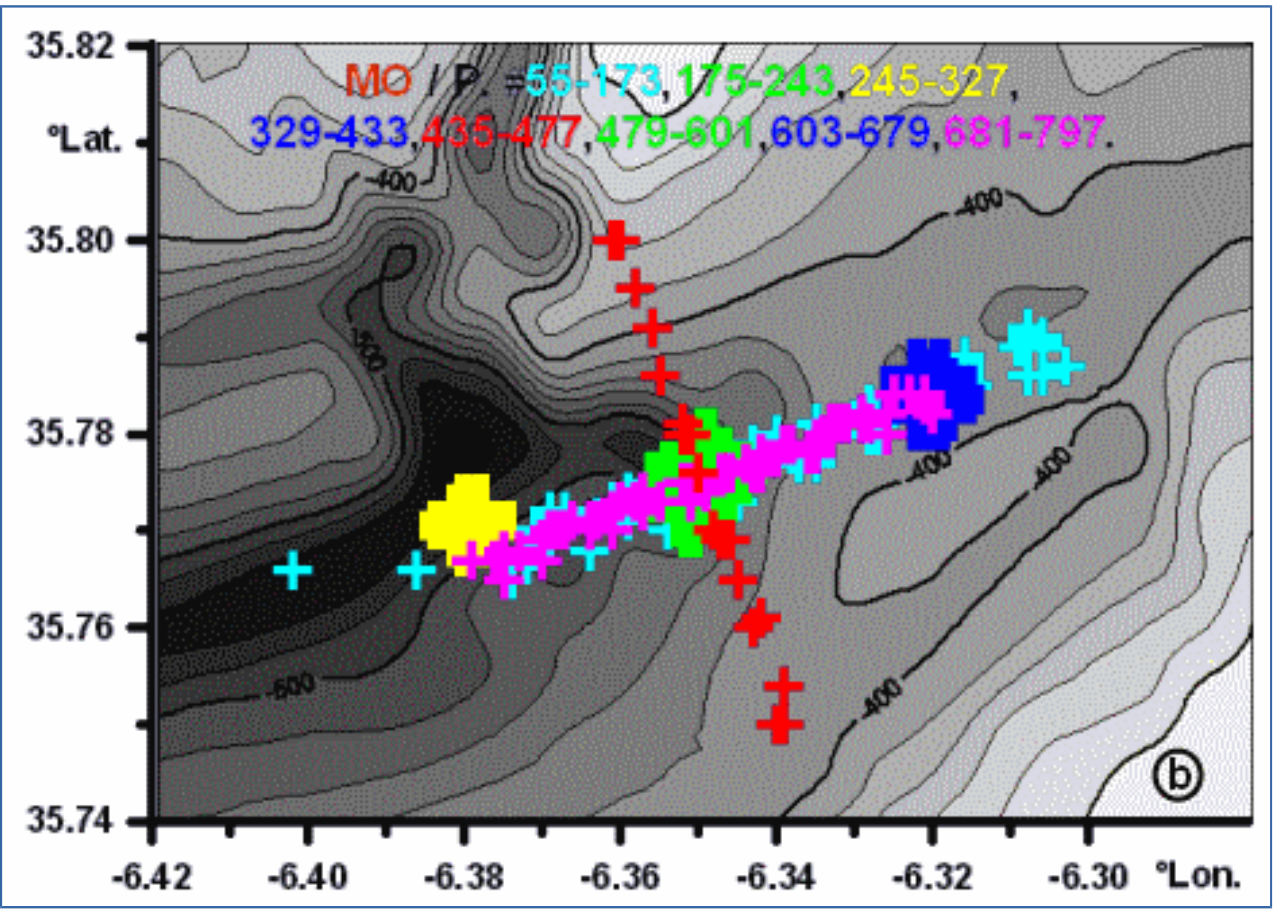

Figure 1b. The central zone studied during the MO-2009 experiment with the cross-MO transect (red), the two along-MO transects (cyan, pink), and the five yo-yo time series at the central (green), north-east (blue) and south-west (yellow) points as specified in Tab.1. Thick (resp. thin) isobaths are $100 \mathrm{~m}$ (resp. $20 \mathrm{~m}$ ) apart.

\begin{tabular}{|l|c|c|c|}
\hline Data sets & Downcasts \# & Date, hour (July, 2009) & $\mathrm{N} / \mathrm{h}$ \\
\hline Regional Survey-1 & $\# 1-53$ & $08,17: 20-09,21: 18$ & $27 / 28$ \\
\hline Along-MO Transect-1 & $\# 55-173$ & $09,23: 35-11,07: 07$ & $55 / 15$ \\
\hline Yo-yo Central Pt-1 & $\# 175-243$ & $11,08: 56-11,20: 16$ & $35 / 11$ \\
\hline Yo-yo South-Western Pt & $\# 245-327$ & $11,21: 14-12,09: 35$ & $42 / 12$ \\
\hline Yo-yo North-Eastern Pt-1 & $\# 329-433$ & $12,10: 42-12,22: 53$ & $58 / 12$ \\
\hline Cross-MO Transect & $\# 435-477$ & $12,23: 41-13,10: 14$ & $22 / 11$ \\
\hline Yo-yo Central Pt-2 & $\# 479-601$ & $14,17: 50-15,18: 25$ & $62 / 24$ \\
\hline Yo-yo North-Eastern Pt-2 & $\# 603-679$ & $15,19: 32-16,08: 03$ & $39 / 13$ \\
\hline Along-MO Transect-2 & $\# 681-797$ & $16,08: 21-17,11: 20$ & $59 / 27$ \\
\hline Regional Survey-2 & $\# 799-835$ & $17,13: 24-18,11: 59$ & $19 / 23$ \\
\hline
\end{tabular}

Table 1. The specific colors associated with the various data sets are those used in Fig.1b and 16 as well as in the title of Fig.17. Dates and hours are those of the first and last out of $\mathrm{N}$ downcasts in the set, the duration of which is just roughly specified in $\mathrm{h}$. 
Ocean Sci. Discuss., https://doi.org/10.5194/os-2017-54

Manuscript under review for journal Ocean Sci.

Discussion started: 1 August 2017

(c) Author(s) 2017. CC BY 4.0 License.

\section{The data analysis}

Among the various data sets that have been collected with the different sampling strategies (surveys, tow-yo transects, yo-yo time series), the unique cross-MO transect (red in Tab.1 and Fig.1b) is of tremendous interest.

This cross-MO transect is in fact mainly composed of four legs that have been repeated from the south-southeast to the north-north-west with a relatively short sampling interval of $\sim 1 \mathrm{~km}$. The 22 profiles \#435-477 considered all together display relatively consistent, significant and contrasted characteristics. Their analysis provide arguments that will allow proposing an objective grouping, hence an objective coloring as we did essentially in Part 1, of all profiles from the other data sets of the experiment, whatever the strategy used.

\subsection{The cross-MO transect}


Ocean Sci. Discuss., https://doi.org/10.5194/os-2017-54

Manuscript under review for journal Ocean Sci.

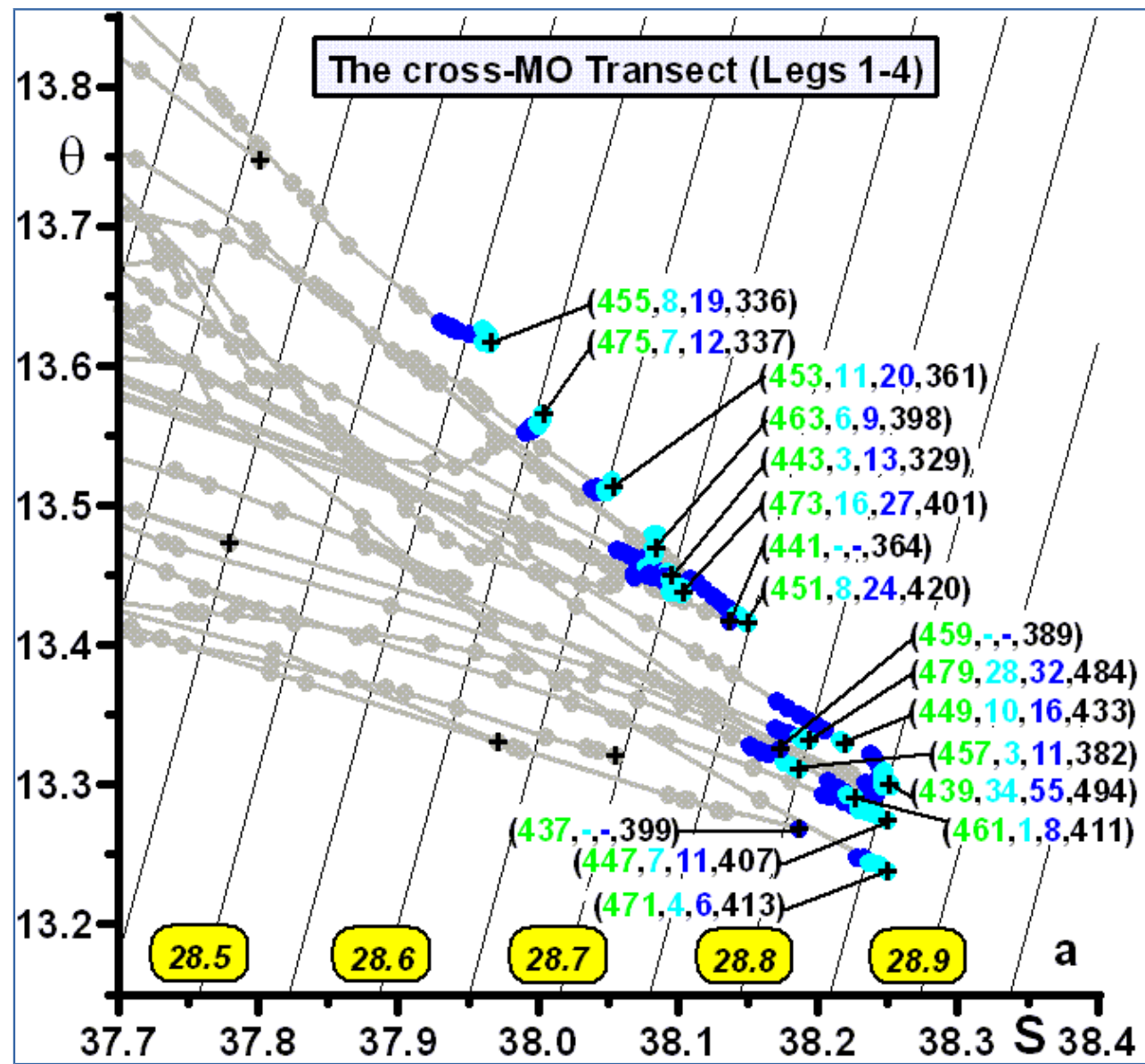

Figure 2a. The q-S diagrams of the profiles from the four legs of the cross-MO transect (at $\sim 6^{\circ} 21^{\prime} \mathrm{W} / 6.35^{\circ} \mathrm{W}$, \#435-477) are plotted together with the $1^{\text {st }}$ profile of the yo-yo time series at the Central Pt-2 $\left(\sim 35,775^{\circ} \mathrm{N}\right.$, \#479) within the specific q-S-S $q$ ranges chosen for all diagrams herein (except Fig.17e, 20). Since all diagrams evidence significant mixing between the AWs and the MWs, they are plotted as all transects in Parts 1 and 2. All data from the 23 profiles are plotted at their 1-m level in gray together with the $\mathbf{S}_{\max }(+)$ of each profile for each downcast (odd number specified in green); also specified are the thicknesses (in m) colored in either cyan or blue over the maximum depth (in $\mathrm{m}$ ) reached by the profile (in black), which gives a visual information about the heterogeneity and thickness of the layer encountered over the bottom. When the profile did not reach a relatively homogeneous layer (\#437, \#441, \#459), only one data is plotted in blue and the thicknesses are not specified (-); the four profiles reaching densities not close enough to others are not associated with any color while two other profiles (out of 23) are out of the figure. Grouping of the information specified for each profile is made according to the classification into four groups proposed in Fig.2b. 
Ocean Sci. Discuss., https://doi.org/10.5194/os-2017-54

Manuscript under review for journal Ocean Sci.

Discussion started: 1 August 2017

(c) Author(s) 2017. CC BY 4.0 License.

Let us first consider the q-S diagrams in Fig.2a that are colored with both cyan and blue to evidence a relatively

homogeneous layer when encountered on the bottom, exactly as all other diagrams in Part 2. Most of them (14/22) display such a more or less homogeneous layer that can be as thick as $\sim 30 \mathrm{~m}$ (\#439, \#479). Three diagrams (\#437, \#441, \#459) do not evidence a homogeneous layer but reach relatively large $\mathbf{S}_{\max }$ (only their densest value is colored in blue), while others reach $\mathbf{S}_{\max }$ significantly lower than the $\mathbf{S}_{\max }$ reached by similar profiles nearby, four being in the figure (\#435, \#445, \#465, \#469) and two being out of it (\#467, \#477). Note that these homogeneous layers have $S_{\max }$ values in a relatively large range of $28.56-28.86 \mathrm{~kg} \cdot \mathrm{m}^{-3}$ and that profiles cannot be selected only according to their $\mathbf{S}_{\max }$ values: the homogeneous layers that are relatively warm and fresh (\#455, \#475) have $S_{\max }$ much lower than, for instance, the $S_{\max }$ of the three diagrams (\#437, \#441, \#459) that do not reach a homogeneous layer.

Two major groups of five-six $\mathbf{S}_{\max }$ values and homogeneous layers are clearly evidenced that support what has been noticed upstream (Part 2) and definitely demonstrates the marked heterogeneity of the MO at the Strait exit. Note that lowest and largest $\mathbf{S}_{\max }$ values cannot be included in these two major groups so that, even if two groups are only represented by few diagrams, a total of four groups must be envisaged. We did not find any simple criterion, such as the $S_{\max }$ ranges from the yo-yo time series at $5^{\circ} 43^{\prime} \mathrm{W}$ (Part 1) or the $S_{\max }$ inferred upstream from the yo-yo time series at $6^{\circ} 05^{\prime} \mathrm{W}$ (Part 2) to objectively group the profiles so that we defined four rectangular zones in a q-S diagram. We did this on the bases of Fig.2a and the analyzes here below, and we colored all profiles just according to the rectangle in which is the associated $\mathbf{S}_{\max }$. Even though such a grouping if not fully scientific, it is totally objective and specific comments and coloring will be proposed for profiles that have a $\mathbf{S}_{\max }$ very close to the limit between two rectangles. Last but not least, the rectangles allow easier visual comparisons between different profiles and their associated $\mathbf{S}_{\max }$, in particular when plotted in different figures.

Figure 2b. An as objective as possible grouping and coloring (orange, red, violet, blue) of the profiles is made herein, just for convenience and easiness of the discussion without having any scientific implication, according 
Ocean Sci. Discuss., https://doi.org/10.5194/os-2017-54

Manuscript under review for journal Ocean Sci.

to the position of the q-S-S $\mathrm{s}_{\max }$ set with respect to the rectangles in green defined from isotherms $(13.65,13.55$, $13.40,13.28$ and $\left.13.18^{\circ} \mathrm{C}\right)$ and isohalines $(37.90,38.02,38.10,38.15,38.20,38.30$ and 38.35$)$. When the set is out of one or the other rectangles, the profile is colored in gray and, when it is very close to one or the other limits of the rectangles it is bi-colored, mainly with respect to the actual position of the set and partly with respect to the color it could have had with a slightly different position (e.g. \#155, Fig.6g).

We thus come with the coloring in orange, red, violet and blue representing, essentially, increasing densities in Fig.2b, this coloring corresponding to the groups of numerical indications for each profile in Fig.2a. The coloring and the indication grouping can be discussed for some profiles: for instance, why \#455 and \#457 are in orange while \#453 is in red, or why \#447 is not violet? Let us just specify that any limit in q-S-S $\mathrm{q}_{\mathrm{q}}$ is necessarily arbitrary and that, obviously, no result hereafter will be dependent on the color: color is just an easy mean to identify this or that profile in this or that group of profiles but will never provide any scientific argument.

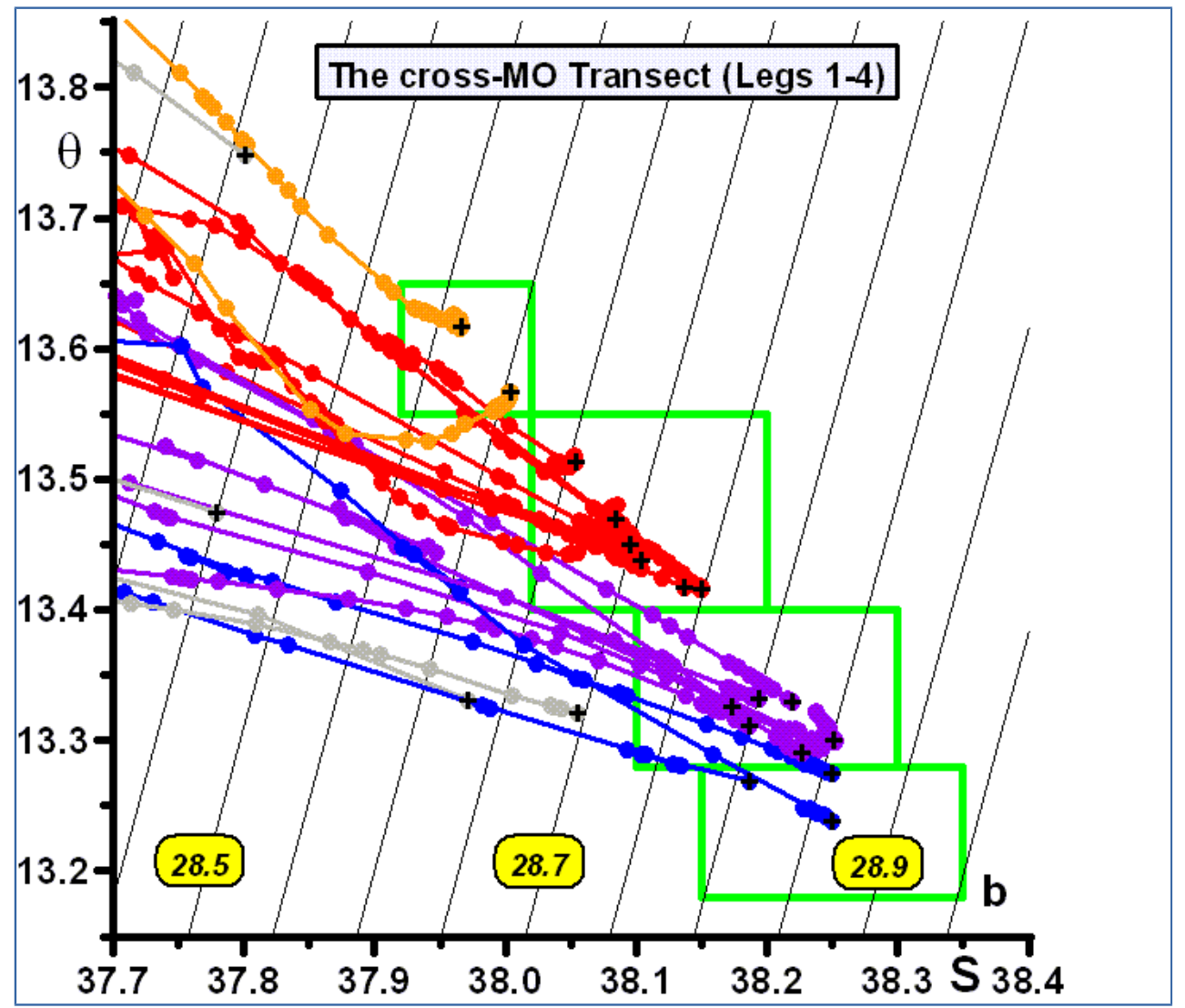
as a function of latitude, hence across the MO. First, the profiles that are out of the Fig.2a ranges (\#467, 477 with 
Ocean Sci. Discuss., https://doi.org/10.5194/os-2017-54

Manuscript under review for journal Ocean Sci.

$\left.S_{\max }=28.1,28.3 \mathrm{~kg} \cdot \mathrm{m}^{-3}\right)$ as well as those that reach relatively low $S_{\max }$ values $(\# 435,445,465,469)$ are at both extremities of the legs, but gray profiles are not observed at both ends of all legs. Second, on all legs, colors blue (dense) to orange (light) are ordered from south to north, i.e. from the left-hand to the right-hand side of the MO, but all colors are evidenced on only one out of the four legs. Third, a given color is not associated with some specific latitudes: for instance, orange (Leg4) is at the latitude of red (Leg1) or gray (Leg3), violet (Leg3) is at the latitude of blue $(\operatorname{Leg} 1,2,4)$ and even gray $(\operatorname{Leg} 4)$. Therefore, and just because of the coherency of the information provided within $11 \mathrm{~h}$, it is clear that i) even a sampling interval as small as $1 \mathrm{~km}$ does not allow evidencing all colors, hence correctly resolving the heterogeneity of the MO, ii) any significant leg must end with a gray color: for instance, orange might have been found in the north of Leg1 and blue might have been found in the south of Leg3 and iii) the MO is markedly meandering with a few-h periodicity. Note that one could also hypothesize that colors are passing by as intermittent bubbles, i.e. not as a set of meandering components of the MO, which will be refuted by the yo-yo time series analysis.

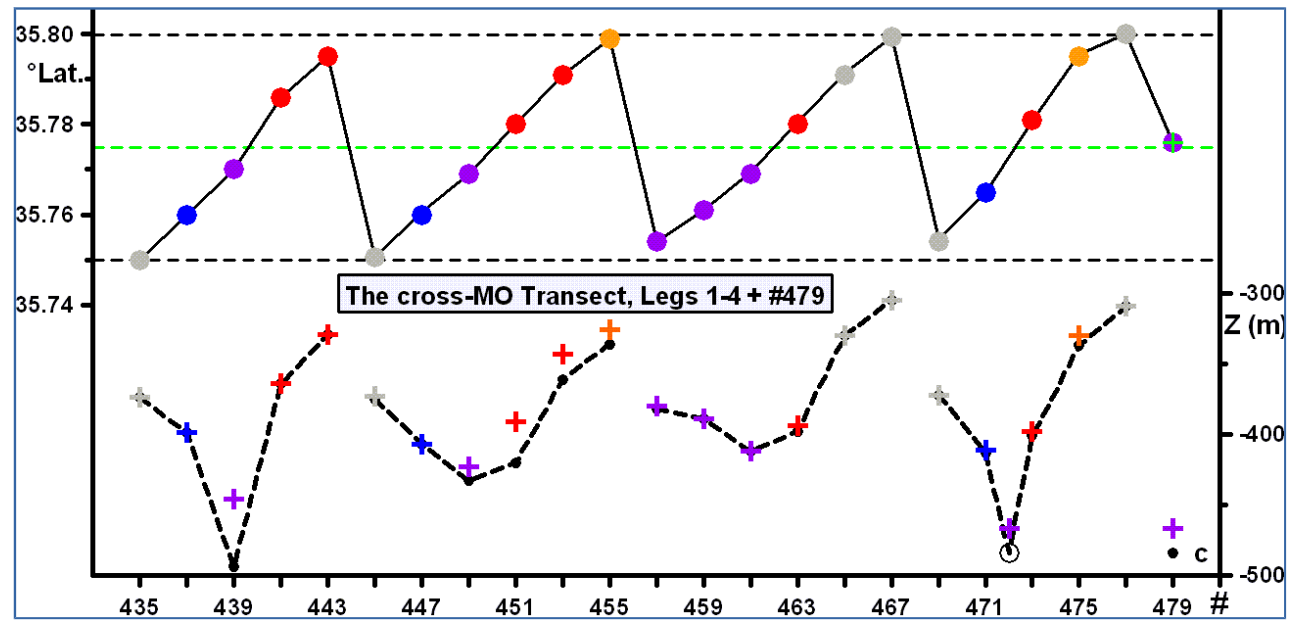

Figure 2c. Top) The 23 profiles (\#435-479) plotted as a function of latitude along the four legs of the cross-MO transect as dots colored according to the groups specified in Fig.2b. Also indicated are the central point mean latitude $\left(35.775^{\circ} \mathrm{N}\right.$, green) and the extreme latitudes $\left(35.75^{\circ} \mathrm{N}\right.$ and $35.80^{\circ} \mathrm{N}$, dark gray) used in Fig. 4 .

Bottom) Depths of the $S_{\max }$ of each profile together with the maximum depth reached by the profile. Values for $\# 479$ have been added in between those for \#471 and \#473. Legs are expected to be straight and along similar positions (Fig.1b).

The lower part of Fig.2c, which represents the distribution with depth of both the colored $\mathrm{S}_{\max }$ and the greatest depth reached by the downcast, first evidences the problems of either the actual location of the profile (recorded at the beginning of the downcast) or the vicinity of the CTD to the actual bottom at the end of the downcast (that was not adjusted with an accurate measurement as could have been provided by using a pinger). Indeed, very different greatest depths have been reached in the central part of the Strait between Leg1 and Legs 2-3 (Leg 4 is a composite); we are unable to specify whether this is due to slightly different locations of the legs or to lowering 
Ocean Sci. Discuss., https://doi.org/10.5194/os-2017-54

Manuscript under review for journal Ocean Sci.

Discussion started: 1 August 2017

(c) Author(s) 2017. CC BY 4.0 License.

Discussions

(c) (i)

of the CTD more or less close to a similar bottom depth found from leg to leg. In any event, the central deepest part of the Strait is not occupied by the densest blue water but by the violet one. Assuming the continuous passing by of any color during $\sim 12 \mathrm{~h}$, it is clear that, for an accurate description of the MO, the repetition of legs does not provide additional information and that a unique cross-MO transect, performed with a few $100 \mathrm{~s} \mathrm{~m}$ sampling interval, hence within less than $12 \mathrm{~h}$ since time for the coming-backs between legs is saved, would have been much more instructive. Note that a single cross-MO transect with a CTD only towed at 10-20 m above the bottom between isobaths of $\sim 250 \mathrm{~m}$ at least would have provided more significant and definitive information.

Now, whatever the arbitrary coloring is, general features as well as marked differences are evidenced by the successive legs, as shown by the q-S diagrams of Legs 2 and 4 (completed by the nearby \#479 profile from the yo-yo central point-2 time series performed just after) in Fig.3a,b. Legs 2 and 4 were chosen because they allow representing all colors while evidencing marked variability in both the AWs and the MWs within $\sim 6 \mathrm{~h}$.

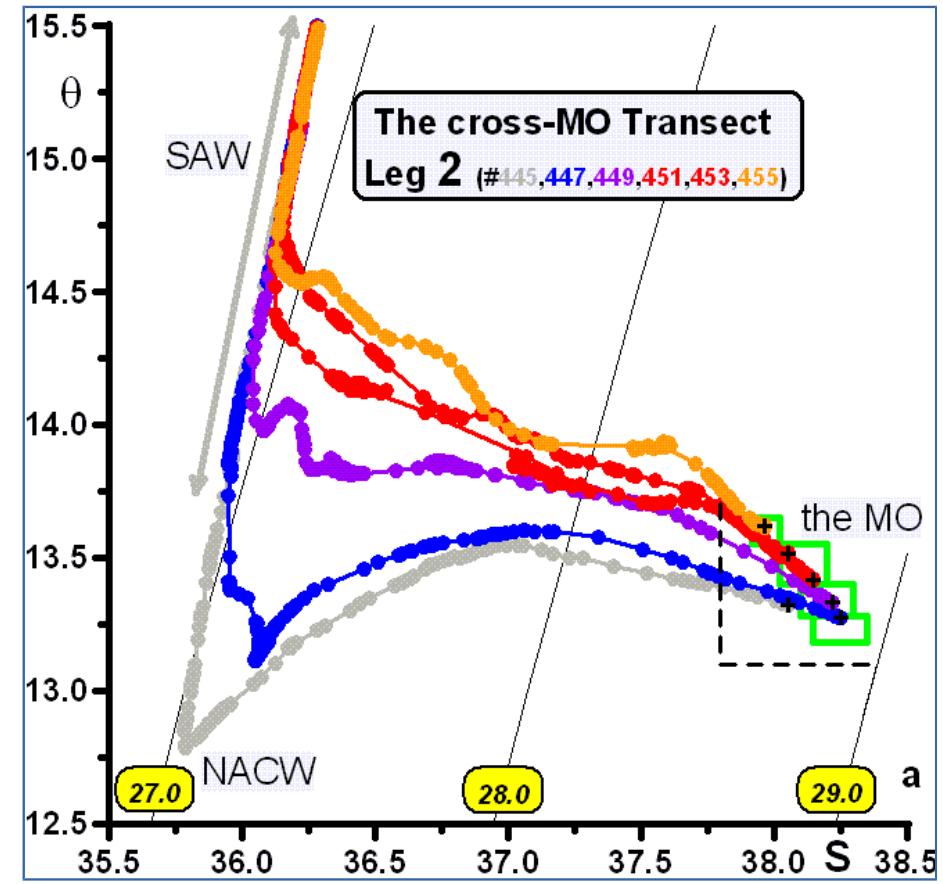

Figure 3a. q-S diagrams of \#445-455 of the cross-MO transect, Leg 2. Colors as in Fig.2b. 
Ocean Sci. Discuss., https://doi.org/10.5194/os-2017-54

Manuscript under review for journal Ocean Sci.

Discussion started: 1 August 2017

(C) Author(s) 2017. CC BY 4.0 License.

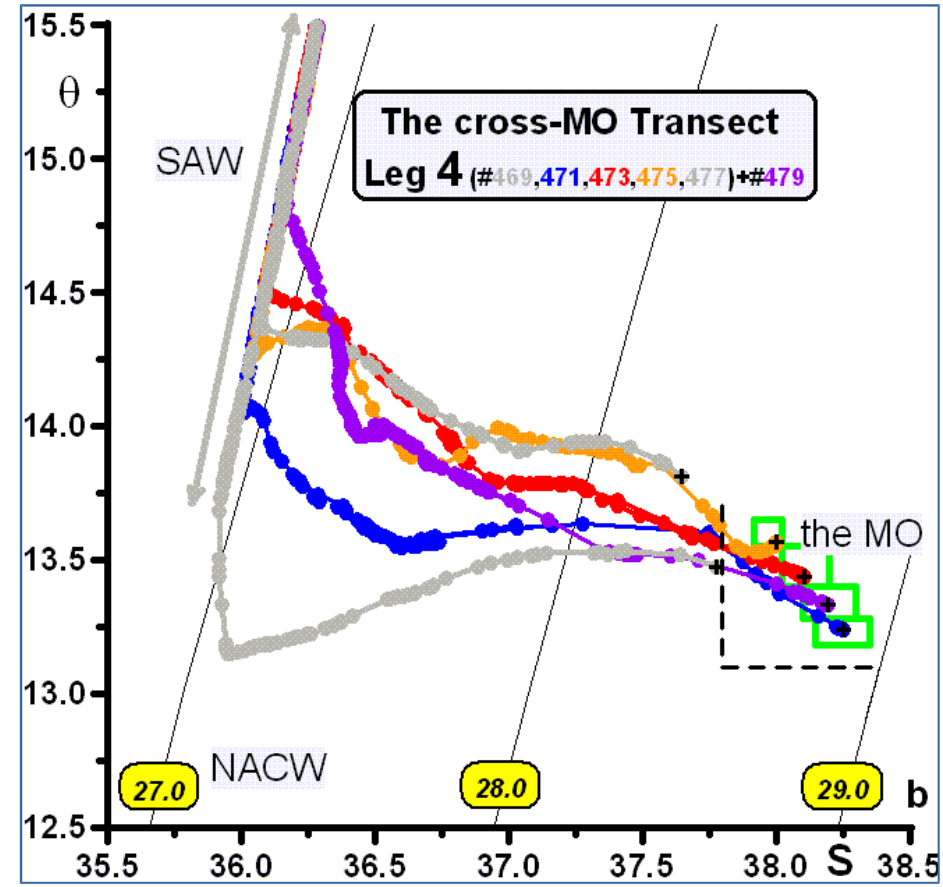

Figure 3b. q-S diagrams of profiles \#469-477+479 of the cross-MO transect, Leg 4. Colors as in Fig.2b.

Overall, one first note the variability associated with NACW mainly illustrated by Fig.3 (also Fig.4), with the NACW influencing, in particular, the two southernmost profiles in gray and blue, more during Leg 2 than during

Leg 4. It is noticeable that the NACW influences the blue profile over the whole depth, down to the $\mathbf{S}_{\max }$ value, leading to a mixing line slope that is markedly smaller during Leg 2 in the ranges associated with the MO. Now, one also notes that even though the violet, red and orange profiles evidence a mixing mainly with the base of the SAW layer, mixing line slopes in the same ranges are larger during Leg 2, which leads to mixing lines more spread during Leg 2 and more parallel during Leg 4. It is thus clear that, whatever the characteristics of the MWs are at a given location along the Strait, they will be continuously evolving downstream while sinking over the bottom and mixing with a relatively variable set of AWs. The fact, already evidenced in Parts 1 and 2, as well as in all our previous publications, that the lightest (warmest and freshest) MWs components are associated with mixing lines that have a relatively large slope as compared to the relatively low slope of the mixing lines associated with the densest (coolest and saltiest) components thus appears to be a general feature from the Strait 
Ocean Sci. Discuss., https://doi.org/10.5194/os-2017-54

Manuscript under review for journal Ocean Sci.

Discussion started: 1 August 2017

(c) Author(s) 2017. CC BY 4.0 License.

The kriging of $\mathrm{q}, \mathrm{S}$ and $\mathrm{S}_{\mathrm{q}}$ in Fig.4a-f (with similar parameters (20 colons and 50 rows) and color ranges) provides complementary and additional information. Fig.4a,b evidence the dramatic changes associated with NACW but also significant changes within the MO: the violet MW is still associated with $\mathrm{q}<13.35^{\circ} \mathrm{C}$ in the deepest part of the transect and the blue MW is still found at $\sim 400 \mathrm{~m}$, but overall values are slightly lower during Leg 2. Fig.4c,d show a homogeneous fresh NACW core and, even though the MO is markedly saltier during Leg 2 below $\sim 350 \mathrm{~m}$, the four components are seemingly rather well identified at roughly similar depths and locations. Coherently with both the $\mathrm{q}$ and $\mathrm{S}$ variations between Legs 2 and 4, Fig.4e,f display a MO significantly denser during Leg 2 than during Leg 4 and the four components are still rather well identified at roughly similar depths and locations. Coherently too with the $\mathrm{S}$ distributions, the $\mathrm{S}_{\mathrm{q}}$ distributions indicate that the light MWs found at 300-350 $\mathrm{m}$ along the northern slope tend to spread southwards all across the Strait over the denser MWs. Whatever the coloring could be, all distributions evidence a very heterogeneous MO that clearly appears as being formed of a series of different components that are juxtaposed side by side from the lower part of the southern slope ( $400 \mathrm{~m})$ to the deeper part of the Strait $(450-500 \mathrm{~m})$ and to the upper part of the northern slope (350-300 m). Obviously, such a large heterogeneity would benefit a lot from a much finer sampling. 
Ocean Sci. Discuss., https://doi.org/10.5194/os-2017-54

Manuscript under review for journal Ocean Sci.

Discussion started: 1 August 2017

(c) Author(s) 2017. CC BY 4.0 License.

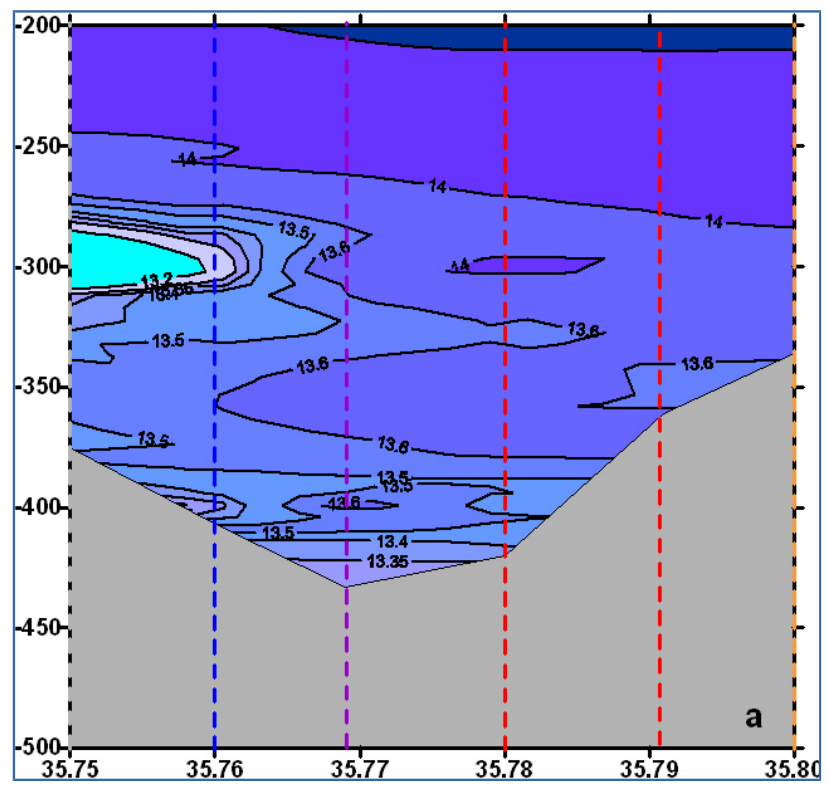

Figure 4a. q distribution on the cross-MO transect, Leg 2. All color scales are similar for Legs 2 and 4. Profiles coloring according to Fig.2b.

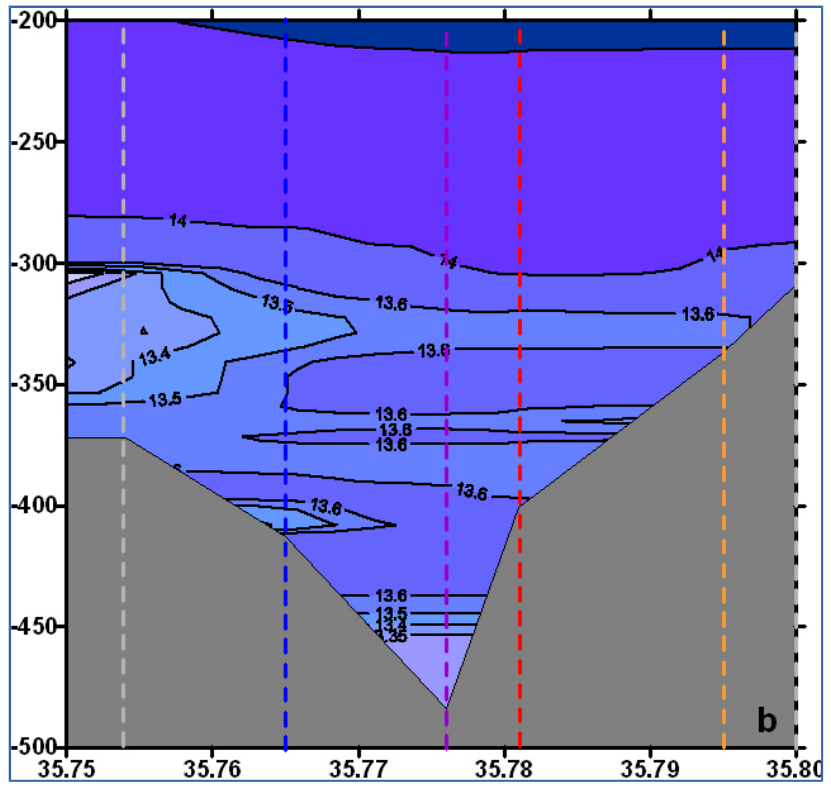

Figure 4b. q distribution on the cross-MO transect, Leg 4. Additional information as in Fig.4a. 
Ocean Sci. Discuss., https://doi.org/10.5194/os-2017-54

Manuscript under review for journal Ocean Sci.

Discussion started: 1 August 2017

(c) Author(s) 2017. CC BY 4.0 License.

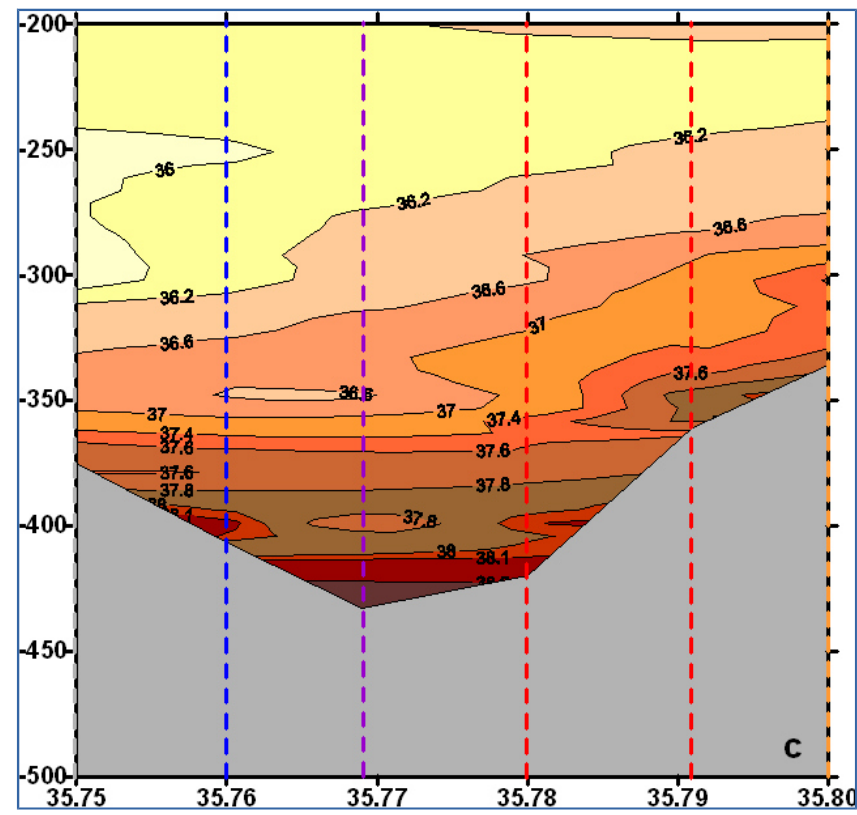

Figure 4c. S distribution on the cross-MO transect, Leg 2. Additional information as in Fig.4a.

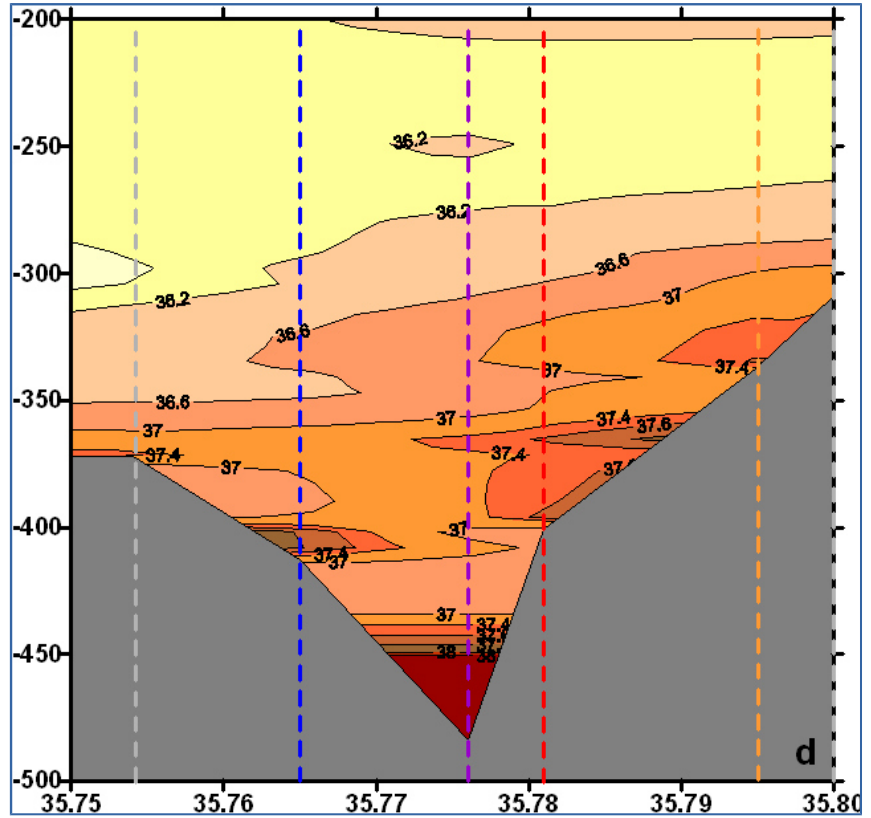

Figure 4d. S distribution on the cross-MO transect, Leg 4. Additional information as in Fig.4a. 
Ocean Sci. Discuss., https://doi.org/10.5194/os-2017-54

Manuscript under review for journal Ocean Sci.

Discussion started: 1 August 2017

(c) Author(s) 2017. CC BY 4.0 License.

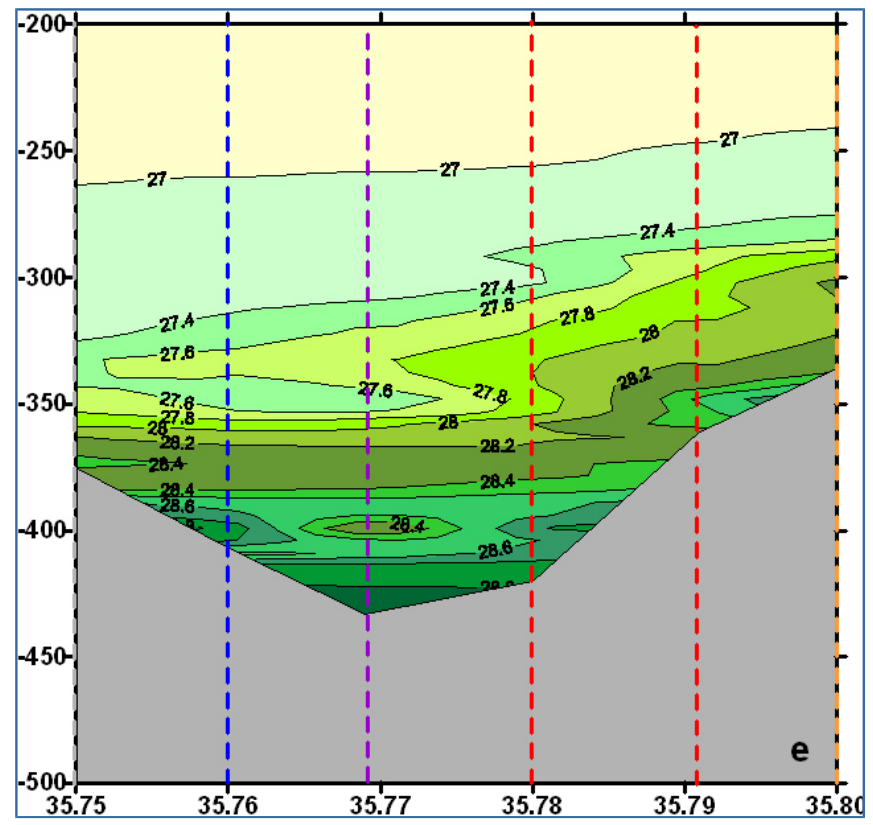

Figure 4e. $\mathrm{s}$ distribution on the cross-MO transect, Leg 2. Additional information as in Fig.4a.

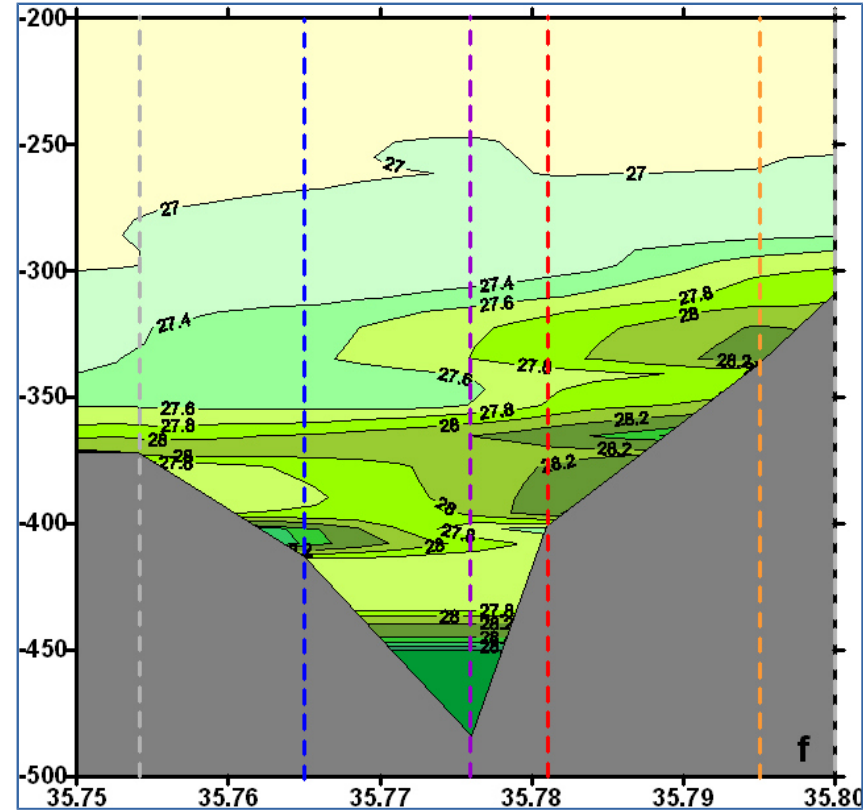

Figure 4f. $\mathbf{s}$ distribution on the cross-MO transect, Leg 4. Additional information as in Fig.4a. 
Ocean Sci. Discuss., https://doi.org/10.5194/os-2017-54

Manuscript under review for journal Ocean Sci.

Discussion started: 1 August 2017

(c) Author(s) 2017. CC BY 4.0 License.

The results above demonstrate that the coloring we propose provides an efficient help in the analysis of groups of profiles so that we analyze now the various data sets presented in Tab.1 with the same coloring and with the basic ideas evidenced from the cross-MO transect in mind.

\subsection{The along-MO Transect-1}

This transect consists of 55 profiles, performed along 9 legs within $15 \mathrm{~h}$, the overall characteristics of which are synthesized in Fig.5 (as in Fig.2c). Note from Fig.1b that the so-called cross-MO transect is not exactly crossStrait, so that the perpendicular along-MO transects do not follow exactly the expected current lines. This is demonstrated by the fact that the blue largest $\mathbf{S}_{\max }$ are in the northern part of the transect, that is on the left hand side of the MO. The legs are valuably analyzed in detail with $\theta$-S diagrams over ranges that focus on the MWs within the rectangles previously defined, and that are thus reduced as compared to the ranges in Fig.2a,b, but still with the same $\mathrm{Dq} / \mathrm{DS}=1{ }^{\circ} \mathrm{C}$ scale to deal with similar slopes of the AWs-MWs mixing lines.

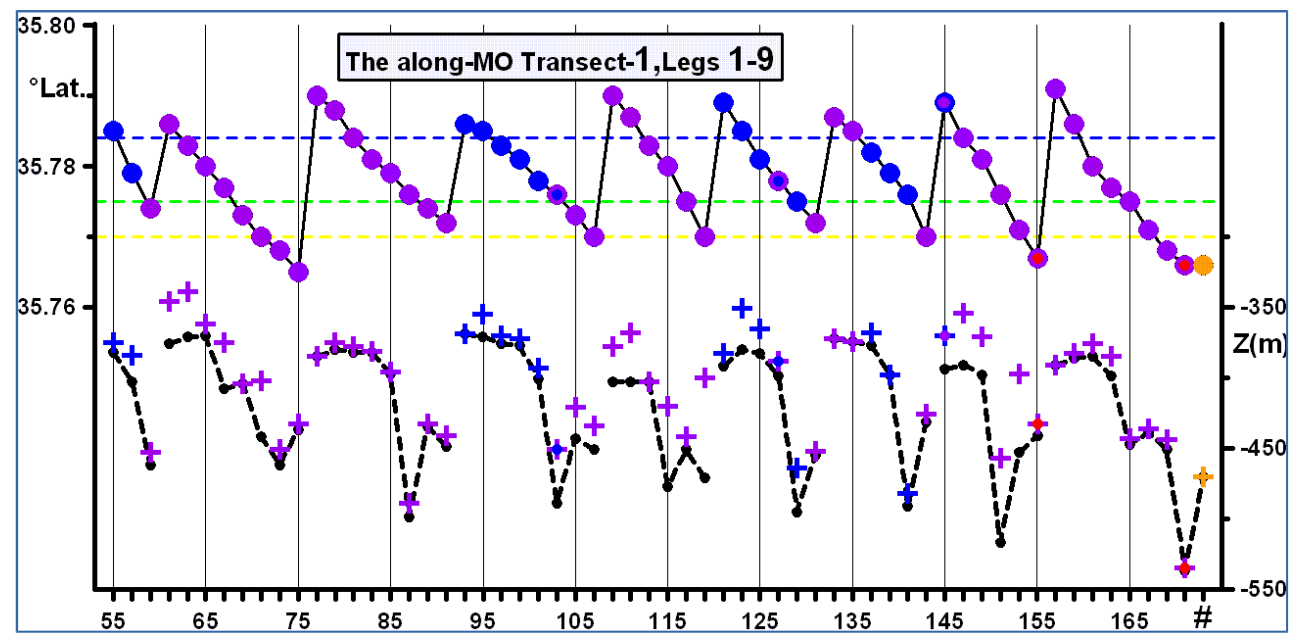

Figure 5. As in Fig.2c for \#55-173 of the along-MO Transect-1. Colors as in Fig.2b. Latitudes of the northeastern, central and south-western points are indicated in blue, green and yellow, resp.. 
Ocean Sci. Discuss., https://doi.org/10.5194/os-2017-54

Manuscript under review for journal Ocean Sci.

Discussion started: 1 August 2017

(c) Author(s) 2017. CC BY 4.0 License.

Profiles \#55-57 from Leg 1 are blue while other profiles, including those at the same position performed $\sim 1 \mathrm{~h}$ after are markedly different and violet, which clearly illustrates, with a bias lower than during the cross-MO transect, the extremely large temporal variability induced by the $\mathrm{MO}$ meandering. Note that all $\mathbf{S}_{\max }$ are roughly

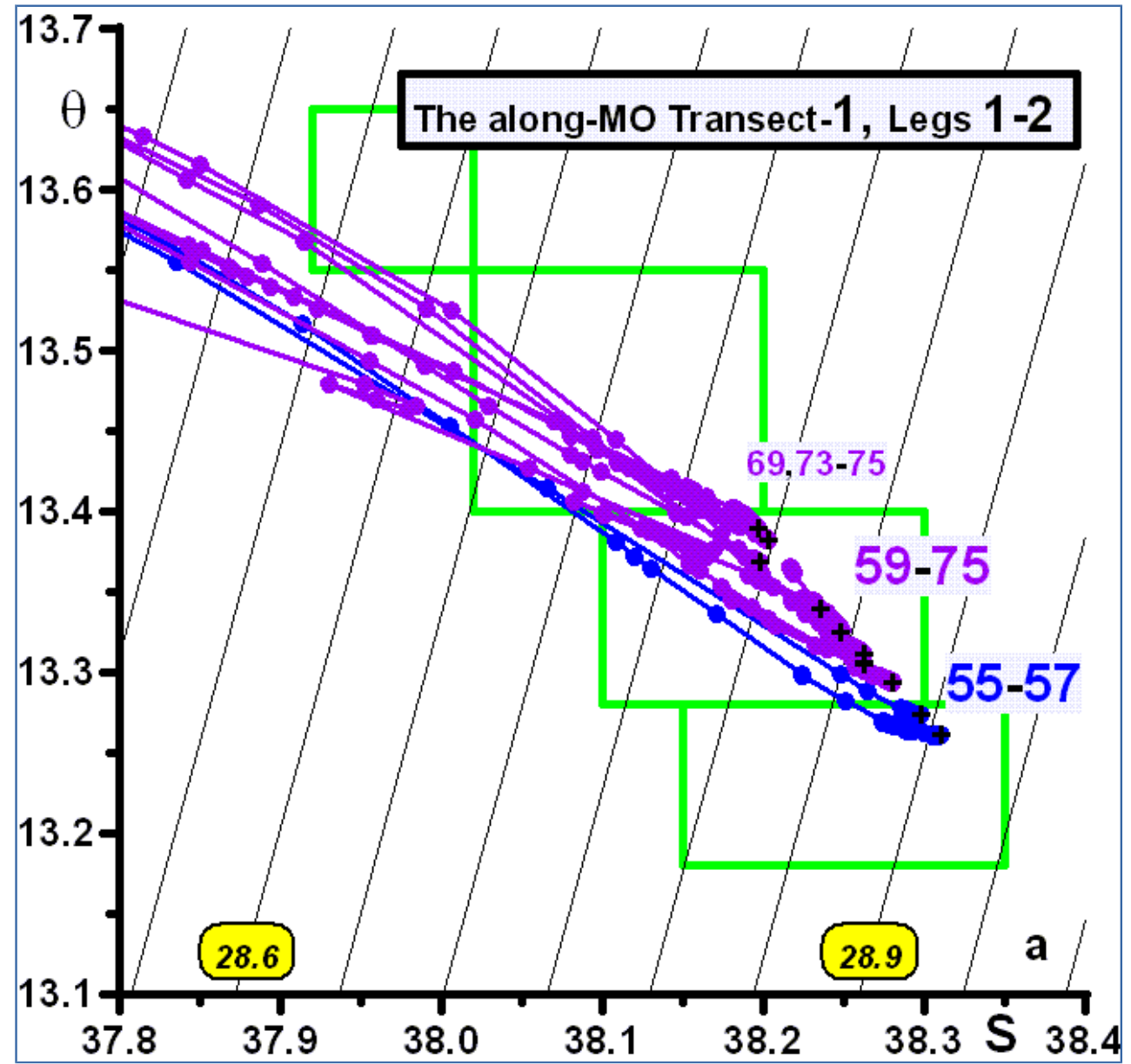

Figure 6a. As in Fig.3a for the along-MO Transect-1, Legs 1-2. 
Ocean Sci. Discuss., https://doi.org/10.5194/os-2017-54

Manuscript under review for journal Ocean Sci.

Discussion started: 1 August 2017

(C) Author(s) 2017. CC BY 4.0 License.

\subsubsection{Leg 3 (Fig.6b)}

Even though all eight profiles are violet, the five northernmost (and shallowest) profiles have relatively large and similar $\mathbf{S}_{\max }$ values while the three relatively low $\mathbf{S}_{\max }$ are from the southernmost (and deepest) ones. These

profiles display mixing lines less straight than during Legs 1,2 and the cross-MO transect, and they have evolved differently from north to south, forming two different groups (\#77-85 and \#87-91). Also note that all $\mathbf{S}_{\max }$ values during Leg 3 are lower, at a given position/latitude, than during Leg 2.

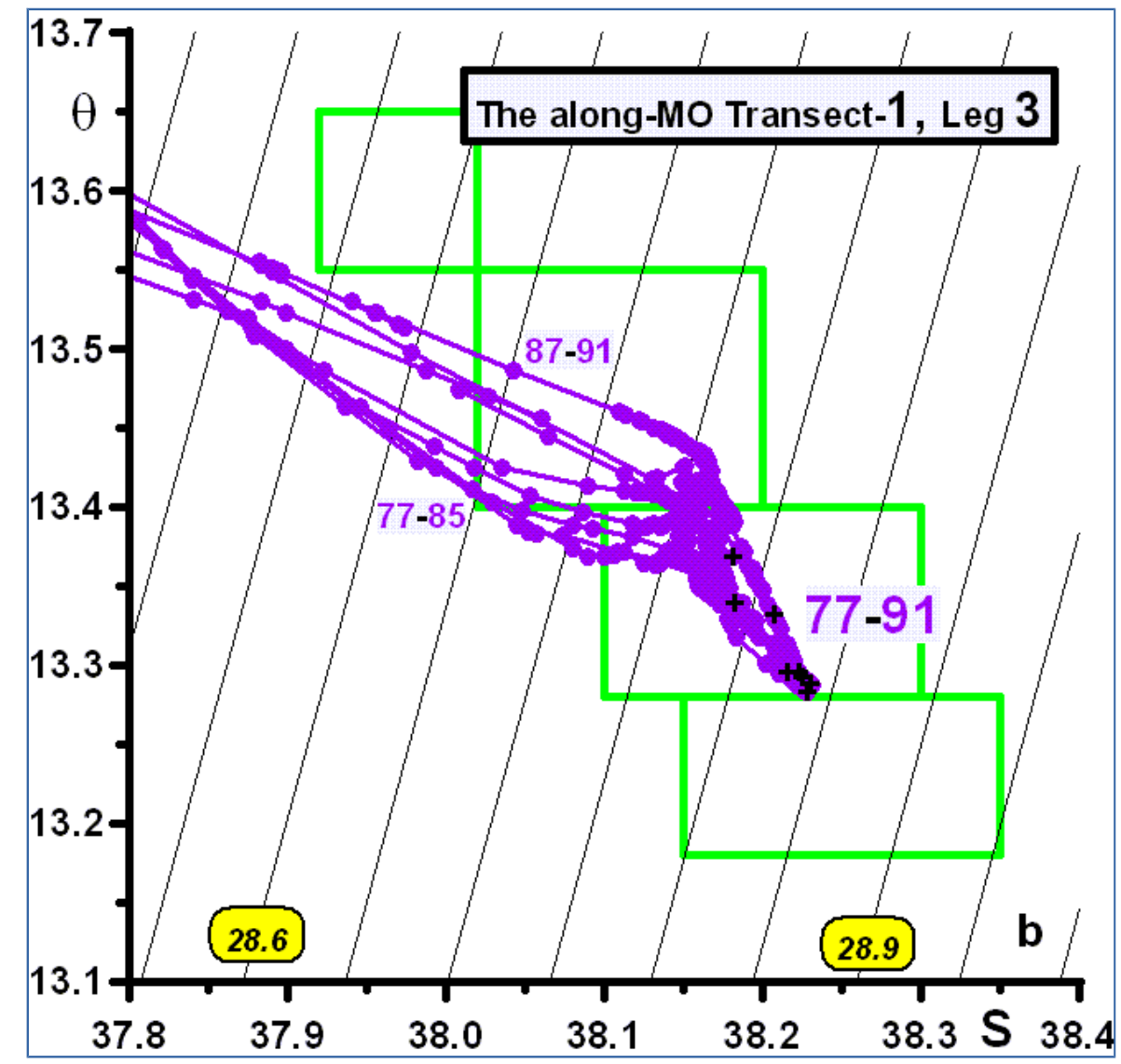

Figure 6b. As in Fig.3a for the along-MO Transect-1, Leg 3. 
Ocean Sci. Discuss., https://doi.org/10.5194/os-2017-54

Manuscript under review for journal Ocean Sci.

Discussion started: 1 August 2017

(c) Author(s) 2017. CC BY 4.0 License.

\subsubsection{Leg 4 (Fig.6c)}

All eight blue and violet profiles are straight mixing lines again. The five blue \#93-101 are in the north while the two violet \#105-107 are in the south and the violet-blue \#103 is in between, which is the classical disposition from the left-hand side to the central part of the MO. Note (on the q scale at $\mathrm{S}=37.8$ ) that the mean slope of all mixing lines from Legs 1-2 to 3 and 4 has reduced, indicating an increasing influence of NACW. Finally, note (Fig.5) that the blue $S_{\max }$ are much shallower than the violet-blue and violet ones.

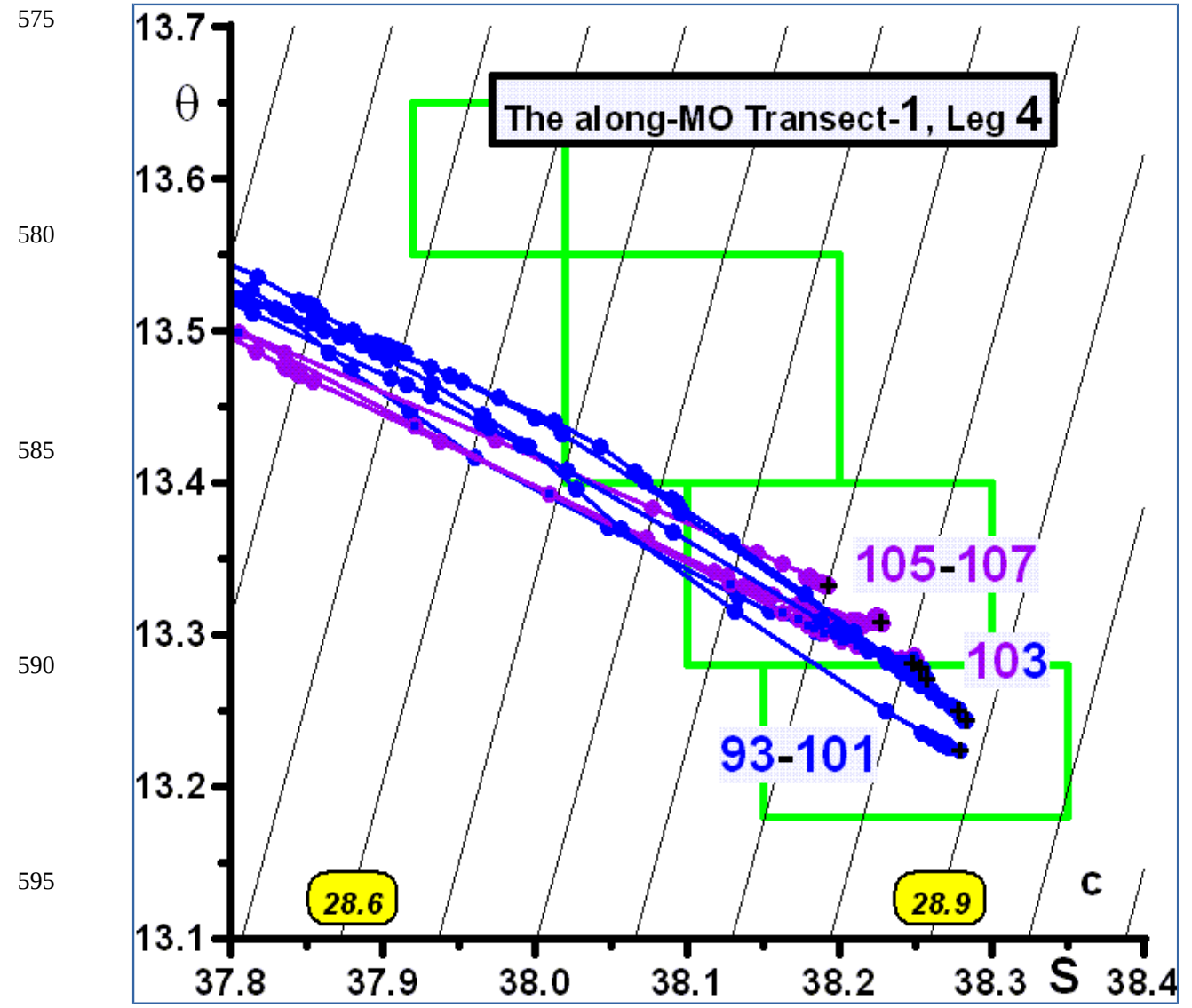

Figure 6c. As in Fig.3a for the along-MO Transect-1, Leg 4. 
Ocean Sci. Discuss., https://doi.org/10.5194/os-2017-54

Manuscript under review for journal Ocean Sci.

Discussion started: 1 August 2017

(c) Author(s) 2017. CC BY 4.0 License.

All six profiles from Leg 5 are clearly violet and very similar to the two southernmost violet \#105-107 from Leg 4 just before, which indicates that this specific violet set AW-MW has invaded, from the south (actually from the central part towards the left-hand side), the whole along-MO transect.

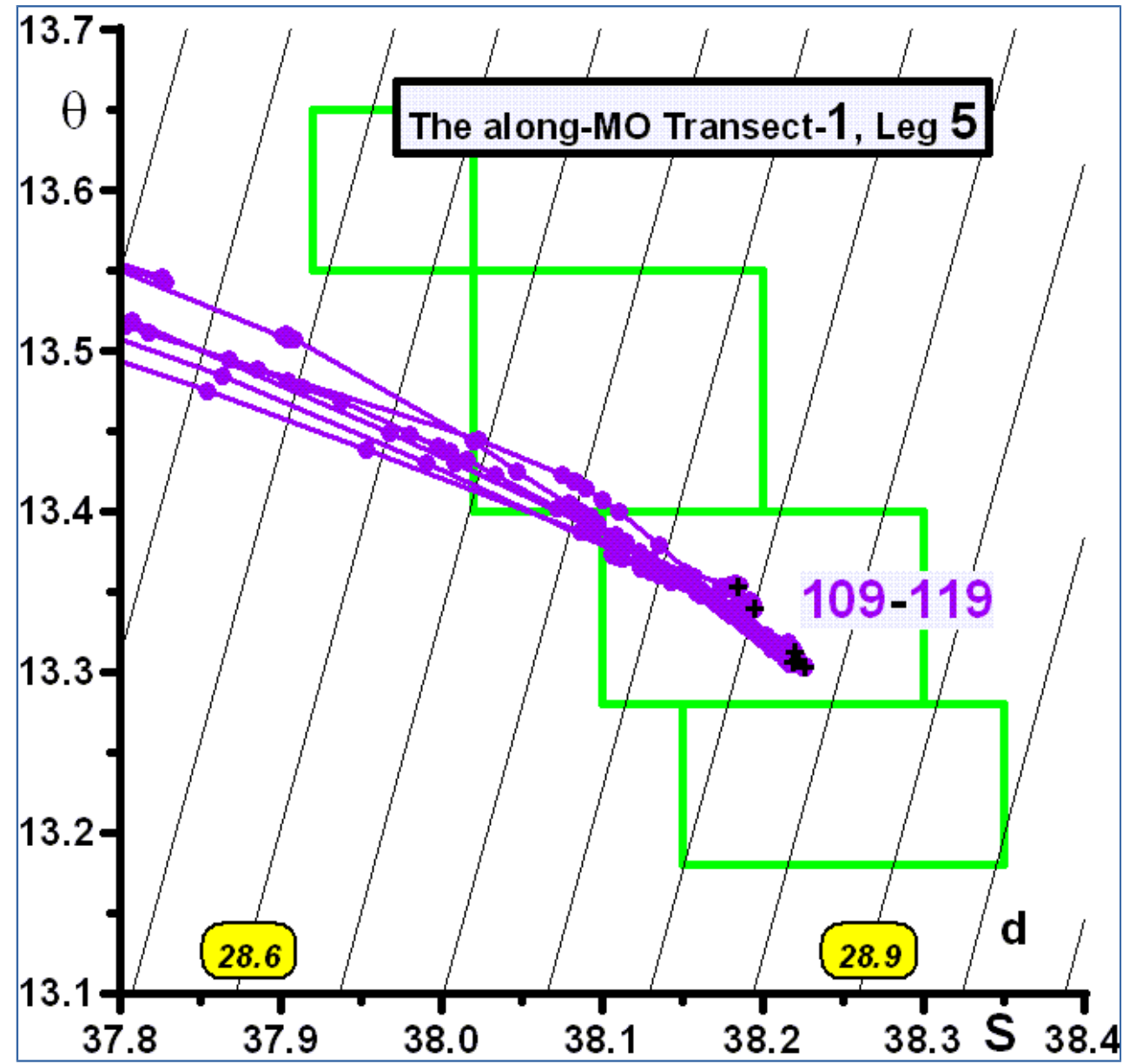

Figure 6d. As in Fig.3a for the along-MO Transect-1, Leg 5. 
Ocean Sci. Discuss., https://doi.org/10.5194/os-2017-54

Manuscript under review for journal Ocean Sci.

Discussion started: 1 August 2017

(c) Author(s) 2017. CC BY 4.0 License.

\subsubsection{Leg 6 (Fig.6e)}

The situation dramatically changed during Leg 6 with the temporary arrival of blue water (\#121-125) followed by violet-blue water (\#127) before coming back with blue water (\#129) and finally retrieving the violet water

(\#131) that was all along the transect during the previous Leg 5. This leg has been clearly collected astride some kind of blue-violet interface so that it is impossible to separate the spatial variability from the temporal one nearby such a turbulent or meandering interface.

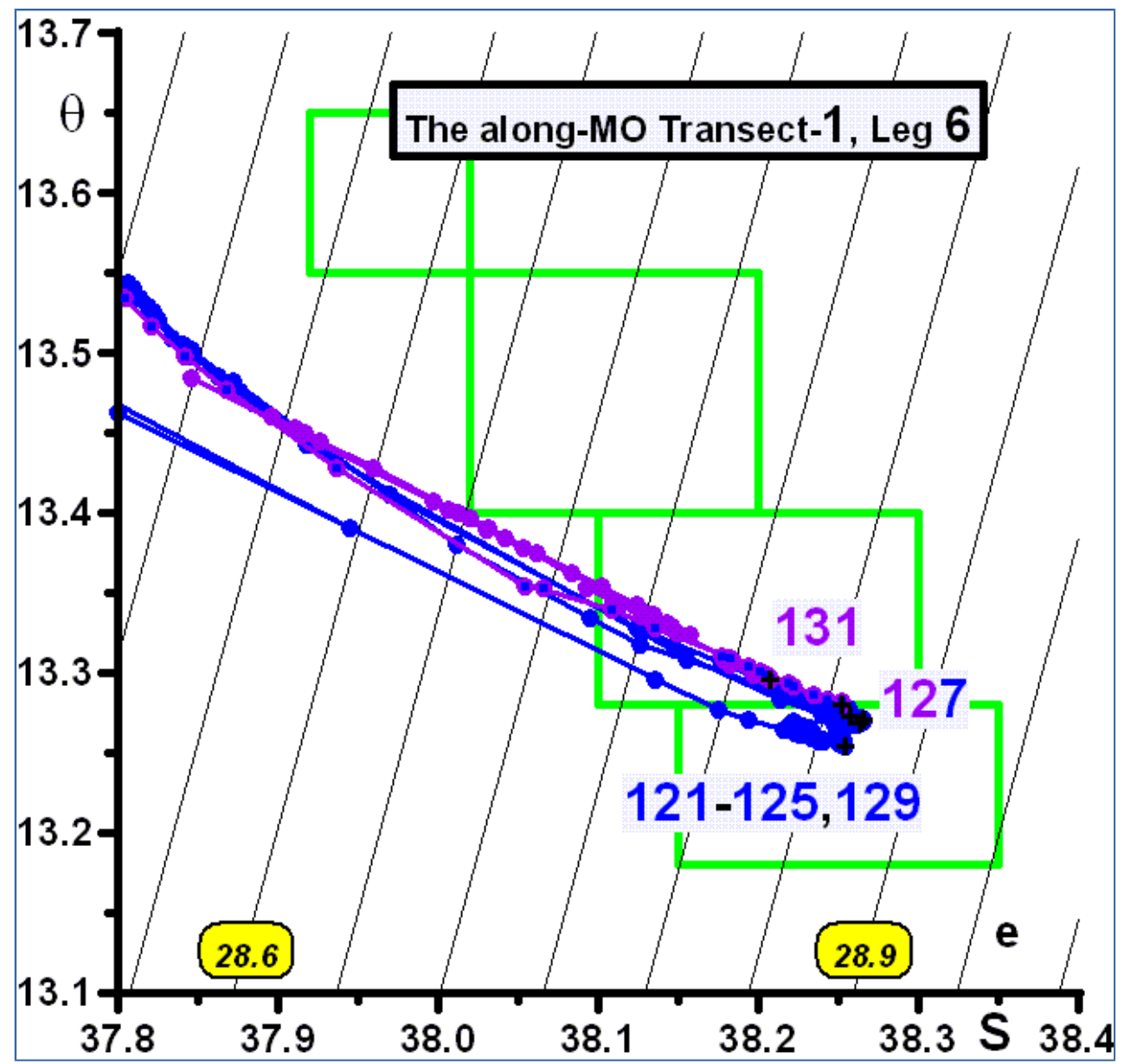

Figure 6e. As in Fig.3a for the along-MO Transect-1, Leg 6. 
Ocean Sci. Discuss., https://doi.org/10.5194/os-2017-54

Manuscript under review for journal Ocean Sci.

Discussion started: 1 August 2017

(c) Author(s) 2017. CC BY 4.0 License.

Markedly different $\mathbf{S}_{\max }$ are associated with the violet profiles at the beginning $(\# 133,135)$ and the end (\#143) of the transect and with the blue \#137-141 in between, which might evidence a relatively steep meander of the MO there. Note that \#139 is characterized by a marked instability with the insertion, where $\mathrm{S}$ is normally $28.66 \mathrm{~kg} . \mathrm{m}$

${ }^{3}$, of denser $\left(\sim 28.76 \mathrm{~kg} . \mathrm{m}^{-3}\right)$ water that should be violet.

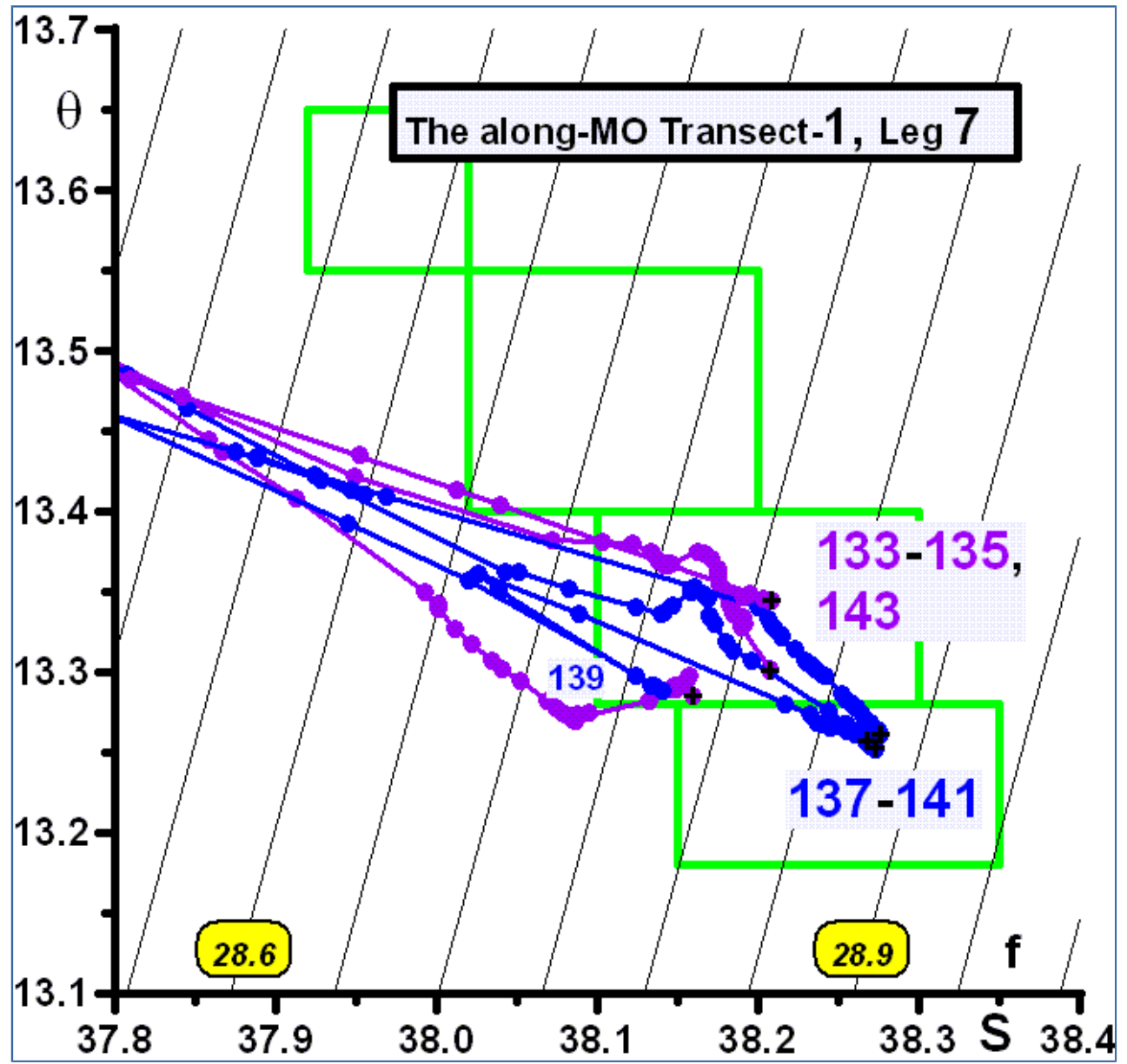

Figure 6f. As in Fig.3a for the along-MO Transect-1, Leg 7. 
Ocean Sci. Discuss., https://doi.org/10.5194/os-2017-54

Manuscript under review for journal Ocean Sci.

Discussion started: 1 August 2017

(c) Author(s) 2017. CC BY 4.0 License.

\subsubsection{Leg 8 (Fig.6g)}

This leg is characterized by $\mathbf{S}_{\max }$ continuously decreasing from the north where the water is blue-violet (\#145) to $\# 147, \ldots, 153$, before becoming in the south violet-red (\#155). Such a distribution over three colors is fully consistent with the one evidenced by the cross-Strait legs. Note (Fig.5) that the violet-red profile was observed at a latitude previously reached only by Leg 2 when there was violet water there.

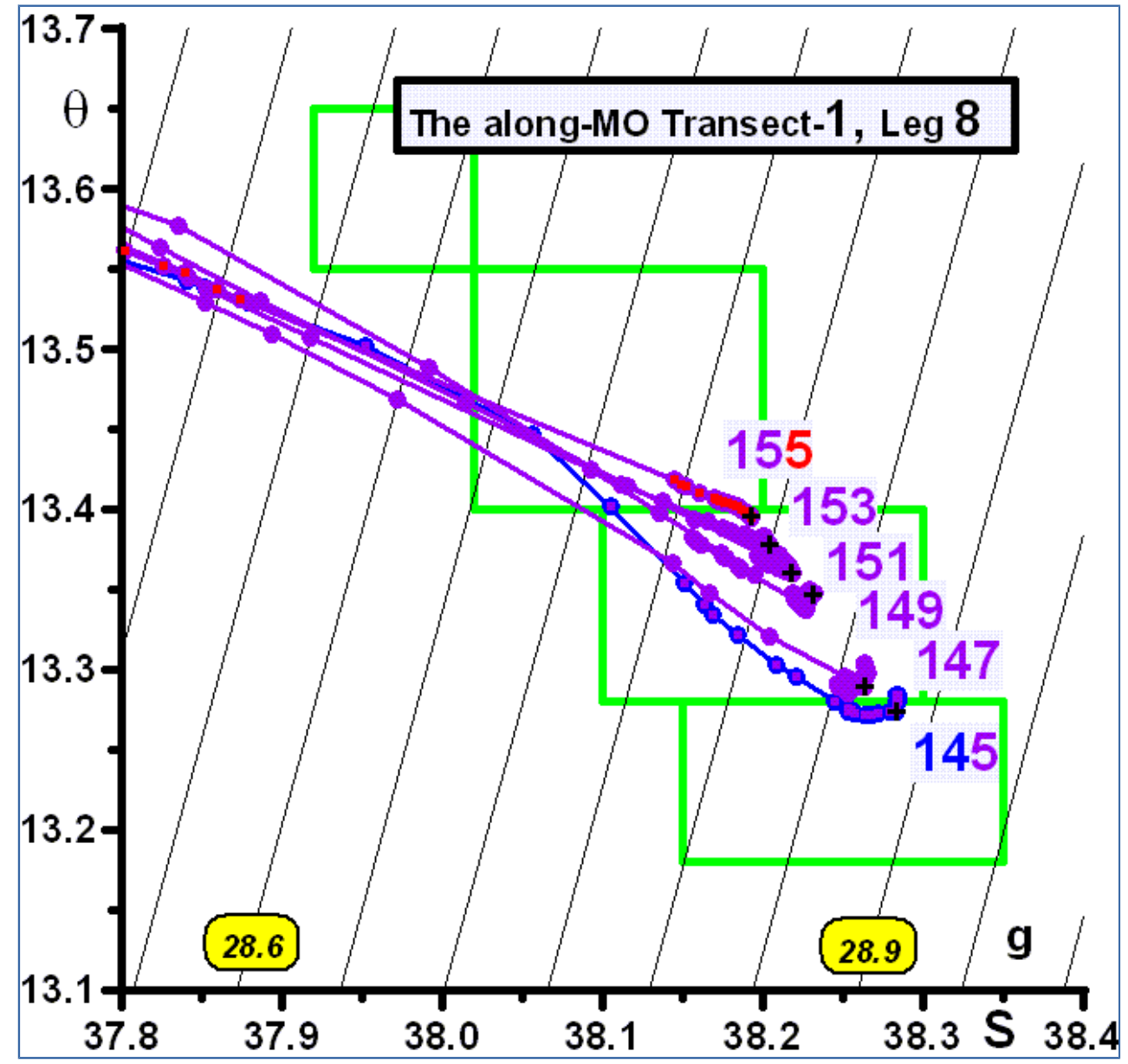

Figure 6g. As in Fig.3a for the along-MO Transect-1, Leg 8. 
Ocean Sci. Discuss., https://doi.org/10.5194/os-2017-54

Manuscript under review for journal Ocean Sci.

Discussion started: 1 August 2017

(c) Author(s) 2017. CC BY 4.0 License.

Discussions

\section{(c) (1)}

\subsubsection{Leg 9 (Fig.6h)}

This leg is extremely interesting because it has been extended westwards with two additional profiles at the same latitude that are clearly identified in cyan (Fig.1b). While the part of the transect (\#157-169) that has been performed during the previous legs is entirely and clearly violet (as were Legs 3 and 5), the first of these two additional profiles in violet-red (\#171) is nearly where the violet-red \#155 was during Leg 8. But the very interesting information is that the westernmost \#173 is clearly orange, and that it is associated with a $S_{\max }$ relatively large, as compared to those associated with the orange water evidenced during the cross-MO transect (Fig.2b) that were more upstream: this illustrates the heterogeneity of the MO components and the difficulty to correctly sample them.

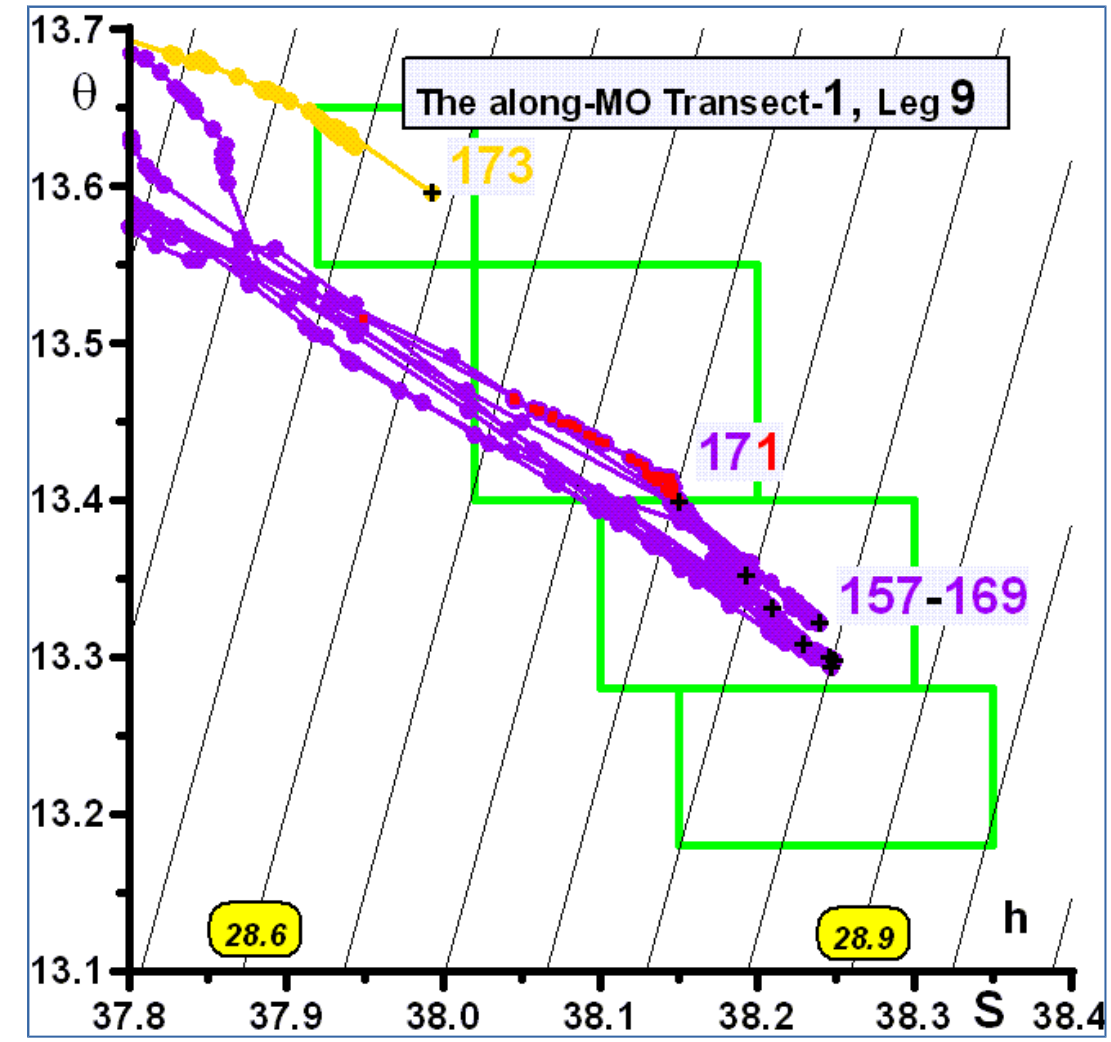

Figure 6h. As in Fig.3a for the along-MO Transect-1, Leg 9. 
Ocean Sci. Discuss., https://doi.org/10.5194/os-2017-54

Manuscript under review for journal Ocean Sci.

Discussion started: 1 August 2017

Discussions

(c) Author(s) 2017. CC BY 4.0 License.

(c) (i)

Whatever these difficulties are, it is clear that, provide the legs are long enough to cross-sample all the MO, blue dense water is found on its left-hand side while orange light water is found on its right hand side, the violet and red waters being in between, and all these waters markedly meandering, in particular at relatively small spatiotemporal scales.

\subsection{The along-MO Transect-2}

This transect of 59 profiles (Fig.7), composed of 8 legs performed within $15 \mathrm{~h}$, is more blue than violet, in particular when compared to the previous one (Fig.5) performed at exactly the same place. At least one week apart and over periods of about half a day, either composition (blue vs. violet amounts) or mean position (of this or that water) can display significant changes. Again, the blue largest $\mathbf{S}_{\max }$ are in the northern part of the transect, that is on the left hand side of the MO. All legs are valuably analyzed in details in Fig. 8 with $\theta$-S diagrams as in Fig.6

680

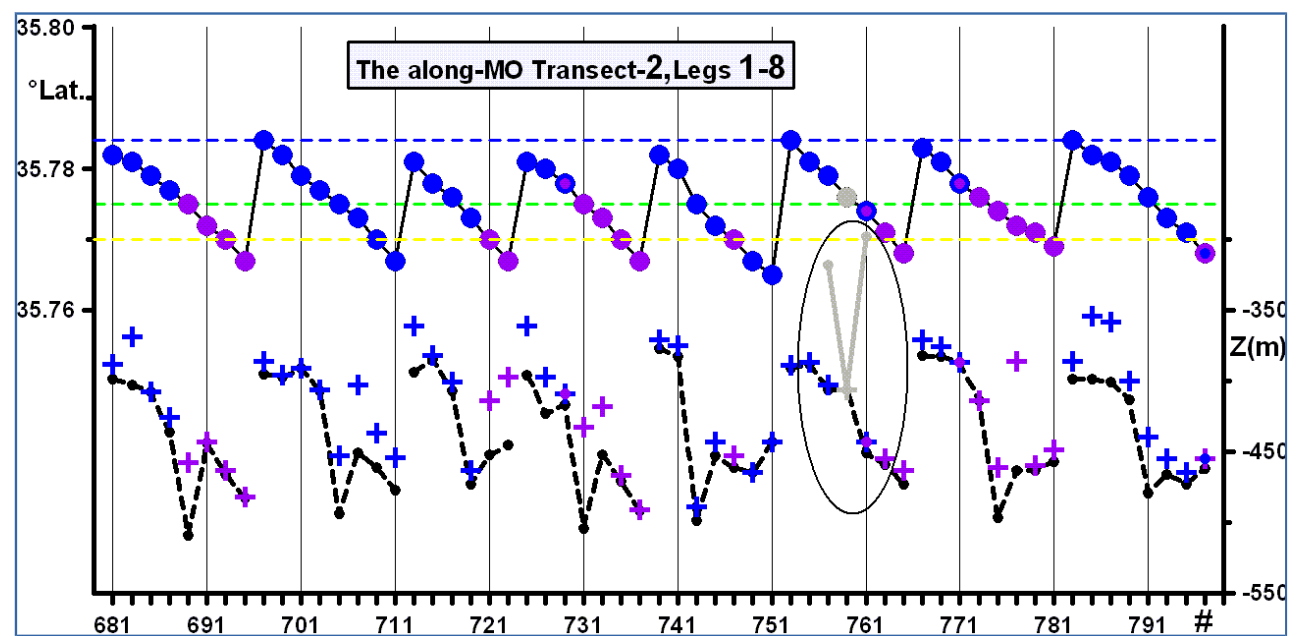

Figure 7. As in Fig.5 for profiles \#681-797 of the along-MO Transect-2. In gray, immersion of the \#759-S $\max _{\max }$ isopycnal at neighboring locations. 
Ocean Sci. Discuss., https://doi.org/10.5194/os-2017-54

Manuscript under review for journal Ocean Sci.

Discussion started: 1 August 2017

(c) Author(s) 2017. CC BY 4.0 License.

The eight \#681-695 have a similar position and shape, but blue profiles are encountered in the north with the same homogeneous $\mathbf{S}_{\max }$ at \#681-685 and a slightly lower $\mathbf{S}_{\max }$ at $\# 687$ while profiles more to the south are violet (\#689-695).

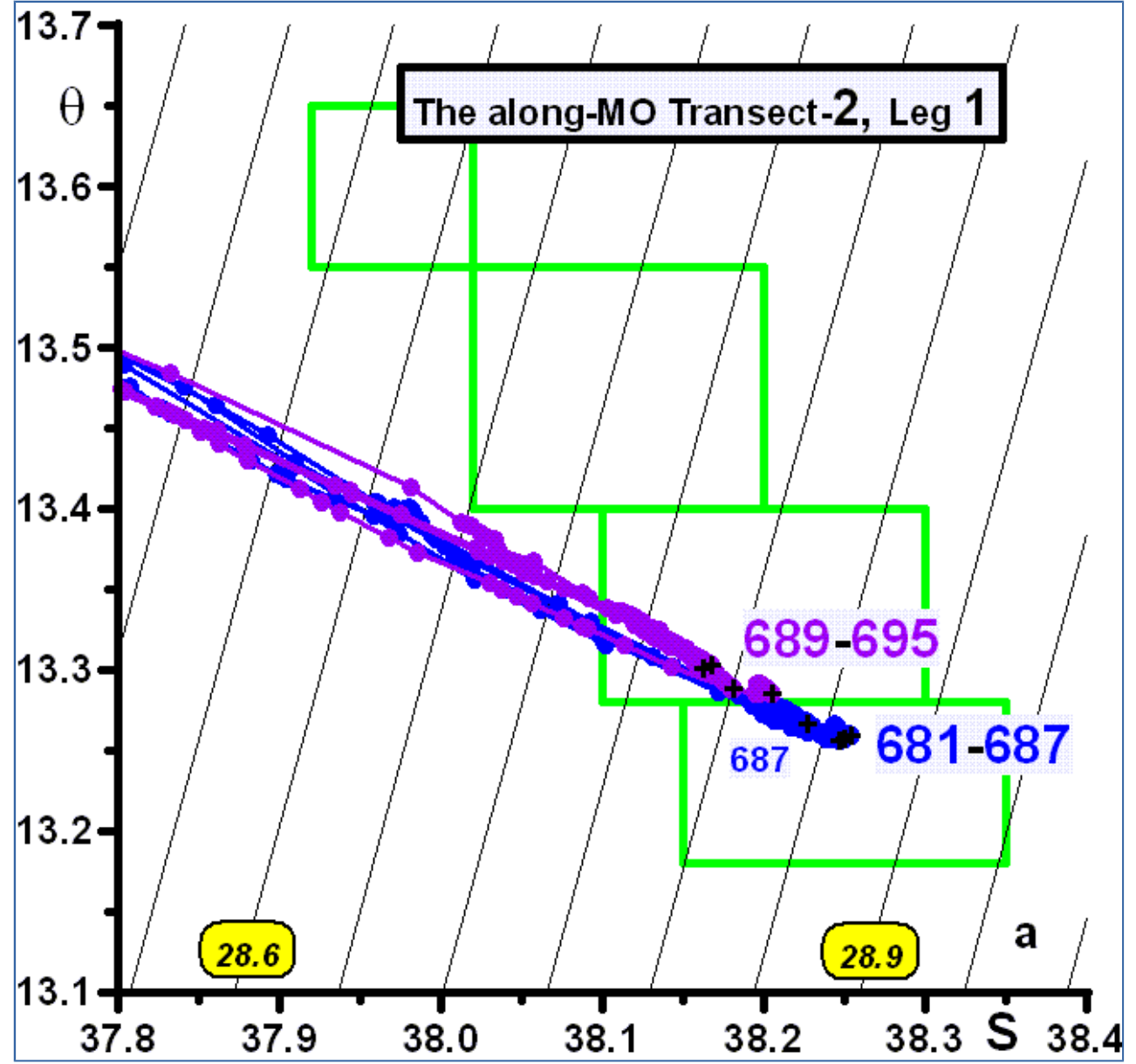

Figure 8a. As in Fig.3a for the along-MO Transect-2, Leg 1. 
Ocean Sci. Discuss., https://doi.org/10.5194/os-2017-54

Manuscript under review for journal Ocean Sci.

Discussion started: 1 August 2017

(c) Author(s) 2017. CC BY 4.0 License.

All eight \#697-711 are blue and still similar, largest $\mathbf{S}_{\max }$ are still found in the north and they decrease southwards (\#709-711) nearly reaching the violet limit. The three northernmost profiles (\#697-701) are not linear and are influenced by violet water.

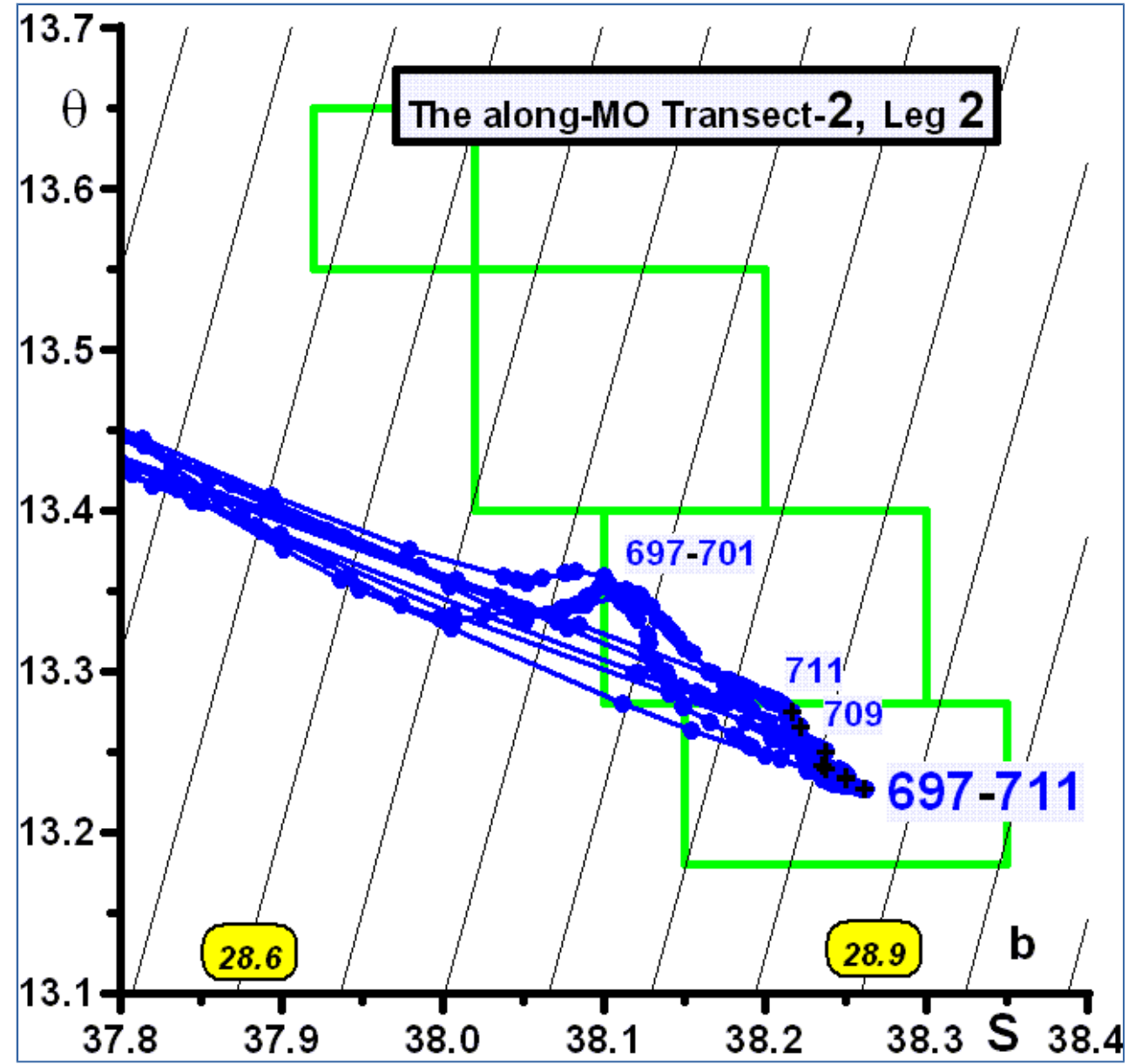

Figure 8b. As in Fig.3a for the along-MO Transect-2, Leg 2. 
Ocean Sci. Discuss., https://doi.org/10.5194/os-2017-54

Manuscript under review for journal Ocean Sci.

Discussion started: 1 August 2017

(C) Author(s) 2017. CC BY 4.0 License.

3.3.3 Leg 3 (Fig.8c)

The classical north-south cross-MO distribution is observed with the northernmost linear profiles in blue having

the largest $\mathbf{S}_{\max }(\# 713-717)$, a slightly lower blue $\mathbf{S}_{\max }$ at $\# 719$ and violet water in the south (\#721-723).

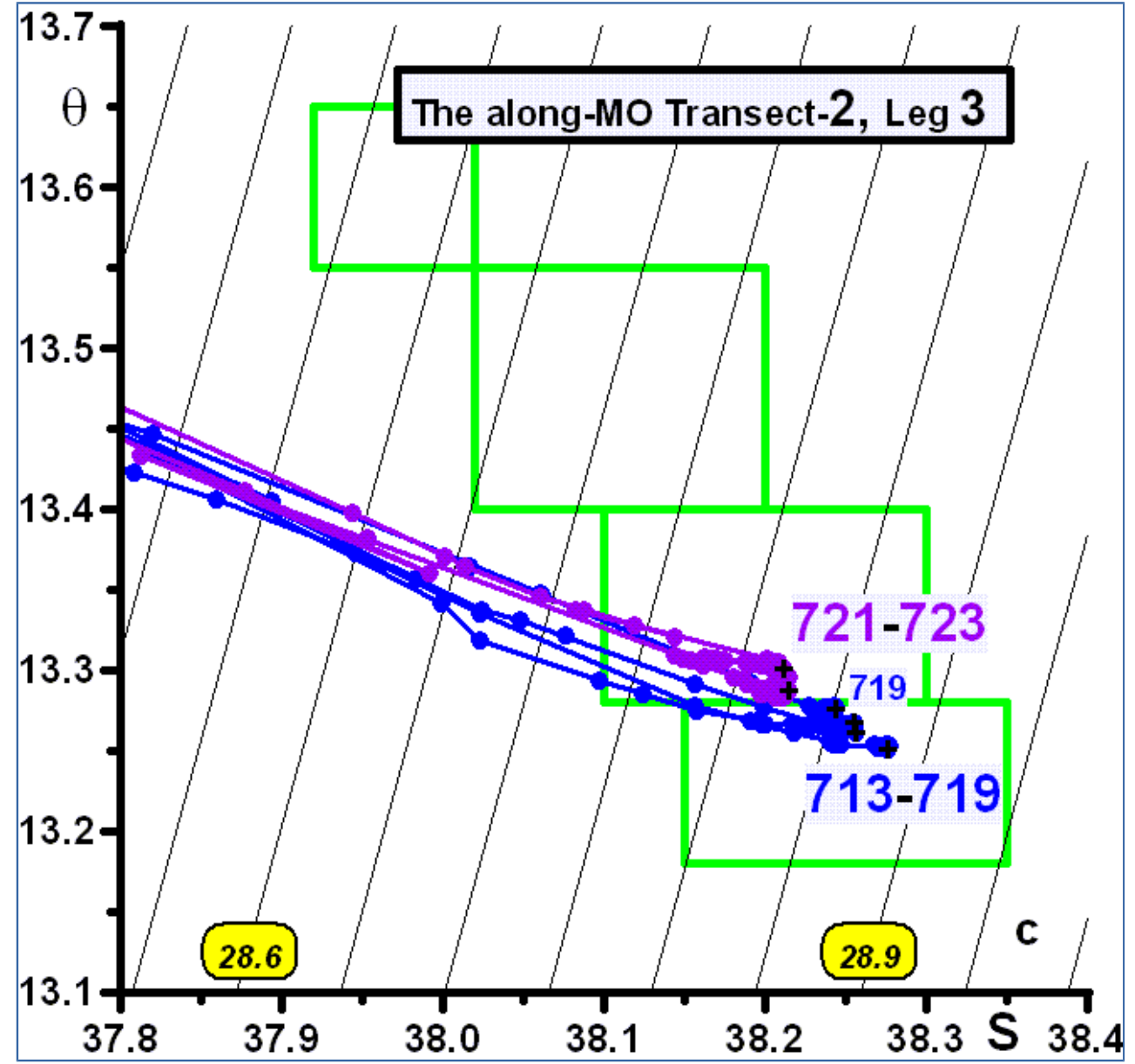

Figure 8c. As in Fig.3a for the along-MO Transect-2, Leg 3. 
Ocean Sci. Discuss., https://doi.org/10.5194/os-2017-54

Manuscript under review for journal Ocean Sci.

Discussion started: 1 August 2017

(c) Author(s) 2017. CC BY 4.0 License.

Leg 4 is very similar to Leg 3: largest $\mathbf{S}_{\max }$ in blue (\#725,727), an intermediate $\boldsymbol{S}_{\max }$ in blue-violet (\#729) and then violet $\mathbf{S}_{\max }$ decreasing from \#731-733 to \#735-737.

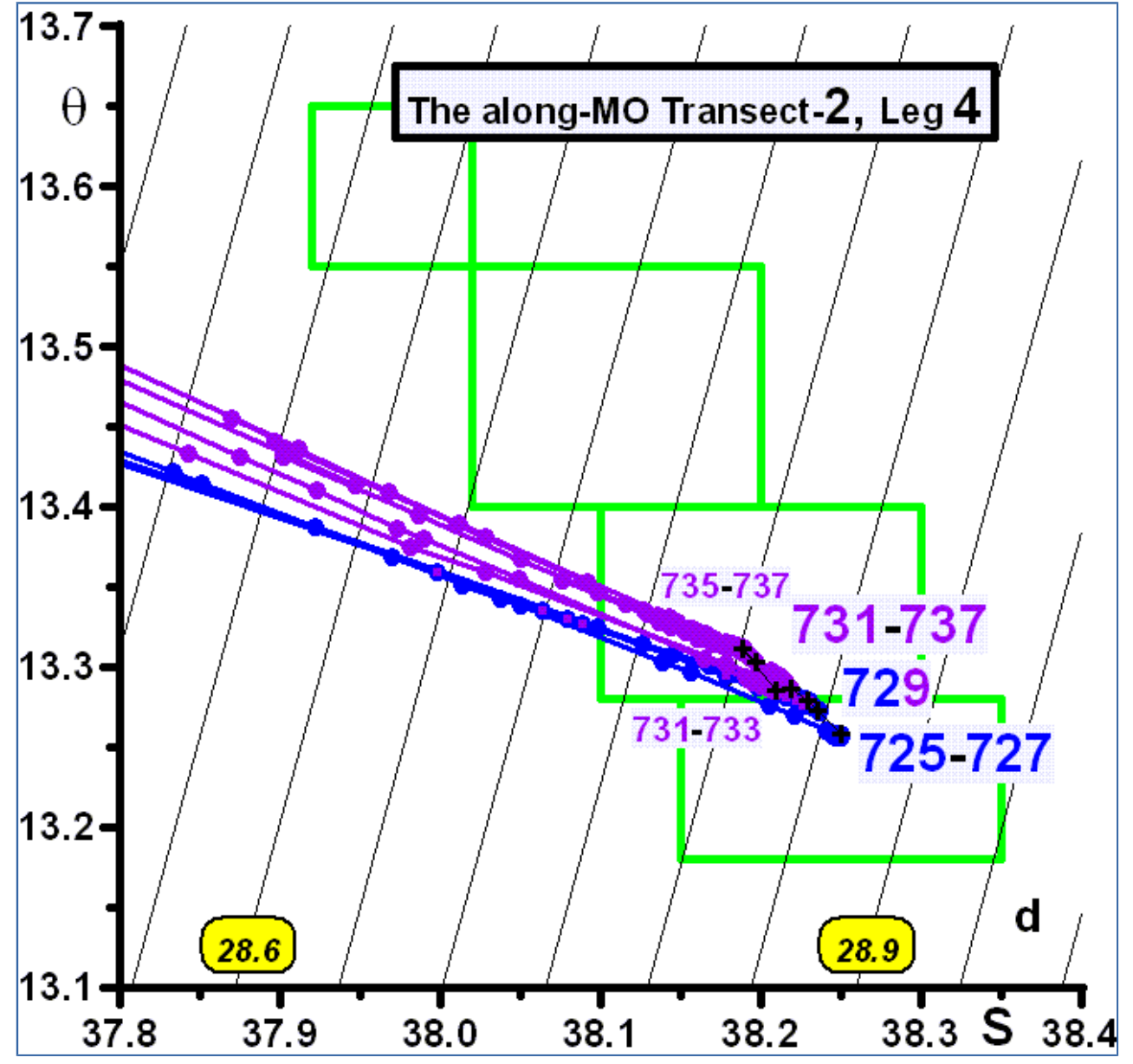

Figure 8d. As in Fig.3a for the along-MO Transect-2, Leg 4. 
Ocean Sci. Discuss., https://doi.org/10.5194/os-2017-54

Manuscript under review for journal Ocean Sci.

Discussion started: 1 August 2017

(C) Author(s) 2017. CC BY 4.0 License.

\subsubsection{Leg 5 (Fig.8e)}

Even though features evidenced during Leg 5 are more complex than during the previous legs, they are consistent and hence especially interesting. It is the only leg of the series evidencing a violet profile (\#747) in between blue ones. Largest $\boldsymbol{S}_{\max }$ are classically in the north (\#739-743), they first reduce (\#745) before becoming violet (\#747) and coming back blue with still relatively small values (\#749,751). Meanwhile, mixing lines start from being straight in the north (\#739-741) before being modified by the red or orange MW in the central part of the leg (\#743-749) and finally becoming straight again (\#751). Of special interest in this respect is the series of similar $\mathbf{S}_{\max } \sim 28.6 \mathrm{~kg} \cdot \mathrm{m}^{-3}$ values displayed on the violet $\# 747$ profile that clearly denote a relatively homogeneous layer of MW at intermediate depths that should be red or orange. All this somehow validates our coloring: the relatively small change in $\mathbf{S}_{\max }$ associated with $\# 747$ that we subjectively colored differently, hence hypothesizing it revealed a different MW, is in fact associated with marked changes over the whole depth and the coloring is thus significant.

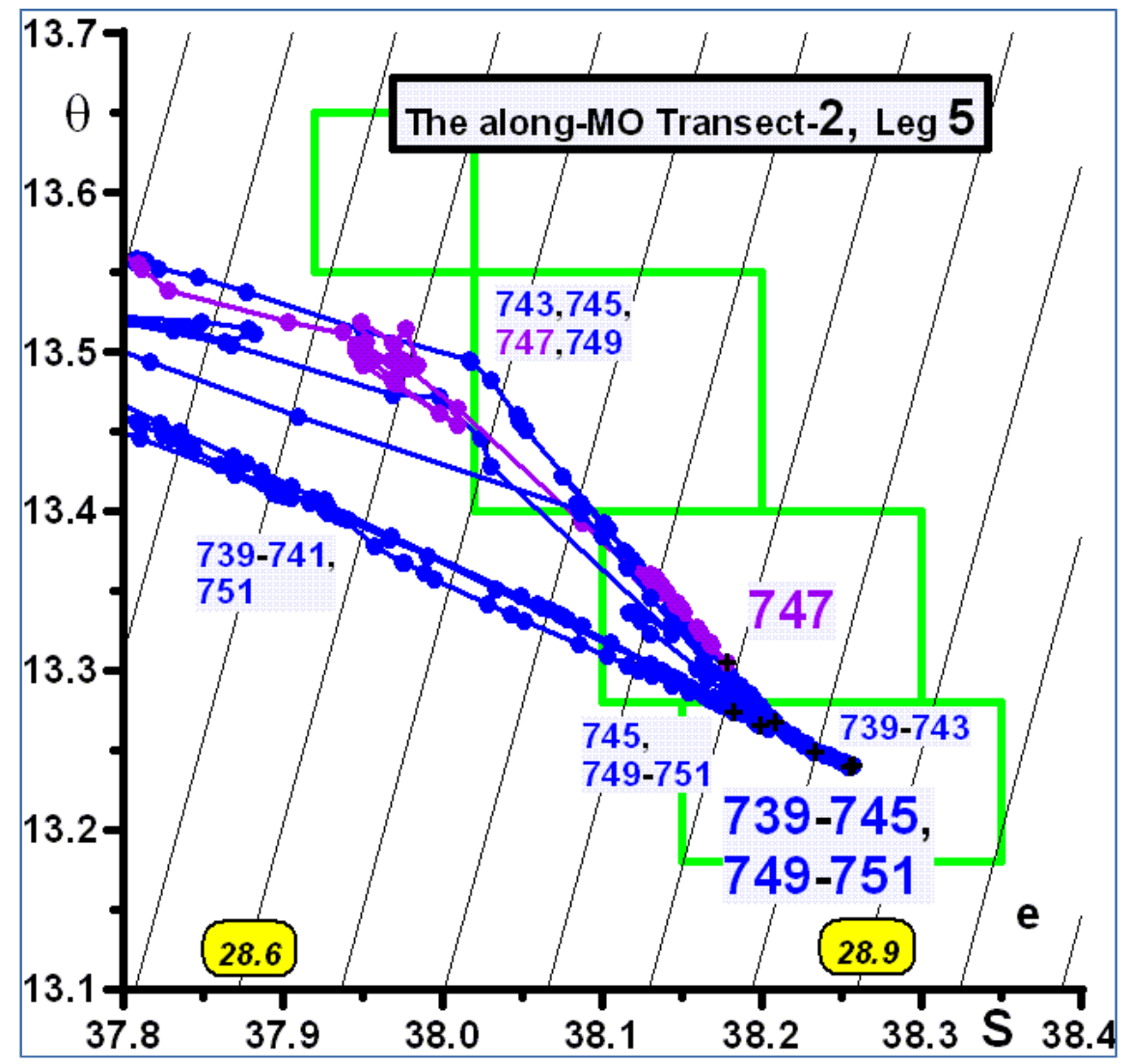

Figure 8e. As in Fig.3a for the along-MO Transect-2, Leg 5. 
Ocean Sci. Discuss., https://doi.org/10.5194/os-2017-54

Manuscript under review for journal Ocean Sci.

Discussion started: 1 August 2017

(C) Author(s) 2017. CC BY 4.0 License.

\subsubsection{Leg 6 (Fig.8f)}

Leg 6 is, for us, the most interesting leg. Classically, most $\mathbf{S}_{\max }$ continuously decrease from the left-hand side (\#753 and \#755) to \#757 still blue, then with the blue-violet \#761, and finally the violet \#763 and \#765. But, just in between these two groups of three profiles, \#759 evidences an extremely low $S_{\max }$ of $27.65 \mathrm{~kg} \cdot \mathrm{m}^{-3}$ at the greatest depth reached by the profile (406 m), which clearly sign (see Fig.3) not very mixed AWs! As indicated by the lower part of Fig.7, \#759 and \#757 reached the same depth of $406 \mathrm{~m}$ (\#761 reached $451 \mathrm{~m}$ ), and values of $\mathrm{S}_{\max } \sim 27.65 . \mathrm{kg} . \mathrm{m}^{-3}$ were encountered at $318 \mathrm{~m}$ for \#757 and $298 \mathrm{~m}$ from \#761 (Fig.7), which are shallower by $\sim 100 \mathrm{~m}$ !

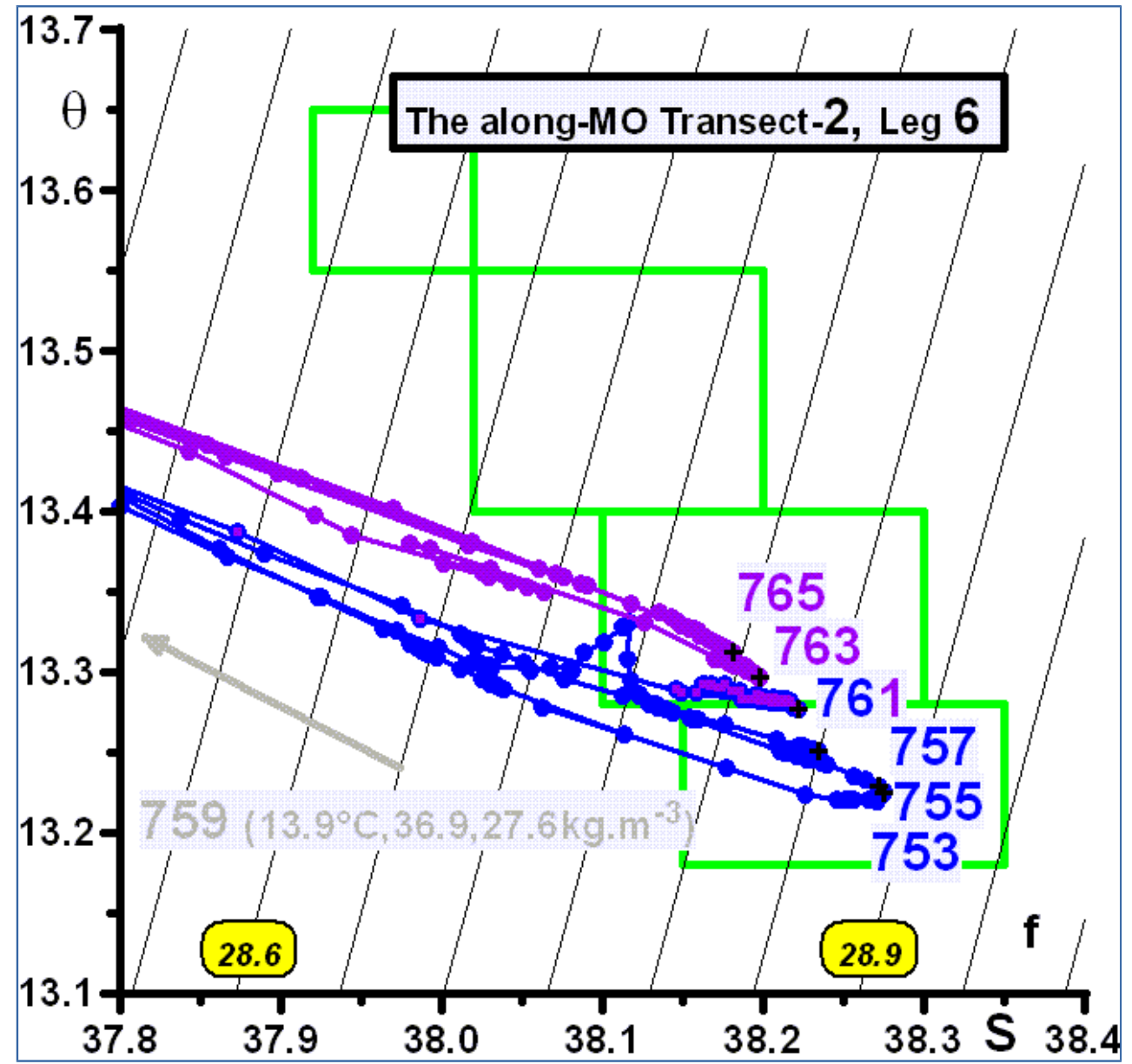

Figure 8f. As in Fig.3a for the along-MO Transect-2, Leg 6. 
Ocean Sci. Discuss., https://doi.org/10.5194/os-2017-54

Manuscript under review for journal Ocean Sci.

Discussion started: 1 August 2017

(c) Author(s) 2017. CC BY 4.0 License.

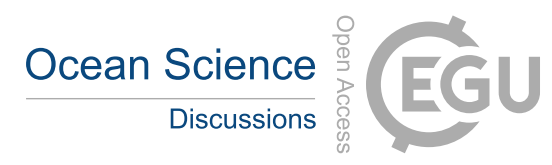

(c) (i)

The kriging for all three parameters $\mathrm{q}, \mathrm{S}$ and $\mathrm{S}_{\mathrm{q}}$ is presented in Fig.9 even though they display very similar distributions, as expected since the q-S diagrams in Fig. $8 \mathrm{f}$ are relatively straight mixing lines; this will allow an easier discussion of the numerical values and a better comparison with a similar situation described below

(Fig.12) that was collected during the Central Point-2 yo-yo time series collected just in between the positions of

\#753 and \#755. 
Ocean Sci. Discuss., https://doi.org/10.5194/os-2017-54

Manuscript under review for journal Ocean Sci.

Discussion started: 1 August 2017

(C) Author(s) 2017. CC BY 4.0 License.
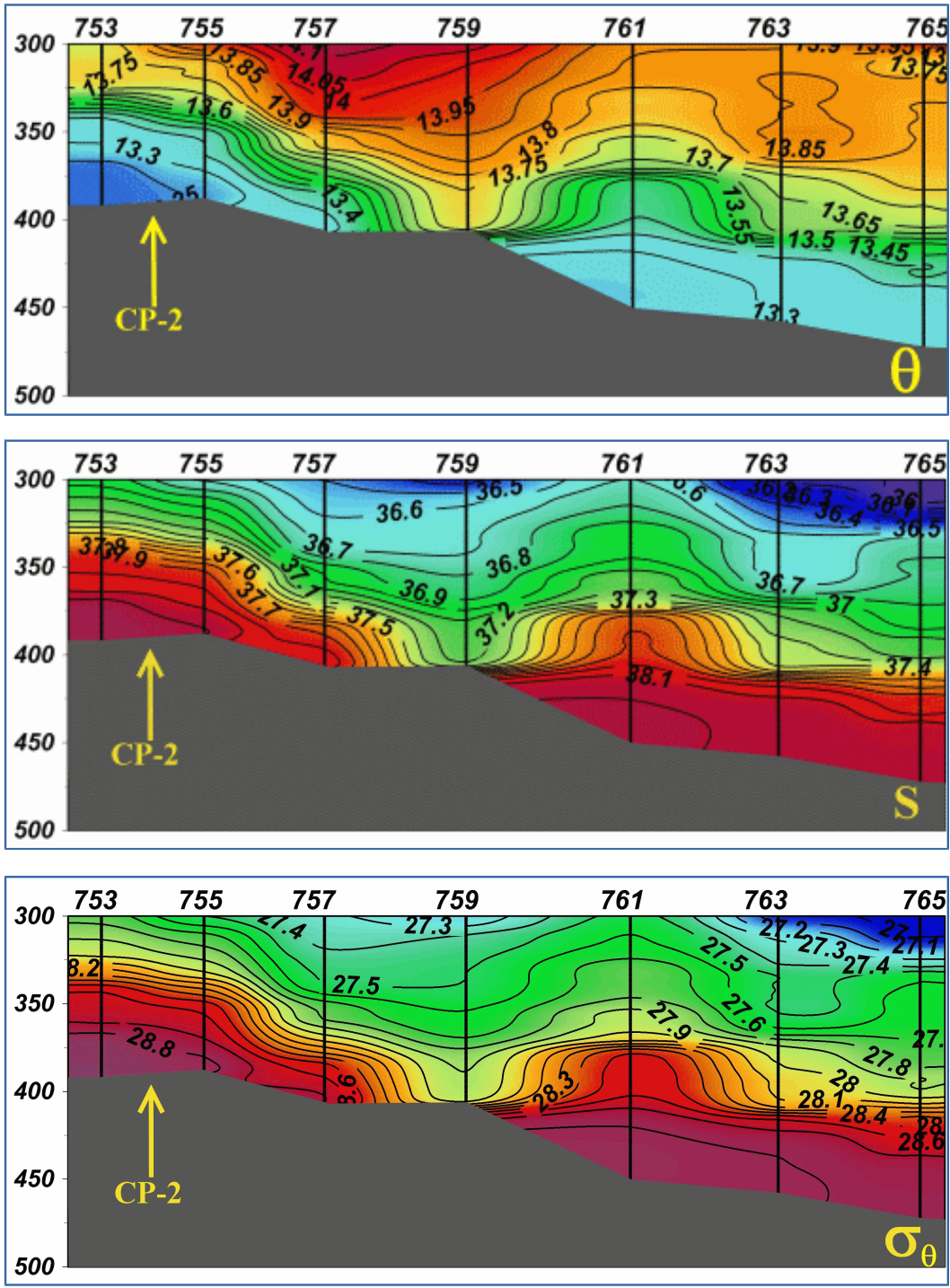

Figure 9. $\mathrm{q}, \mathrm{S}$ and $\mathrm{s}_{\mathrm{q}}$ distribution on the along-MO Transect-2, Leg 6, corresponding to Fig. $8 \mathrm{f}$ in which \# 753, $\# 755$ and \#757 are blue, \#759 is gray and \#761 is considered to be violet together with \#763 and \#765. These plots were performed with ODV (Schlitzer, 2014), in particular to benefit easily from the rich color scale (the ranges for the sets of data from this transect and from the yo-yo time series shown in Fig.12a with the same color scale are Dq: $13.0-14.2(0.05){ }^{\circ} \mathrm{C}$, DS: $36.0-38.4(0.1)$, Ds $\mathrm{q}$ : 26.7-28.9 $\left.(0.1) \mathrm{kg} \cdot \mathrm{m}^{-3}\right)$. Note that, even though this was a tow-yo transect, only data from the downcasts are considered and plotted at the only position reported when the CTD is at the surface ( $\sim 1 \mathrm{~km}$ apart). Indeed, kriging does not allow considering data irregularly distributed (as along the actual V-shaped trajectory of the CTD) and considering also the upcasts (thus necessarily plotted away from the upcasts) would have introduced significant bias since both casts would 
Ocean Sci. Discuss., https://doi.org/10.5194/os-2017-54

Manuscript under review for journal Ocean Sci.

Discussion started: 1 August 2017

(c) Author(s) 2017. CC BY 4.0 License. and the upcasts can be merged only near mid-depth of a tow-yo transect. The yellow arrow indicates the position of the Central Point-2 time series discussed in Fig.11a and 12a.

The overall information given by Fig. 9 is that the thickness of the two veins of MWs lying on the bottom regularly reduces toward \#759 that does not evidence any MW at all, so that \#759 does correspond to actual data and is not due to some malfunctioning of the CTD. However, note that kriging, as usual, smooths extreme values when they are very different from neighbors: for instance, $\mathbf{S}_{\max }$ associated with \#759 is computed as $\sim 28.0 \mathrm{~kg} . \mathrm{m}^{-3}$ in Fig.9 while its actual value is $27.65 \mathrm{~kg} \cdot \mathrm{m}^{-3}$. Also, relatively slight differences are not correctly reproduced: for instance, the relatively cool vein on the left-hand side of the MO (and on the left of the plots) is easily identified with the blue component on the q-S diagrams in Fig.8f, but the denser and saltier characteristics of this blue component as compared to the violet one are not well represented. Whatever the case, note that the lightest (violet) vein in the MO central part (and on the right of the plots) is at depths larger by $\sim 50 \mathrm{~m}$ than where the densest (blue) vein is, but still over the southern slope of the Strait (not in its deeper part). This is the best example provided by the MO-2009 experiment of the interface layers separating two components of the MO and the fact that the MO has split much before the Strait exit with already very different hydrological characteristics that are linked to its origin, and not to some different mixing processes linked to local bathymetric features. Arguments detailed in Part 1 and 2, as the necessity for mixing lines to converge towards a given q-S-S $\mathrm{q}$ set in case of different mixing processes of a hypothetically homogeneous MO must be clearly in mind: the violet and blue mixing lines do not converge, at least towards a realistic q-S-S $\mathrm{q}_{\mathrm{q}}$ set.

Such a leg and the occurrence of a profile such as \#759 do not evidencing any MW clearly indicate that two MWs juxtaposed side by side can be separated by some interface without any MW. Note that because such a situation has been encountered on other occasions (see below), even if in a less clear way, it is not a rare situation. In the study area at least, such an interface is probably relatively narrow and it can be clearly sampled on the vertical only if the MO is not meandering too much or not too turbulent; its sampling with a CTD towed some tens of meters above the bottom would, on the contrary, be trivial. Unfortunately, only few LADCP data are available during this leg. 
Ocean Sci. Discuss., https://doi.org/10.5194/os-2017-54

Manuscript under review for journal Ocean Sci.

Discussion started: 1 August 2017

(C) Author(s) 2017. CC BY 4.0 License. to \#769), then to blue-violet (\#771) and finally to violet ones in the south (\#773-781).

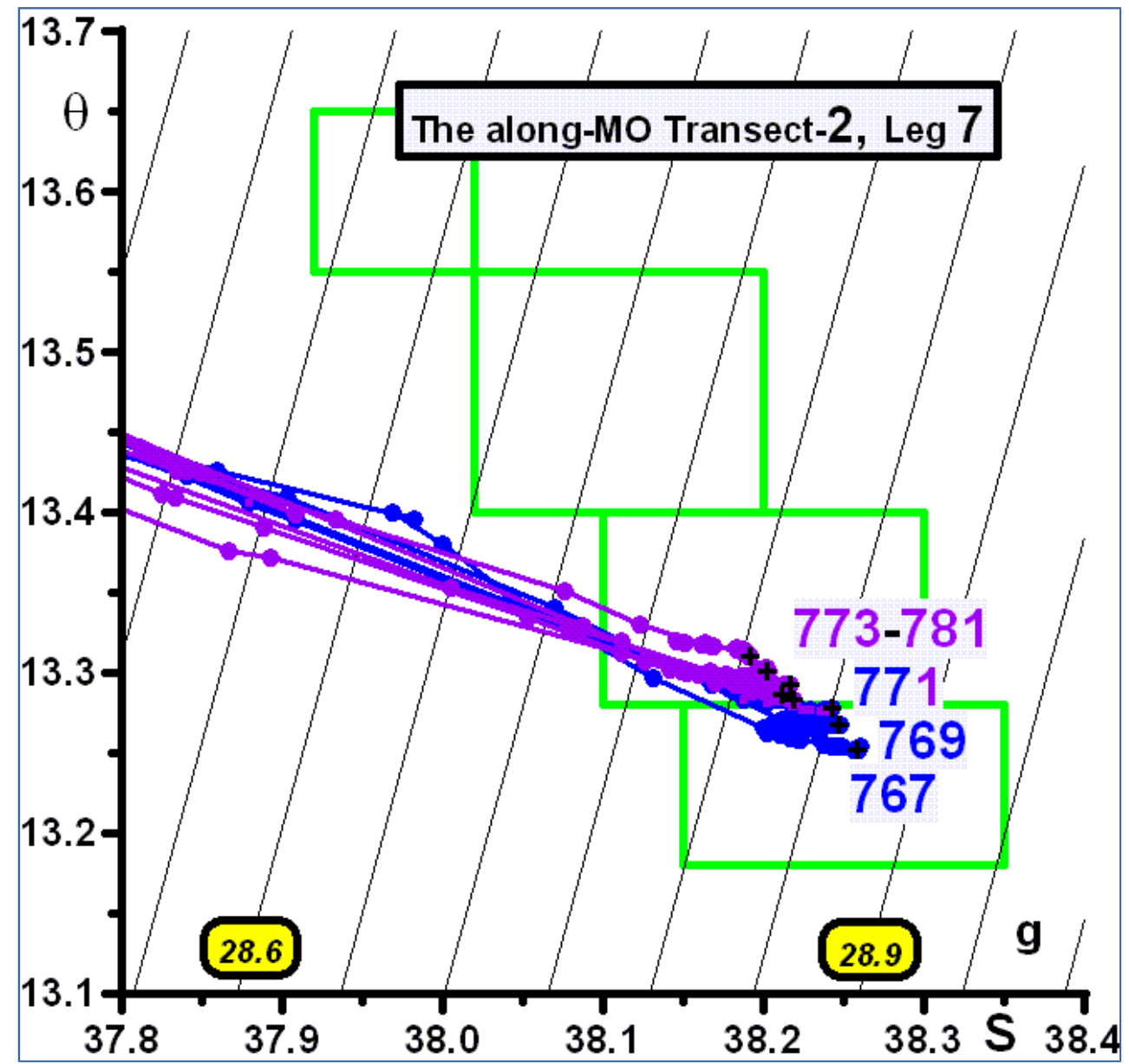

Figure 8g. As in Fig.3a for the along-MO Transect-2, Leg 7. 
Ocean Sci. Discuss., https://doi.org/10.5194/os-2017-54

Manuscript under review for journal Ocean Sci.

Discussion started: 1 August 2017

(c) Author(s) 2017. CC BY 4.0 License.

A similar situation is encountered during Leg 8 with a homogeneous blue water in the north (\#783-795) and a markedly different violet-blue water in the south (\#797). Note that \#795 indicates, at intermediate depths, a transition between the two types of waters evidenced on neighboring profiles.

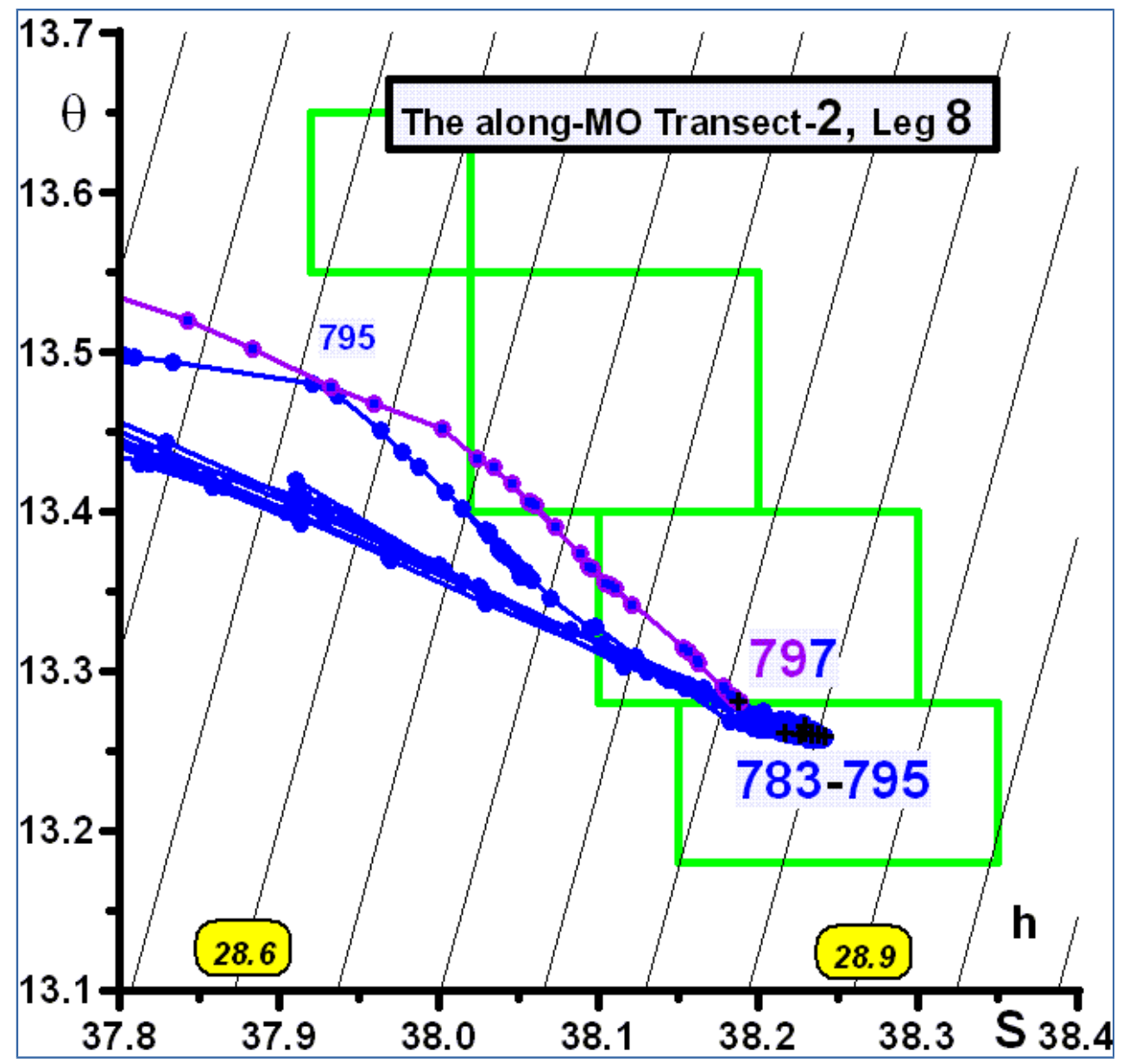

Figure 8h. As in Fig.3a for the along-MO Transect-2, Leg 8. 
Ocean Sci. Discuss., https://doi.org/10.5194/os-2017-54

Manuscript under review for journal Ocean Sci.

Discussion started: 1 August 2017

(c) Author(s) 2017. CC BY 4.0 License.

\subsection{Yo-yo time series at specific points}

835 The yo-yo time series collected at the specific locations indicated in Tab.1 and Fig.1b evidence features as important as the features evidenced by the transects and much deserve detailed analyzes. Most time series are cut in two for clarity of the figures, and they are analyzed first with q-S diagrams and then with a focus on the $\mathrm{S}_{\max }$ characteristics as a function of time, as previously done for the transects as a function of space (e.g. Fig.2c, 5, 7).

\subsubsection{Central Point-1 (Fig.10a-c)}

At the beginning of the time series (\#175-209, Fig.10a), the first profile (\#175) is blue and relatively isolated. The following \#177 is violet but still relatively different from the next violet \#179 profile and other ones (\#191$209)$ as well. Then, \#181 is found in gray before the sampling of blue water again (\#183-187) that is not far from

845 the blue-violet limit; even though if less marked than for \#759 during Leg 6 of along-MO Transect-2, \#181 is another indication of an interface between the violet and blue waters. Some kind of an interface is also represented by the next violet-blue \#189 that is collected before continuously sampling (\#191-209) violet water again. We consider that the same violet-blue interface, that was not properly sampled during the first shift from blue to violet (it could have been sampled in between the blue \#175 and the violet \#177) has been more clearly sampled twice during the following shifts from violet to blue (the gray \#181) and then blue to violet (the violetblue \#189). Whatever the MO actual structure, these shifts at some given place are obvious evidence of a MO meandering. 
Ocean Sci. Discuss., https://doi.org/10.5194/os-2017-54

Manuscript under review for journal Ocean Sci.

Discussion started: 1 August 2017

(C) Author(s) 2017. CC BY 4.0 License.

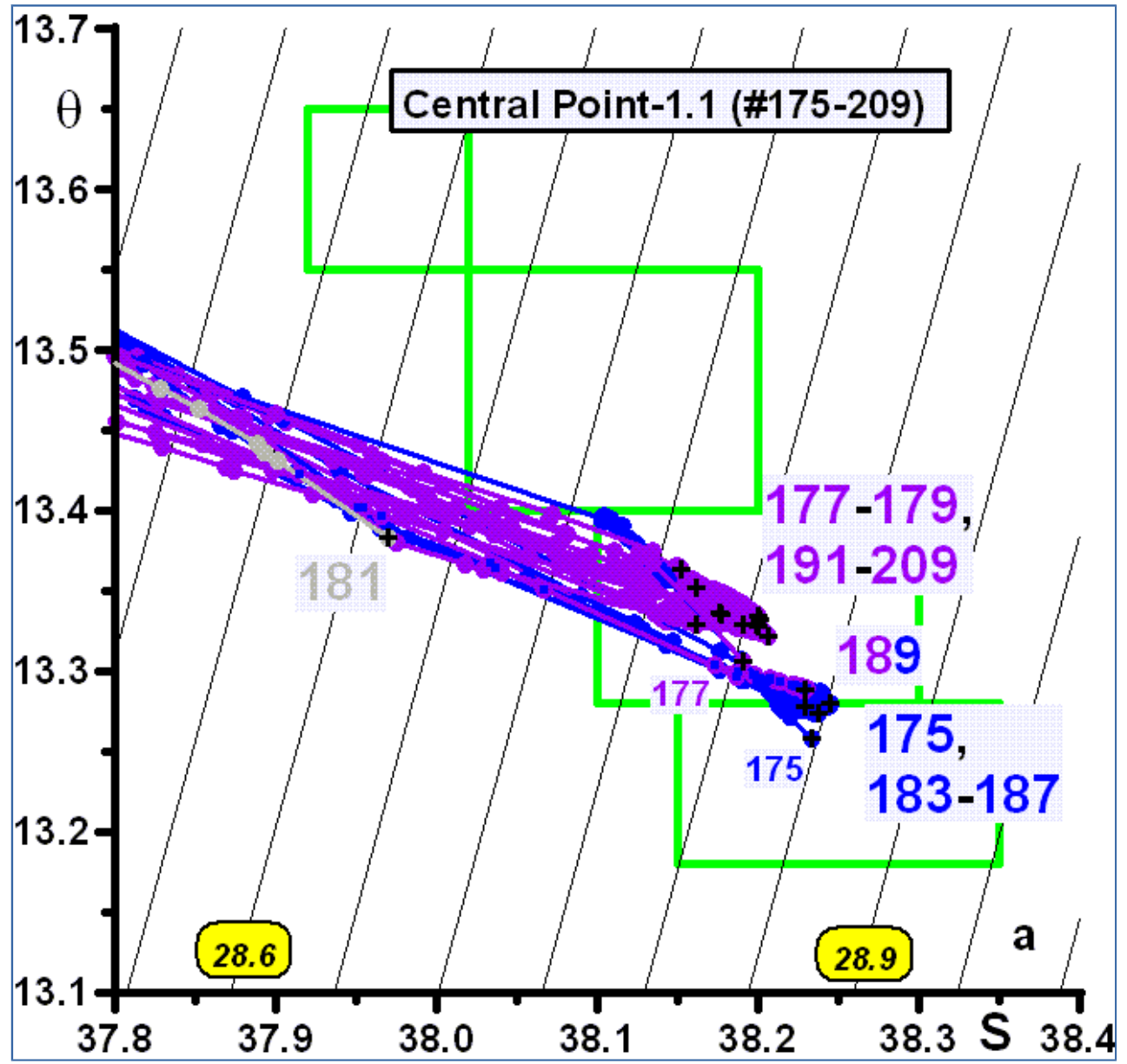

Figure 10a. As in Fig.3a for the Central Point-1, part 1.

We cut the Central Point-1 time series for convenience during the sampling of violet water actually sampled continuously from \#191 to \#225, which represents a relatively long period of time indicating that the MO was not markedly meandering and that sampling occurred just over the violet MO component. However, Fig.10b indicates that \#211-217, relatively similar to \#209, are significantly different from \#219-225, the latter having larger $\mathbf{S}_{\max }$ values so that the difference with the gray \#227 (that could have been easily gray-violet) and, mainly, the gray \#229 $\left(\mathrm{s}_{\max } \sim 28.4 \mathrm{~kg} \cdot \mathrm{m}^{-3}\right)$ is relatively important. Furthermore, \#231 as well as the other ones till \#243 are blue; note that some could have been blue-violet but colors are used just for easiness of the description. The important result is that an interface has been sampled by two profiles $(\# 227,229)$ in between the relatively light MW sampled by eighteen profiles (\#191-225) and the relatively dense MW sampled by seven (at least since the time series was stopped then) profiles (\#231-243). 
Ocean Sci. Discuss., https://doi.org/10.5194/os-2017-54

Manuscript under review for journal Ocean Sci.

Discussion started: 1 August 2017

(C) Author(s) 2017. CC BY 4.0 License.

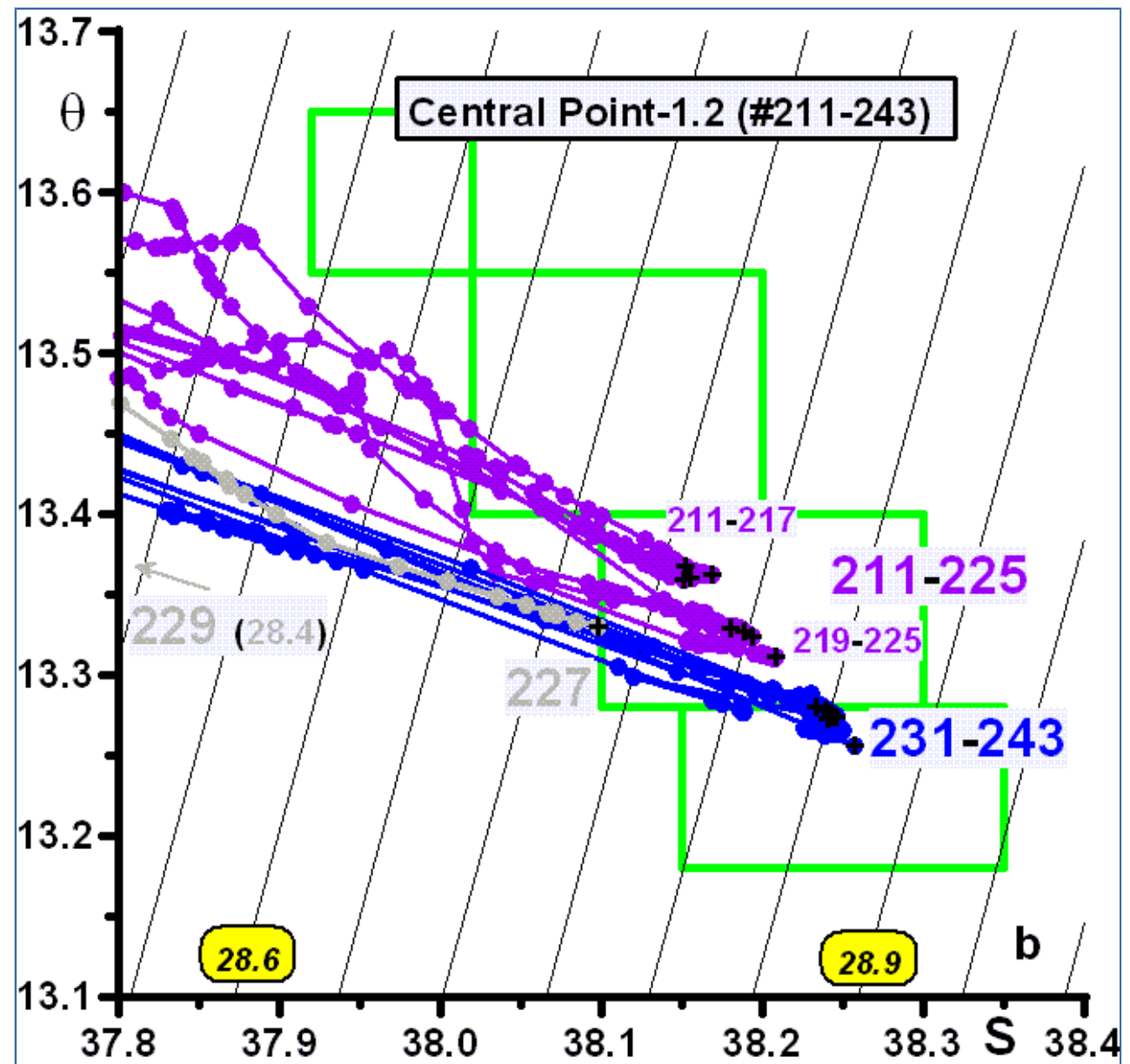

Figure 10b. As in Fig.3a for the Central Point-1, part 2.

Before analyzing the additional information provided by Fig.10c, let us specify that it is simpler than Fig.2c, 5 and 7 since the position recorded at the beginning of the downcasts only changed by $\sim 10^{-3} \circ$ in both latitude and longitude (as during the other time series at other points), so that the position of the ship is supposed to be permanent during all a given time series; note that this was not the case during the GIBEX yo-yo time series, so that we specified the ship positions (as defined by radar measurements) as an insert into the q-S diagrams. Note

that since profiles were performed down to depths ranging from $440 \mathrm{~m}$ to $500 \mathrm{~m}$, we cannot specify whether these differences are due to drifts of the ship during the downcasts that were compensated during the upcasts, and/or to variable drifts of the CTD during the downcasts and/or to lowering of the CTD more or less close to the bottom due to the experimental procedure without any pinger. 
Ocean Sci. Discuss., https://doi.org/10.5194/os-2017-54

Manuscript under review for journal Ocean Sci.

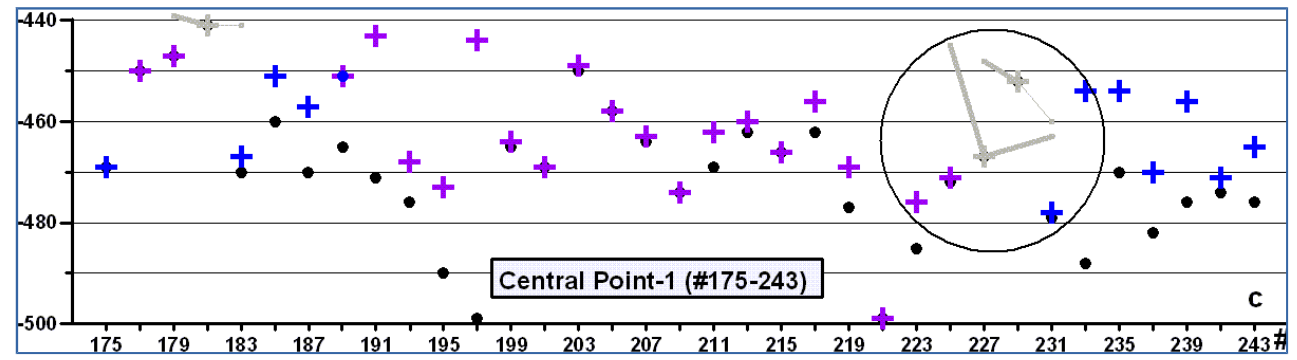

Figure 10c. Depths of the $S_{\max }$ of each profile (colored +) from the yo-yo time series at Central Point-1 together with the maximum depth (black dot) reached by the profile. In gray, immersion of the $\# 227-S_{\max }$ isopycnal at neighboring locations (also for \#181, 229).

Figure 10c shows that, even though the \#181 $\mathrm{S}_{\text {max }}$ was lower than the \#227 $\mathrm{S}_{\max }$, it was found at a relatively shallow depth $(440 \mathrm{~m})$ that was roughly the same as for the violet profile before and the blue profile after; even though significant for what concerns the hydrological differences between the MWs before and after, the information provided by \#181 is not very significant from a dynamical ( $\mathrm{S}_{\max }$ slope) point of view. Roughly similar comments can be made for the $\# 229 \mathrm{~S}_{\max }$ that was found at a relatively shallow depth $(452 \mathrm{~m})$ not markedly different from the depth the associated isopycnal has during the profiles before (448 $\mathrm{m}$ ) and after (460 $\mathrm{m})$. However, \#227, even if not characterized by a very low $S_{\max }$, sampled it at a relatively large depth of $467 \mathrm{~m}$ while similar densities (28.727 kg.m $\mathrm{m}^{-3}$ ) were found before (\#225) at $445 \mathrm{~m}$ and much after (\#231) still (not found with \#229) at $463 \mathrm{~m}$. From a dynamical point of view, as from a hydrological one, \#227 might thus be the most significant for characterizing the interface between the violet and the blue MWs.

\subsubsection{Central Point-2 (Fig.11a-c)}

This data set reveals interesting, although complex, features that benefit from LADCP data at its beginning and are thus analyzed first with figures (Fig.11a-c) similar to those drown for the other data sets as well as from plots vs. time (Fig.12) that can advantageously be considered all together.

Three days later (Tab.1) at the same place and during the first half of this new yo-yo time series (Fig.11a), violet water was observed at the beginning (\#481-485) with straight mixing lines up to \#487 that suddenly displays a marked inflexion towards the orange rectangle, with the $28.55 \mathrm{~kg} \cdot \mathrm{m}^{-3}$ found near $440 \mathrm{~m}$. Surprisingly, since \#487 has a $S_{\max }=28.75 \mathrm{~kg} \cdot \mathrm{m}^{-3}$ at $460 \mathrm{~m}$, the next $\# 489$ clearly displays orange water with a much lower $\mathrm{S}_{\max }=28.55$ $\mathrm{kg} . \mathrm{m}^{-3}$ now at a deeper immersion of $467 \mathrm{~m}$ (information can be retrieved in Fig.11c); both the sudden and large difference in $\mathrm{S}_{\max }$ together with the facts that no red water was observed in between and the orange mixing line is not straight (towards the AWs) are rare features. The next \#491 looks similar to \#489, but we will present arguments from Fig.11c that account for our gray coloring. The next \#493 is violet and it displays a marked inflexion similar to the \#487 one, which clearly accounts for an event (orange \#489+ gray \#491) having passed back and forth the CTD mean location. Such an inflexion is also observed on the next profiles (\#495-499) that 
Ocean Sci. Discuss., https://doi.org/10.5194/os-2017-54

Manuscript under review for journal Ocean Sci.

(C) Author(s) 2017. CC BY 4.0 License.

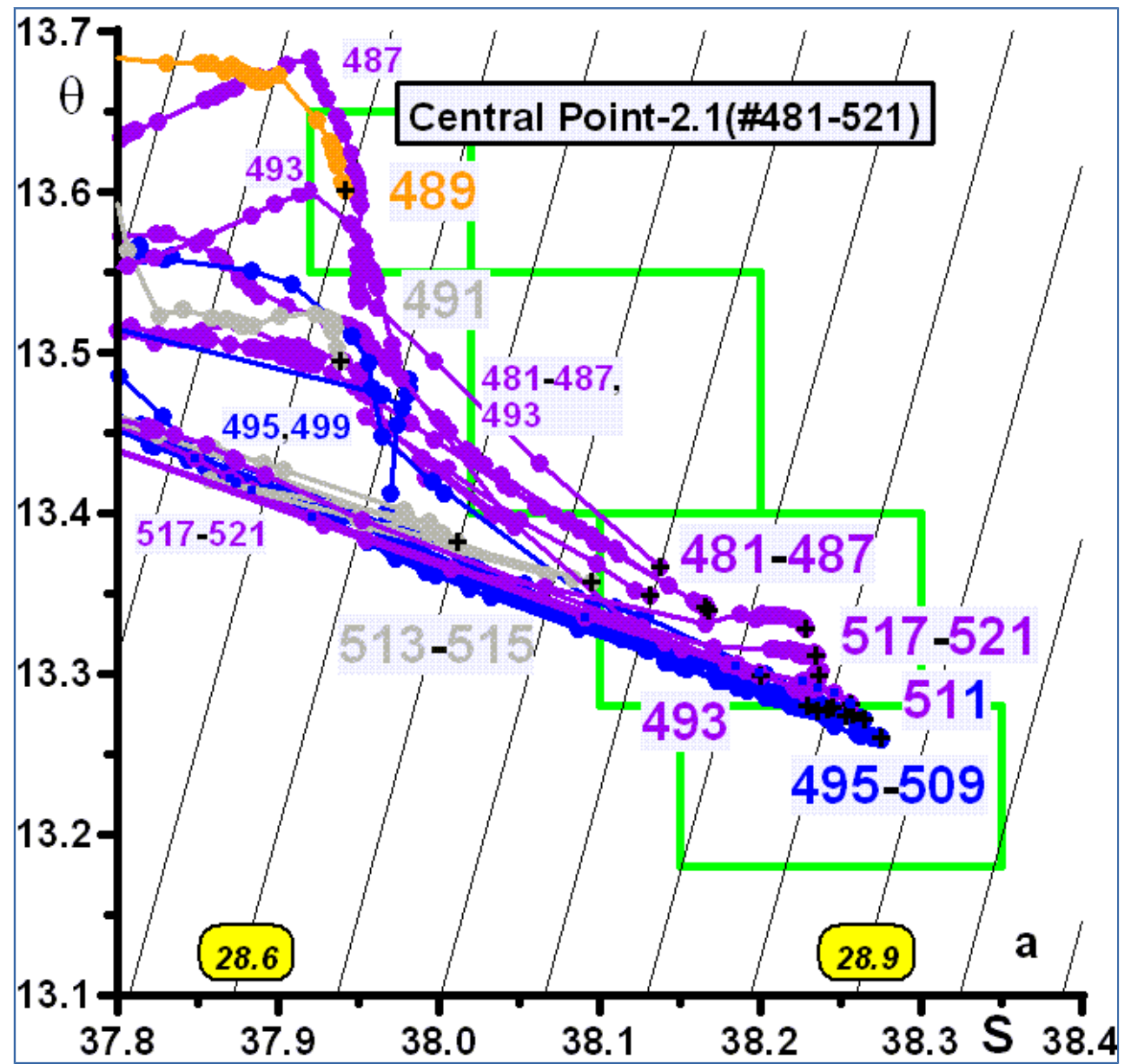

Figure 11a. As in Fig.3a for the Central Point-2, part 1.

This long (till \#551, Fig. 11b) violet period, during which profiles are straight mixing lines, ends with the blueviolet \#553 that starts bending towards the red water and with the violet \#555 that evidences a marked bending in the red rectangle and a relatively homogeneous intermediate layer of $\sim 28.69 \mathrm{~kg} \cdot \mathrm{m}^{-3}$ near $455 \mathrm{~m}$ while its

$S_{\max }=28.83 \mathrm{~kg} \cdot \mathrm{m}^{-3}$ is just below at $460 \mathrm{~m}$. Surprisingly too, and as for the orange \#489, the next profile \#557 is clearly red with $S_{\max }=28.69 \mathrm{~kg} \cdot \mathrm{m}^{-3}$ at the bottom of $450 \mathrm{~m}$; but contrary to the gray \#491, the next profile \#559 that is gray according to our rectangles should be more significantly red (see below). Profiles then are alternatively violet (\#561), blue (\#563), violet (\#565), blue (\#567-571) and violet (\#573-581) before \#583, which 
Ocean Sci. Discuss., https://doi.org/10.5194/os-2017-54

Manuscript under review for journal Ocean Sci.

(C) Author(s) 2017. CC BY 4.0 License.

(c) (i)

is gray because of a relatively low $\boldsymbol{S}_{\max }$ possibly due to its depth of $430 \mathrm{~m}$, and the final series of violet \#585-601.

Note that, as for the orange \#489, the red \#557 mixing line is not straight towards the AWs.

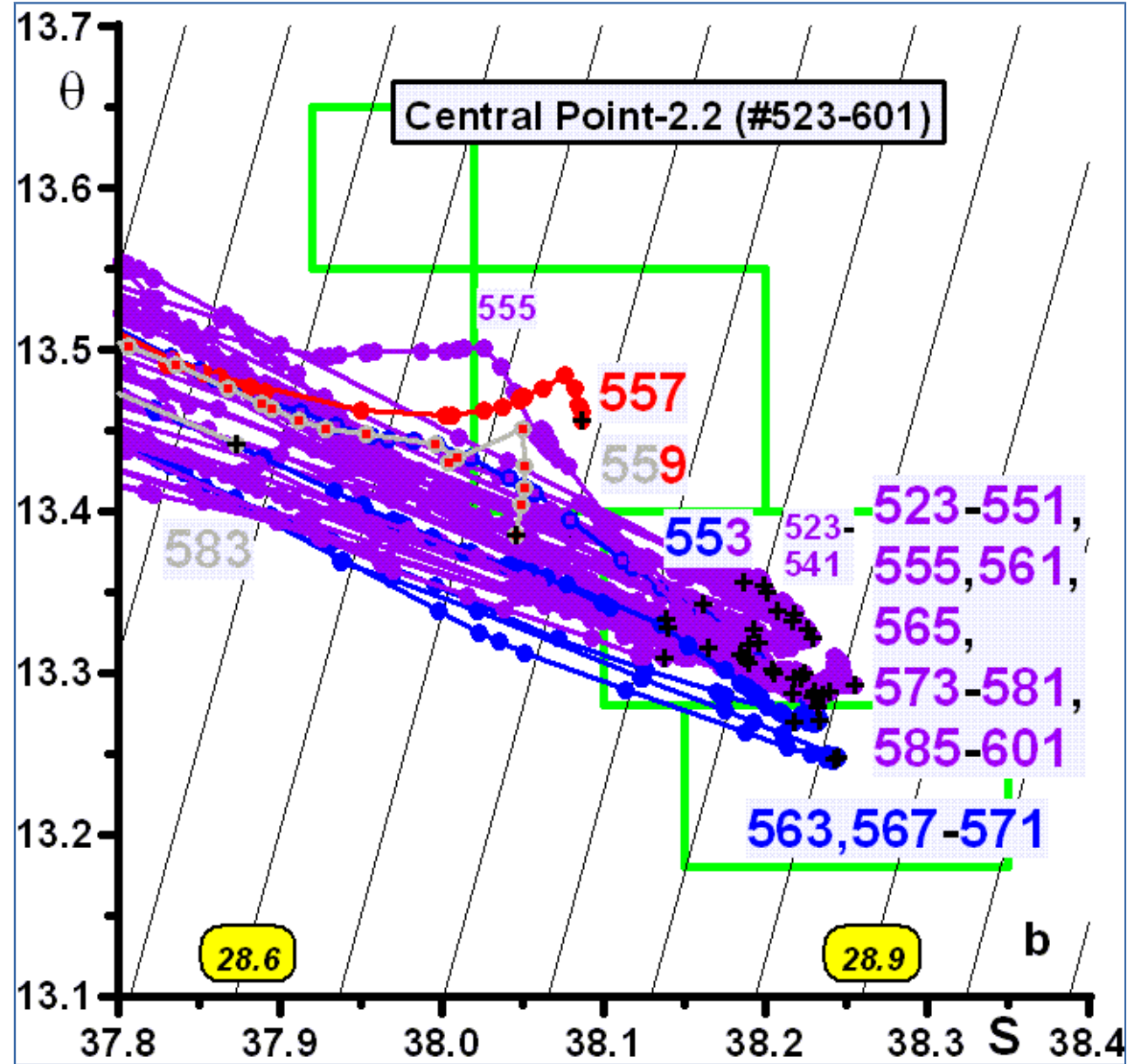

Figure 11b. As in Fig.3a for the Central Point-2, part 2.

Figure 11c shows, in particular, the orange $\# 489 \mathrm{~S}_{\max }$ at $467 \mathrm{~m}$ with its associated value of $28.55 \mathrm{~kg} \cdot \mathrm{m}^{-3}$ shallower by $25 \mathrm{~m}$ on the two neighboring profiles, which validates the fact that it evidences an actual light MW.

This is not the case for \#491 and its $S_{\max }=28.57 \mathrm{~kg} \cdot \mathrm{m}^{-3}$ at $445 \mathrm{~m}$ that is found at deeper locations on profiles \#487 and \#493, which validates the occurrence of a relatively dense MW that cannot be defined since the profile was not deep enough. The arguments already provided for the gray $\# 513,515$ are clearly illustrated. As for the red \#557, note that violet, hence denser, $S_{\max }$ neighbors are at the same depth of $450 \mathrm{~m}$, which is the same depth of the $\# 559 \mathrm{~S}_{\max }=28.68 \mathrm{~kg} \cdot \mathrm{m}^{-3}$ found at depths shallower by $5-20 \mathrm{~m}$ on the two neighboring profiles. 
Ocean Sci. Discuss., https://doi.org/10.5194/os-2017-54

Manuscript under review for journal Ocean Sci.

Discussion started: 1 August 2017

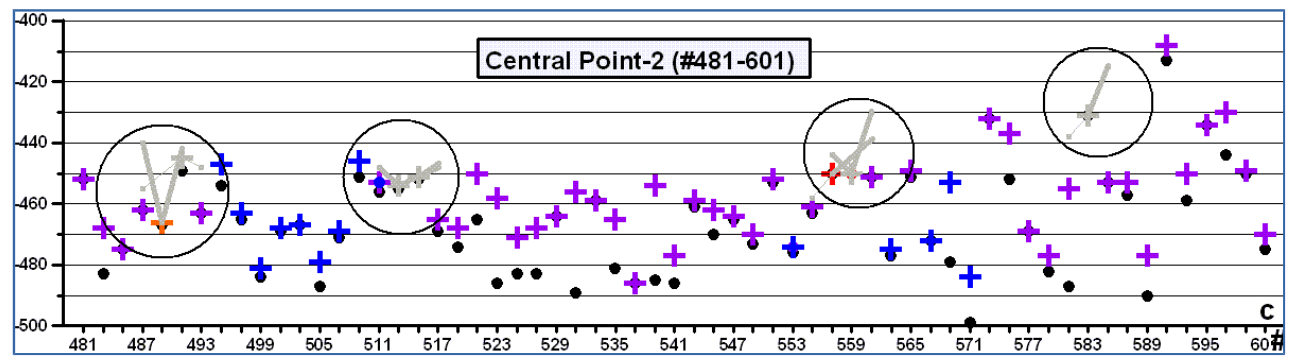

Figure 11c. As in Fig.10c for Central Point-2.

The somehow abstracted information provided by Fig.11a-c during the first half of the time series at Central Point-2 and the somehow subjective analysis we made with our coloring and argumentation can be forgotten before analyzing, in a purely objective and more classical way, the $\mathrm{q}, \mathrm{S}$ and $\mathrm{S}_{\mathrm{q}}$ plots in Fig.12a. Over all, the distribution and values of all three parameters demonstrate that MWs have always been lying on the bottom since characteristic values below $\sim 400 \mathrm{~m}$ are $\mathrm{q}<\sim 13.75^{\circ} \mathrm{C}, \mathrm{S}>37.0$ and $\mathrm{S}_{\mathrm{q}}>\sim 28.55 \mathrm{~kg} \cdot \mathrm{m}^{-3}$. Such a large scale distribution is thus very different from that in Fig.9 (\#753 to \#765) while the nominal position of the time series is just in between $\# 753$ and $\# 755$. 
Ocean Sci. Discuss., https://doi.org/10.5194/os-2017-54

Manuscript under review for journal Ocean Sci.

Discussion started: 1 August 2017

(C) Author(s) 2017. CC BY 4.0 License.
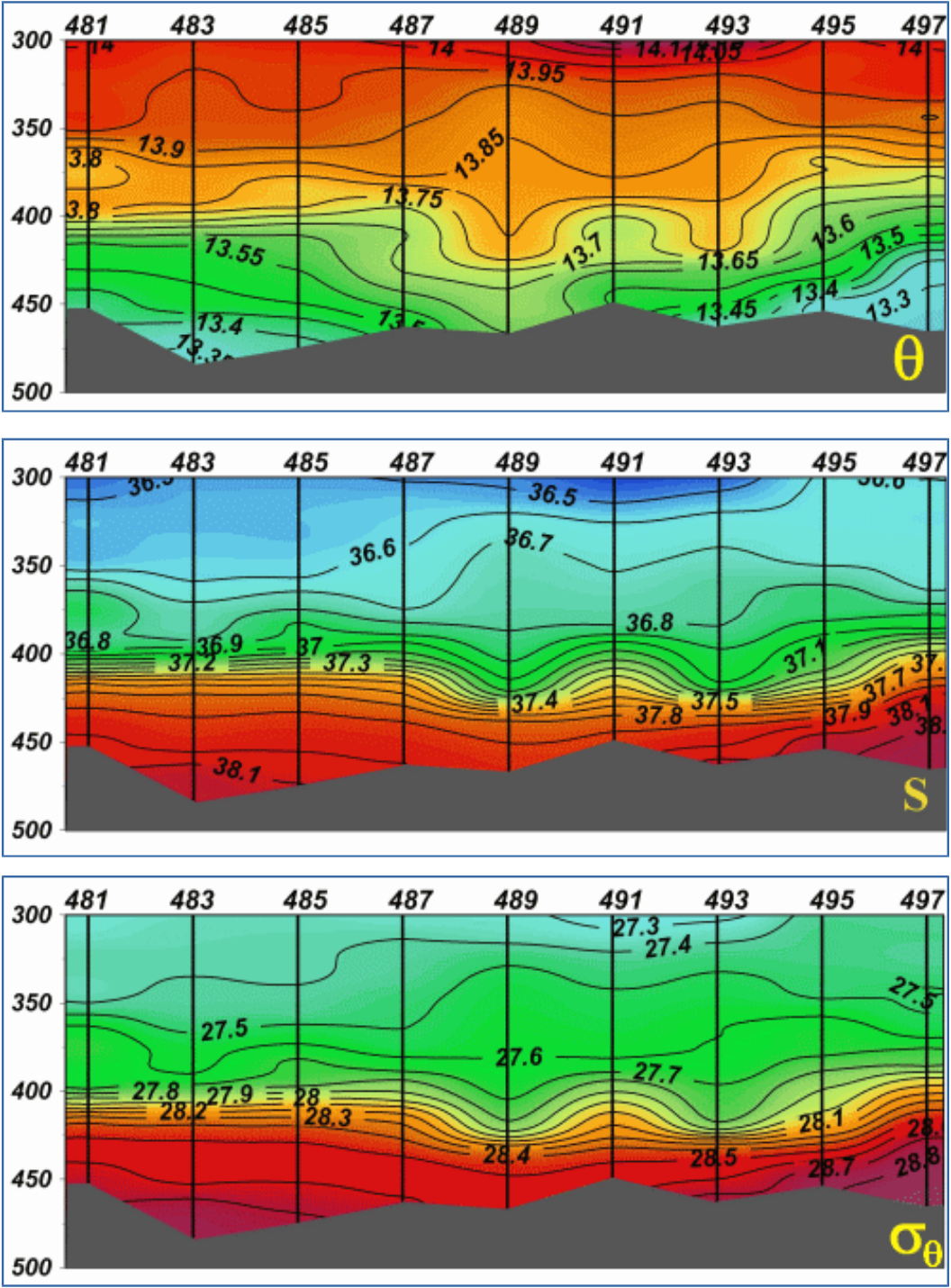

Figure 12a. $q, S$ and $S_{q}$ distribution at the beginning of the yo-yo time series at Central Point- 2 corresponding to Fig.11a. These plots were performed with ODV (Schlitzer, 2014), the color and depth scales are the same as those used in Fig.9 where the Central Point-2 appears to be located in between \#753 and \#755; the ranges for the sets of data from this yo-yo time series and from the transect shown in Fig.9 are Dq: 13.0-14.2 (0.05) ${ }^{\circ} \mathrm{C}$, DS: 36.0-38.4 (0.1), Ds q 26.7-28.9 (0.1) kg.m ${ }^{-3}$. As indicated in Tab.1 (62 profiles in $24 \mathrm{~h}$ ), profiles were performed less than $0.5 \mathrm{~h}$ apart. Note that only the downcasts of this yo-yo time series are plotted with a specific time step for reasons already specified in the legend of Fig.9. 
Ocean Sci. Discuss., https://doi.org/10.5194/os-2017-54

Manuscript under review for journal Ocean Sci.

Discussion started: 1 August 2017

(c) Author(s) 2017. CC BY 4.0 License.

Before describing the distribution of the three parameters associated with the various MWs that have been observed in succession over the bottom, let's note that they all display differences much lower than on Fig.9 while varying more smoothly so that kriging correctly represents actual values; for instance $S_{\max }=28.55 \mathrm{~kg} \cdot \mathrm{m}^{-3}$ for \#489 (Fig.11a) is correctly represented in Fig.12b. For easiness of the analysis below, and to more definitely forget about our possibly subjective analysis above, let us consider three groups of three profiles (which explains why we limit this analysis to \#481-497).

As for q, the first group (\#481-485) has relatively mild values (minima of $\sim 13.35^{\circ} \mathrm{C}$ ), the second group (\#487491) has relatively high values $\left(>13.60^{\circ} \mathrm{C}\right)$ while the third group ( $\left.\# 493-497\right)$ reaches low values $<13.30{ }^{\circ} \mathrm{C}$. Similar differences are clear for $\mathrm{S}$ with the third group being the saltiest $(>38.2)$, the first group having mild values $(>38.1)$ and the second group being the freshest $(<38.0)$. So that, one clearly notes for $\mathrm{S}_{\mathrm{q}}$ the successive occurrence of intermediate $\left(>28.7 \mathrm{~kg} \cdot \mathrm{m}^{-3}\right)$, relatively low $\left(>28.5 \mathrm{~kg} \cdot \mathrm{m}^{-3}\right)$ and relatively large $\left(>28.8 \mathrm{~kg} \cdot \mathrm{m}^{-3}\right)$ values. Just comparing the $S_{\mathrm{q}}$ variability of $\sim 0.3 \mathrm{~kg} \cdot \mathrm{m}^{-3}$ at a given place of the Strait exit within a couple of hours with the range of $\sim 0.55 \mathrm{~kg} . \mathrm{m}^{-3}$ permanently observed along the Iberian peninsula (Ambar et al., 2008) definitely demonstrates that the MO is markedly heterogeneous with a heterogeneity that has nothing to do with local bathymetric features at the Strait exit.

Note that this yo-yo time series was collected, according to data reports, exactly in between \#753 and \#755 (Fig.9), which illustrates the difficulty to work in such a place and/or the very complex topography. Indeed, the CTD reached maximum depths of 380-390 $\mathrm{m}$ at \#753 and \#755 during the tow-yo transect while maximum depths in between ranged between $\sim 450 \mathrm{~m}$ and $\sim 480 \mathrm{~m}$ during the yo-yo time series. This could be due either to depths actually larger at the position of the time series and/or to such a position located a bit more seaward than reported and/or to the fact that, in particular due to the absence of a pinger, the CTD was lowered closer to the bottom during the time series, thanks to much easier experimental conditions. Whatever the case, note that measured thicknesses of the different MWs are relatively similar ( $100 \mathrm{~m}$; actual thicknesses being obviously larger), which should indicate that sampling was made at best using both strategies. Now, while Fig.9 illustrates, with a sampling interval of $\sim 1 \mathrm{~km}$, the extremely large spatial variability (along a so-called along-MO transect), Fig.12a illustrates, with a sampling interval of $\sim 0.5 \mathrm{~h}$, the extremely large temporal variability which is even larger when $\# 753$ and $\# 755$, performed $\sim 2$ days after, are considered.

This hydrological variability can be compared with the dynamical variability evidenced by the LADCP data (Fig.12b). To be noticed first is that the $\mathrm{U}$ component in the direction of the mean current $\left(247^{\circ} \mathrm{T}\right.$, computed as

1015 indicated in the legend of Fig.12b) provides a definition of the MO much finer than only considering the magnitude M: the MO thickness was clearly $\sim 100 \mathrm{~m}$ and maximum values can be precisely attributed to the MO. Note that this direction is larger than the direction of $\sim 240^{\circ} \mathrm{T}$ indicated by Nash et al. (2012) who did not specify how they got it. Whatever the case, both can be compared with the $250^{\circ} \mathrm{T}$ orientation of the so-called along-MO transects (Fig.1b). It is amazing to realize that, due to so-called along-MO transects relatively long as compared 
Ocean Sci. Discuss., https://doi.org/10.5194/os-2017-54

Manuscript under review for journal Ocean Sci.

Discussion started: 1 August 2017

(c) Author(s) 2017. CC BY 4.0 License.

1020 to the MO wideness, a difference in the alignment of such transects with respect to the current lines as low as $\sim 10^{\circ}$ allows sampling both the left-hand and the right-hand sides of the MO.

Now, and even though the MO is always/everywhere roughly directed towards the west-south-west, a large temporal variability is also observed between profiles. However, relationships between both sets of CTD and

1025 LADCP data are not obvious: the U maximum at \#483 could correspond to the core of the first (violet) MW and the U minimum at \#489 could correspond to the core of the second (orange) MW but the core at \#493 does not correspond to the core of the third (blue) MW. Also to be noticed is the fact that the V maxima do not correspond to the U maxima, being either aside (\#485 vs. \#483) or significantly above (375 m vs. $450 \mathrm{~m}$ for \#493). Without any willingness to explain so complex features, we just note that, with our conviction (and the demonstration from the cross-MO transect) that the MO is composed of components juxtaposed side by side in a specific order (blue, violet, red and orange) while meandering, the occurrence of orange water in between the violet and blue ones can be explained by some kind of "turbulence", which should be consistent with the occurrence of relatively low velocities. Let us specify that, even though we already collected and analyzed a lot of moored ADCP data, we are not familiar with the treatment of LADCP data; whatever the case, the MO is clearly heterogeneous from a dynamical point of view at a relatively short time scale. 
Ocean Sci. Discuss., https://doi.org/10.5194/os-2017-54

Manuscript under review for journal Ocean Sci.

Discussion started: 1 August 2017

(c) Author(s) 2017. CC BY 4.0 License.

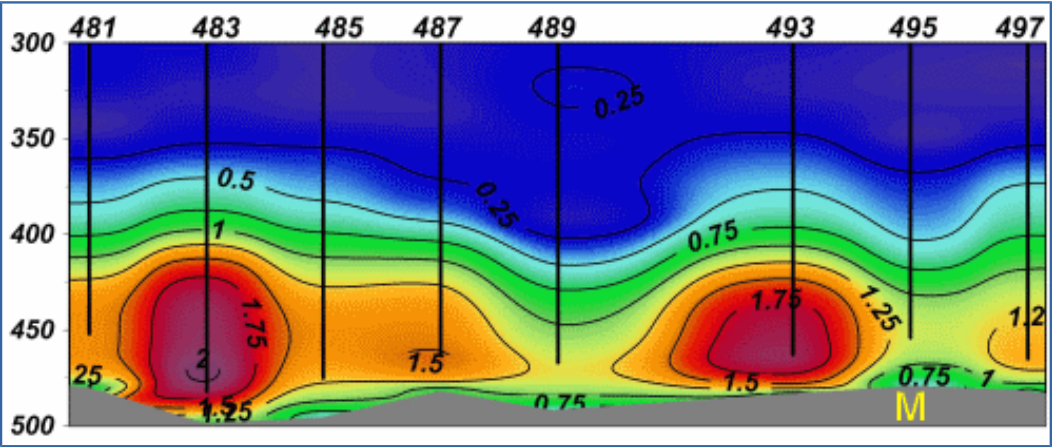

1045

1050

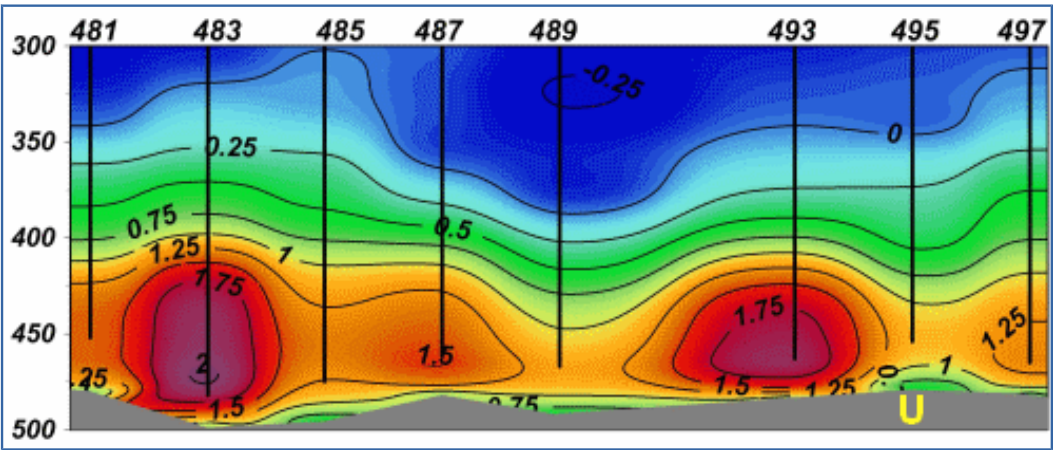

1055

1060

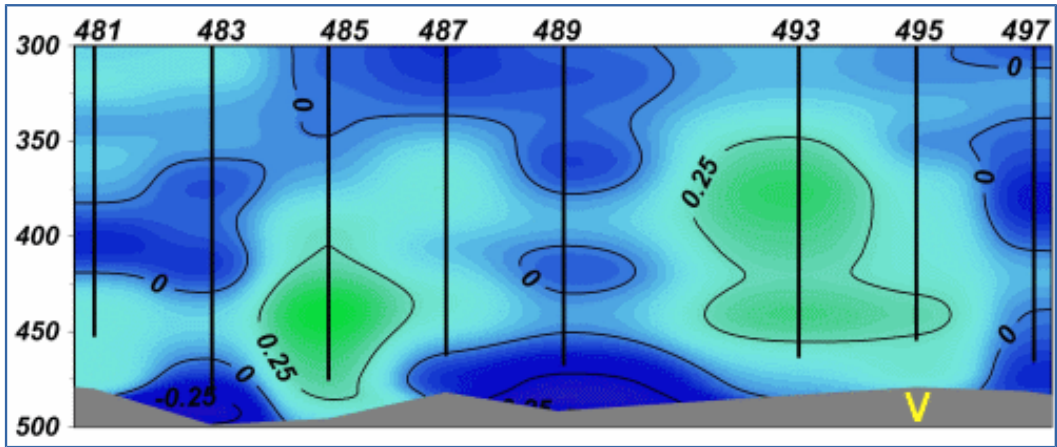

1065

Figure 12b. LADCP data (not available for \#491) collected simultaneously with the CTD downcasts in Fig.12a down to depths that can be deeper by 20-30 m than the depth of the instruments. Data, in $\mathrm{m} . \mathrm{s}^{-1}$, as provided by $\mathrm{H}$. Peters (pers. com.), are projected along (for $\mathrm{U}$ ) and perpendicular to (for $\mathrm{V}$ ) the mean current direction $\left(247^{\circ} \mathrm{T}\right)$ that is computed from the vectorial sum of all current data available from all 8 profiles below $300 \mathrm{~m}$. The magnitude (M) distribution and amplitude being very similar to those of the $U$ component, both reaching maxima much larger than those of the $\mathrm{V}$ component, indicate a relatively unidirectional MO. Note that the average of all $\mathrm{V}$ values is 0 and that color scales for $\mathrm{M}$ and $\mathrm{U}, \mathrm{V}$ are not exactly the same, in particular for low values. 
Ocean Sci. Discuss., https://doi.org/10.5194/os-2017-54

Manuscript under review for journal Ocean Sci.

Discussion started: 1 August 2017

(c) Author(s) 2017. CC BY 4.0 License.

This yo-yo time series was collected in between the two former ones at the central point (Tab.1). It displays a relatively simple situation with a period of violet water in between periods of slightly different blue waters.

Figure 13a shows the first period or relatively light blue water (\#329-341) associated with relatively similar and

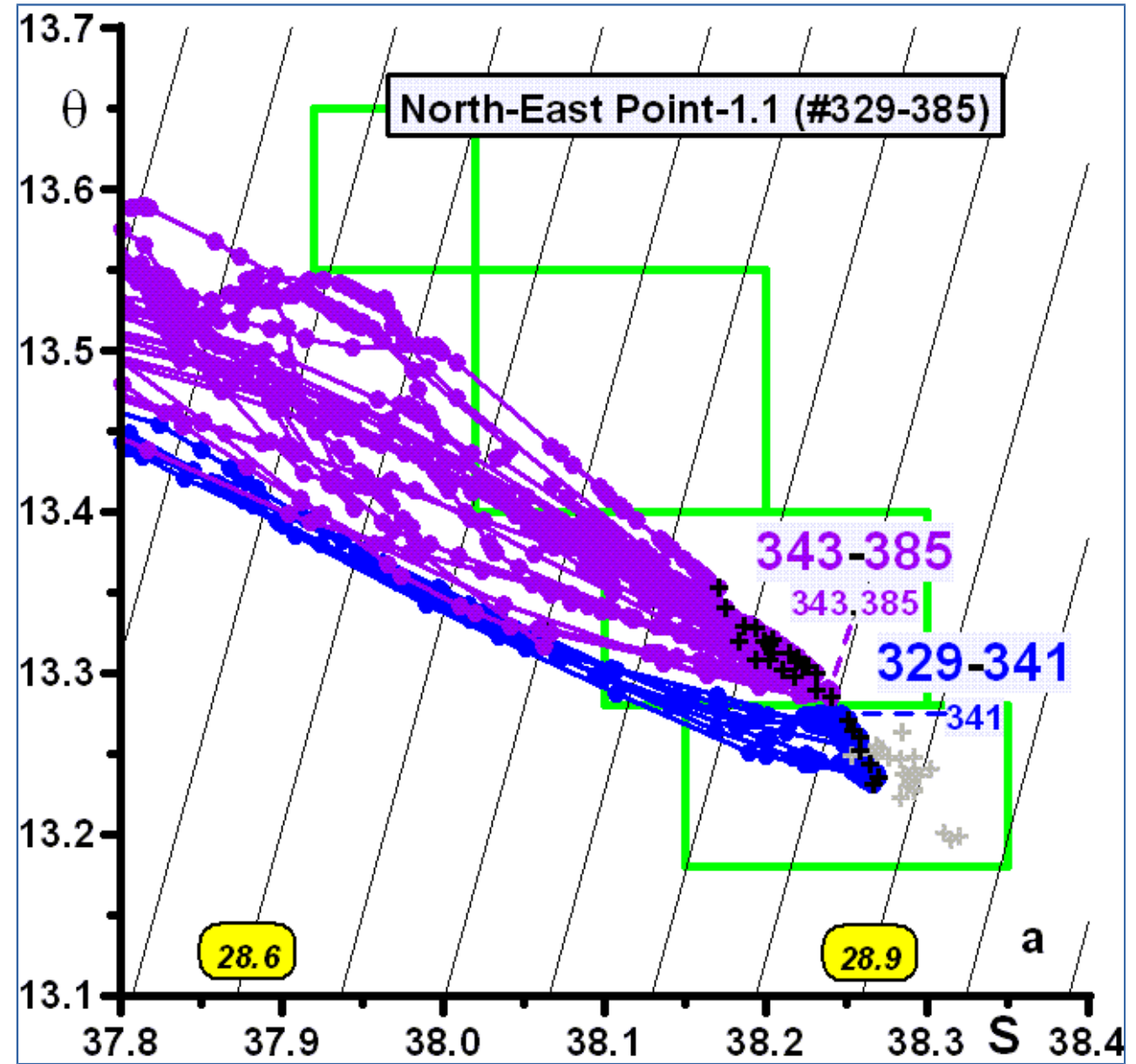

Figure 13a. As in Fig.3a for the North-East Point-1, first blue period. Gray crosses for the second blue period. 
Ocean Sci. Discuss., https://doi.org/10.5194/os-2017-54

Manuscript under review for journal Ocean Sci.

Discussion started: 1 August 2017

(C) Author(s) 2017. CC BY 4.0 License.

Figure $13 \mathrm{~b}$ evidenced the same violet group together with the relatively dense blue one (\#387-433) at the end of the time series; note that the relatively short sampling rate allows validating \#417-421 that would be suspected if isolated from the remainder of the group.

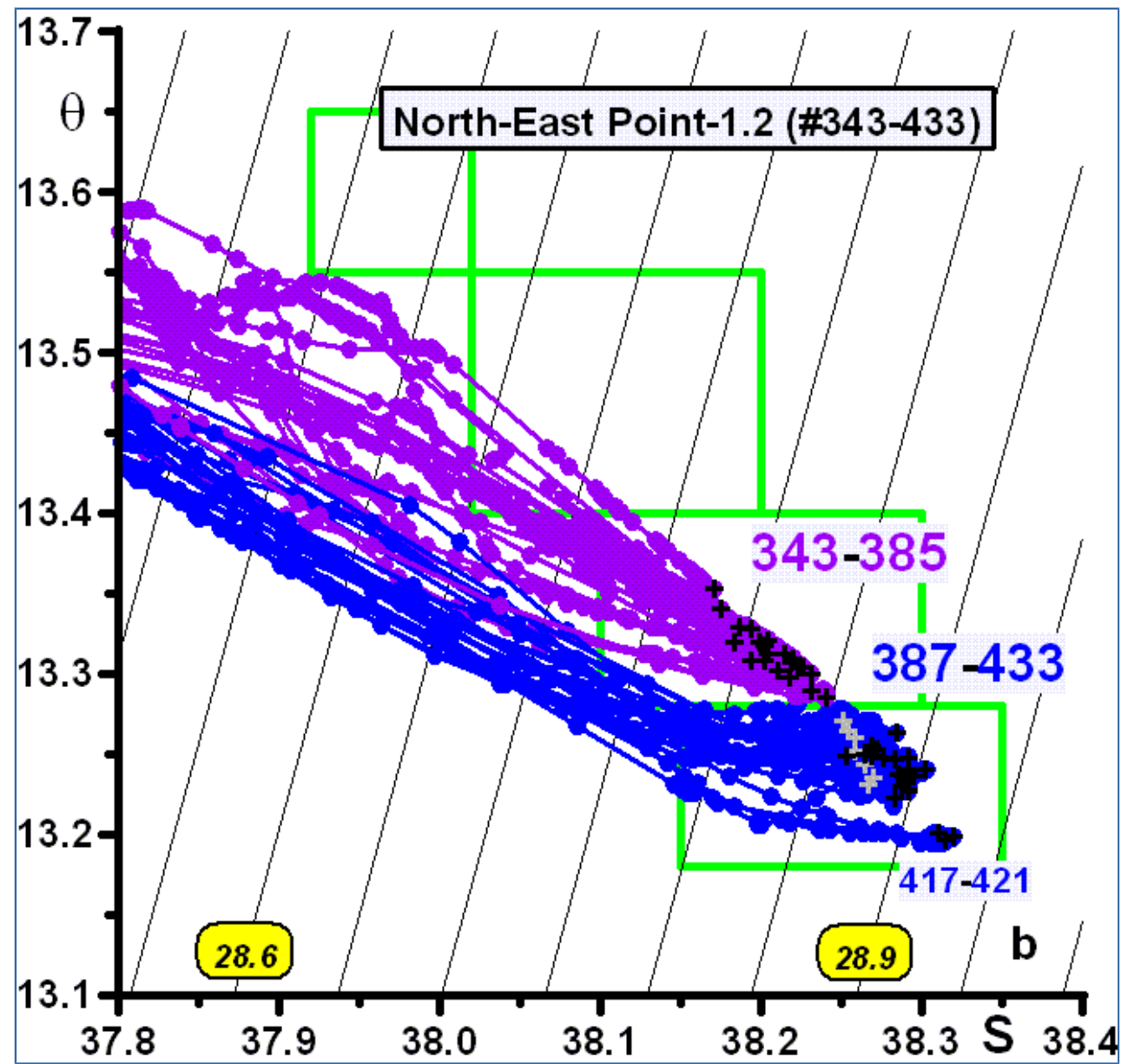


Ocean Sci. Discuss., https://doi.org/10.5194/os-2017-54

Manuscript under review for journal Ocean Sci.

Discussion started: 1 August 2017

(c) Author(s) 2017. CC BY 4.0 License.

(c) (i)

We do not see any specific feature to especially analyze with Fig.13c except that, on some profiles (e.g. \#335,

1100391 ), $\mathrm{S}_{\max }$ was observed $\sim 30 \mathrm{~m}$ above the maximum depth reached by the profile.

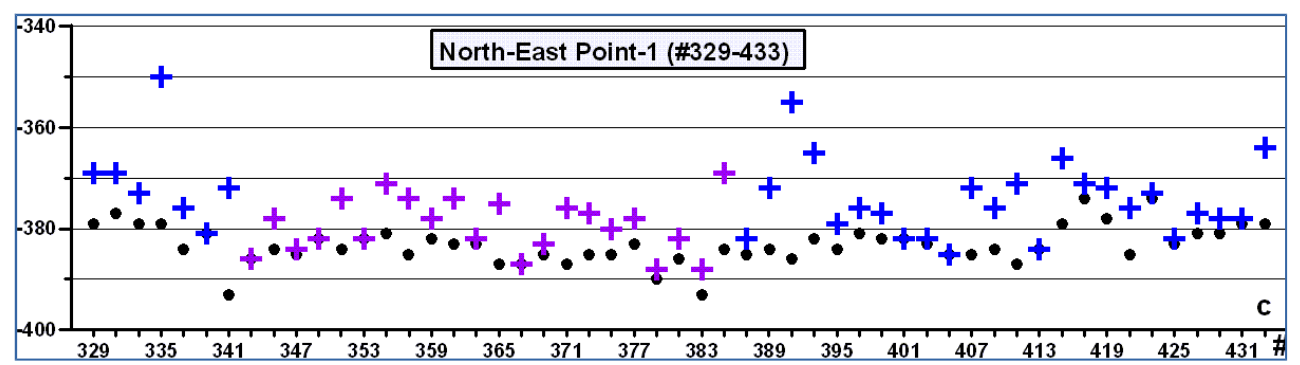

Figure 13c. As in Fig.10c for North-East Point-1. 
Ocean Sci. Discuss., https://doi.org/10.5194/os-2017-54

Manuscript under review for journal Ocean Sci.

(C) Author(s) 2017. CC BY 4.0 License.

(c)

Figure 14a shows that this is a period with mainly blue profiles that starts with relatively small $\mathbf{S}_{\max }$ values (\#603-619, light blue). This light blue water is temporarily replaced by slightly larger $\mathrm{S}_{\max }$ values associated with cooler and saltier water (\#621-627, medium blue), itself replaced by denser and mainly saltier water (\#629-653, dark blue). The last profile of this dark blue group (\#653) occupies an extreme position that is close to that of \#655 (light blue group), which somehow announces the sole violet \#657 of the time series. An intermediate blueviolet \#659 is sampled before a set of, again, light blue \#661-681.

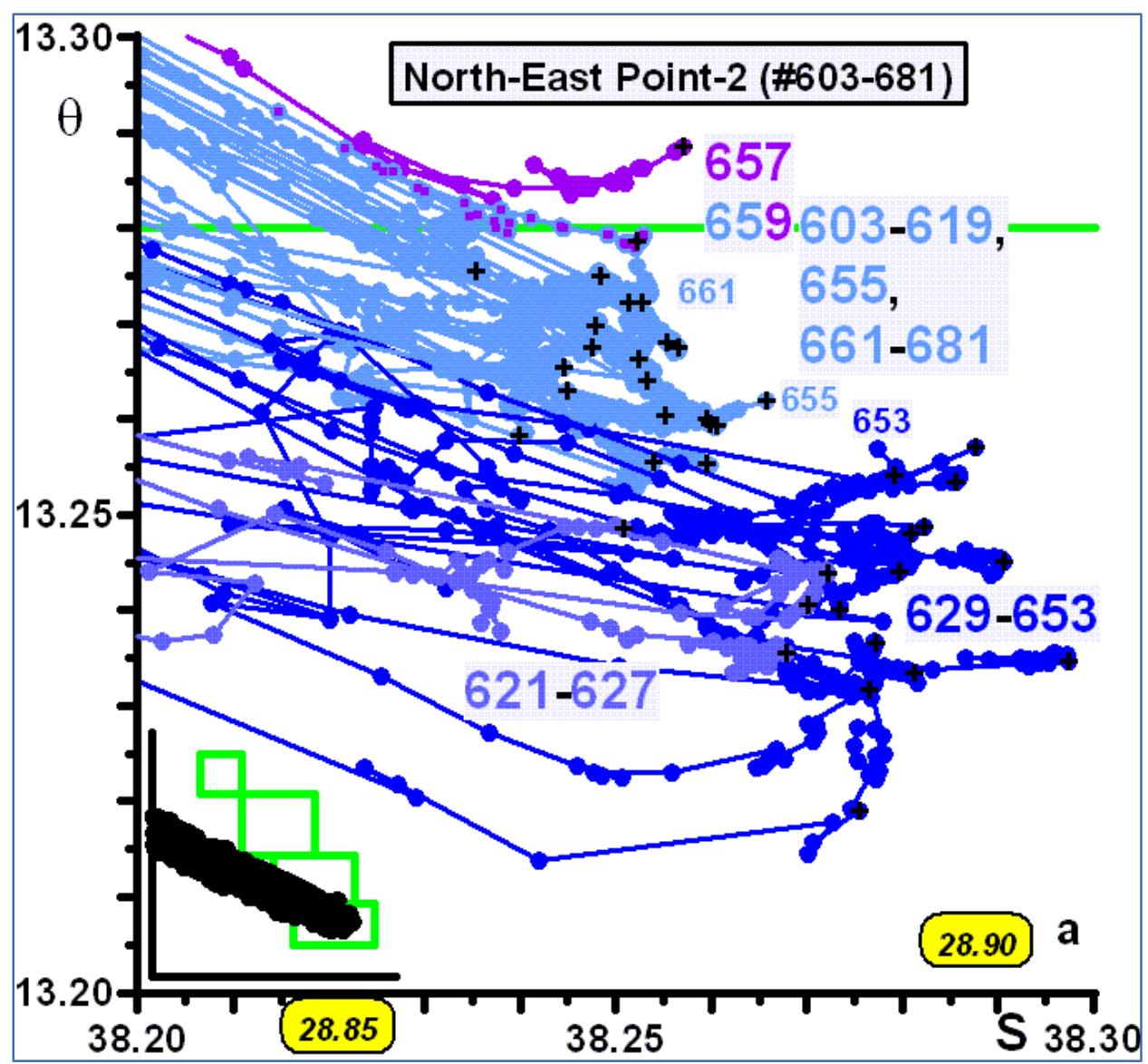

Figure 14a. As in Fig.3a for the North-East Point-2. 
Ocean Sci. Discuss., https://doi.org/10.5194/os-2017-54

Manuscript under review for journal Ocean Sci.

Discussion started: 1 August 2017

(c) Author(s) 2017. CC BY 4.0 License. by the profile. On the contrary, the medium blue group is not homogeneous at all since the $S_{\max }$ are found at the maximum depth (as the violet profile) while the dark blue group has an intermediate homogeneity.

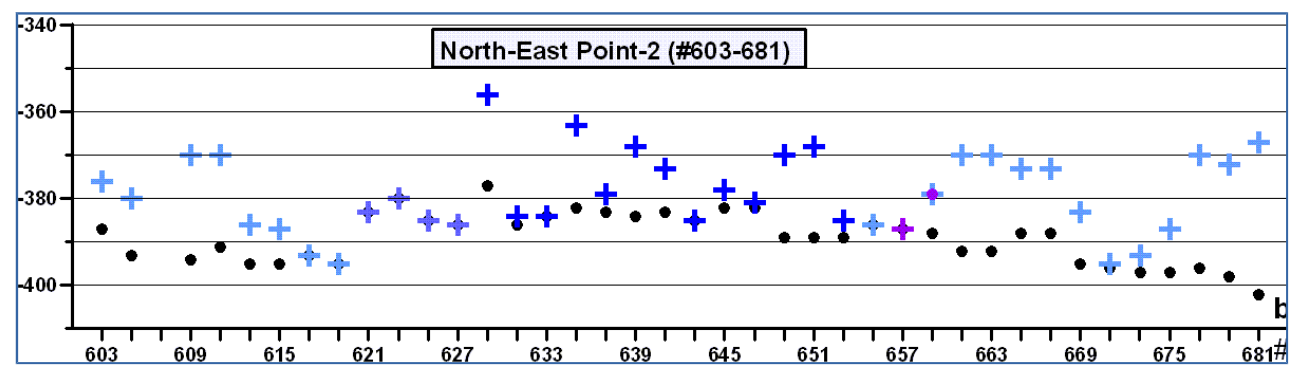

1125 Figure 14b. As in Fig.10c for North-East Point-2. 
Ocean Sci. Discuss., https://doi.org/10.5194/os-2017-54

Manuscript under review for journal Ocean Sci.

Discussion started: 1 August 2017

(c) Author(s) 2017. CC BY 4.0 License.

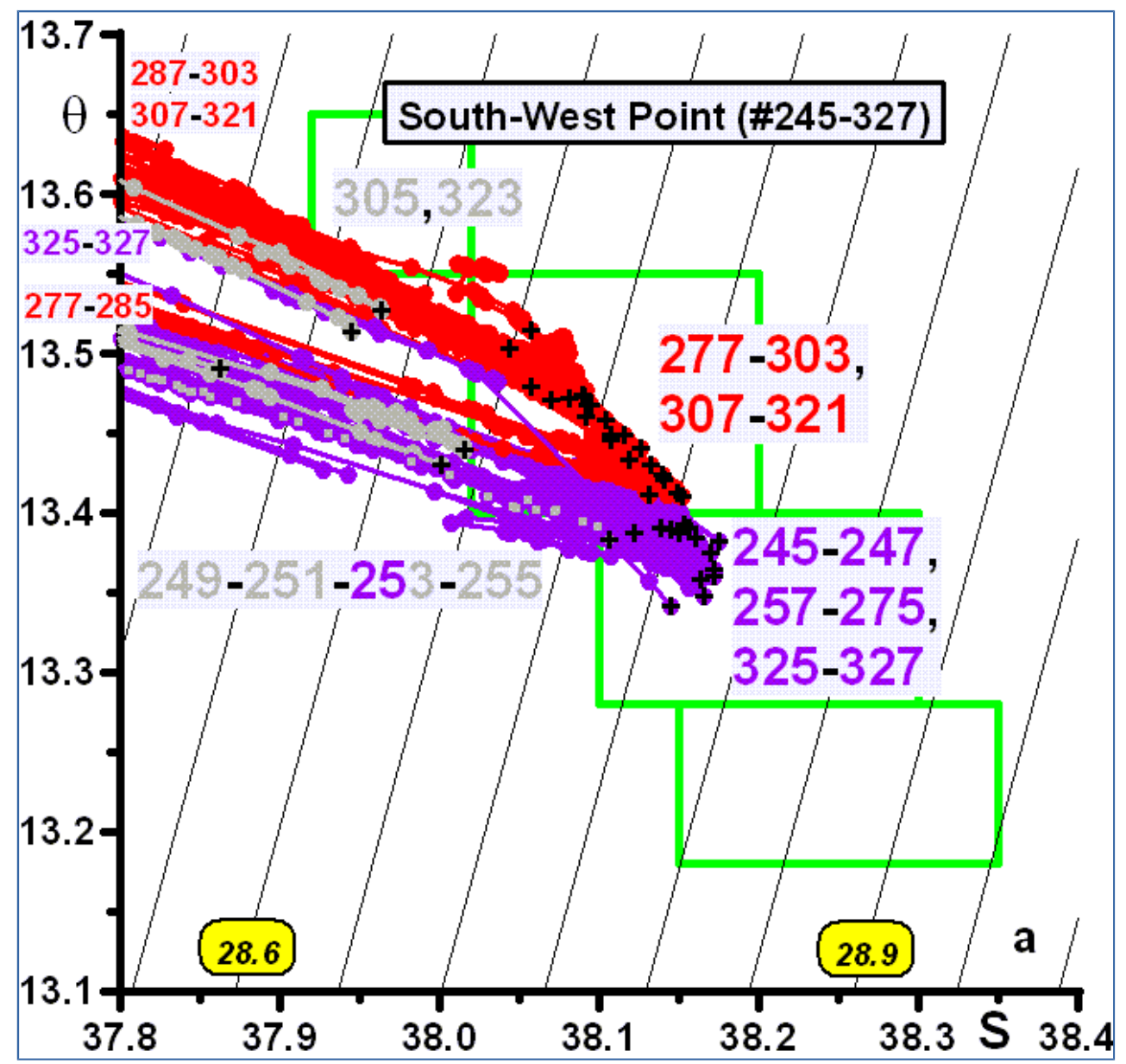

Figure 15a. As in Fig.3a for the South-West Point. 
Ocean Sci. Discuss., https://doi.org/10.5194/os-2017-54

Manuscript under review for journal Ocean Sci.

Discussion started: 1 August 2017

(c) Author(s) 2017. CC BY 4.0 License.

Discussions

(c) (i)

The time series starts with two violet \#245-247 followed by a set or mainly gray \#249-255, what is not very informative since they are associated with relatively shallow depths (Fig.15b). Profiles then come to be violet

1140 again (\#257-275) before coming red with mixing lines indicating mixing with first the same AW (\#277-285) and then another AW (\#287-303). Since \#305 is gray but associated with relatively shallow depths (Fig.15b), the last red group might be the same as the next one (\#307-321). Profile \#323 however, also similar to \#305, is in fact much deeper $(505 \mathrm{~m})$ and similar $\mathbf{S}_{\max }$ are found at depths shallower by $15-20 \mathrm{~m}$ at neighboring profiles that have larger $\mathbf{S}_{\max }$ at shallower depths of $495-500 \mathrm{~m}$ (Fig.15b). Additionally, while \#305 was in between red profiles, \#323 separates the red \#321 from the violet \#325 and \#327 that have similar mixing lines in the same density ranges. All these arguments support the fact that $\# 323$ did evidence the red-violet interface. Unfortunately, no LADCP data are available.

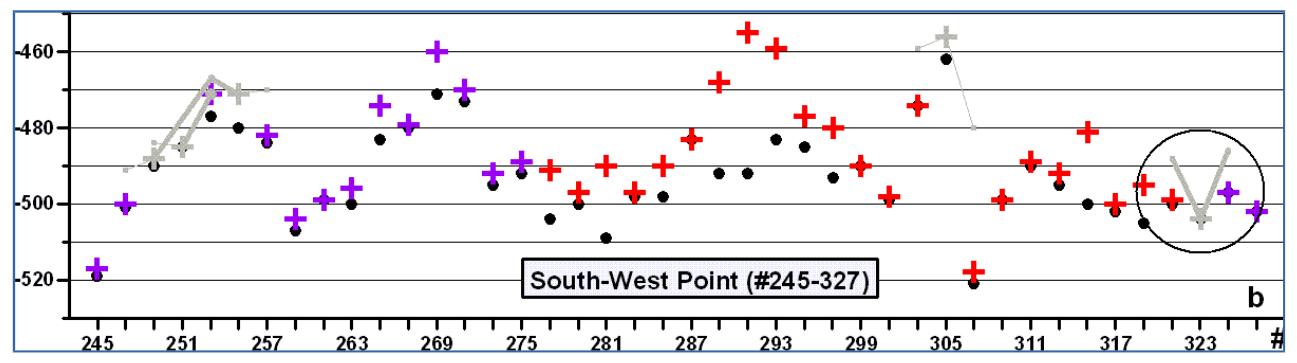

Figure 15b. As in Fig.10c for South-West Point. 
Ocean Sci. Discuss., https://doi.org/10.5194/os-2017-54

Manuscript under review for journal Ocean Sci.

Discussion started: 1 August 2017

\subsection{Regional surveys}

Two regional surveys were performed from east to west at the beginning and the end of the MO-2009 experiment, hence $\sim 10$ days apart (Tab.1), with a $\sim 5$-km sampling interval along more or less long north-south transects followed in one or the other direction (Fig.16). Considering the fact that even a 1-km interval does not allow correctly sampling the MO (as during the cross-MO transect), it is obvious that a rigorous description of it cannot be inferred from such coarse surveys. It must be noticed that, more significantly than over the relatively reduced central zone previously analyzed, all transects in the south (resp. north) will evidence a total mixing (as defined in Part 1) of the MO components with the NACW layer (resp. the base of the SAW layer). In addition, these surveys cover the MO over a relatively large east-west distance along which characteristics of each of the components markedly evolve, the MWs being less (resp. more) mixed than in the central zone located downstream (resp. upstream) where a coloring based on specific rectangles in a q-S diagram has been shown to be reliable.

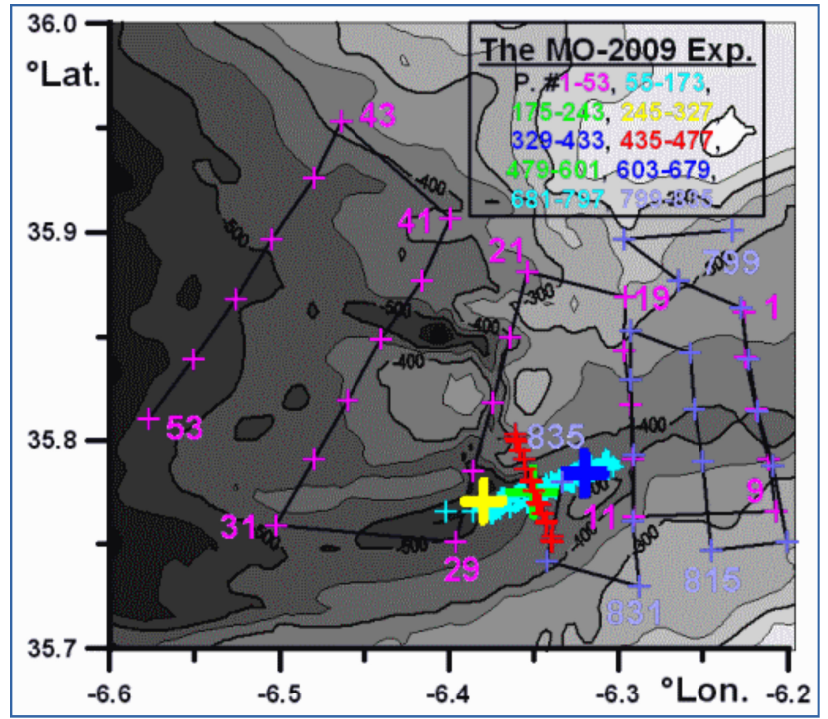

Figure 16. The MO-2009 experiment over the bathymetry (m). See Table 1 for details.

Even though our analysis of such data sets cannot be as definite as what was done in the relatively narrow central zone, significant information will be provided on both the spreading and the splitting of the MO in the whole studied area. Both surveys are presented together to evidence consistent information and/or to show figures with significant information. The green rectangles are still displayed in the figures hereafter to allow easier comparisons with previous ones, but since the coloring must consider the along-stream mixing, figures must be analyzed with Fig.16 in mind. In addition, Survey-1 will provide valuable information, in particular about the orange water in the west of the studied area and out of the ranges $\left(13.1-13.7^{\circ} \mathrm{C}, 37.8-38.4\right)$ of most figures 
Ocean Sci. Discuss., https://doi.org/10.5194/os-2017-54

Manuscript under review for journal Ocean Sci.

Discussion started: 1 August 2017

(c) Author(s) 2017. CC BY 4.0 License.

herein, so that a specific figure has been drawn as Fig.17e; some of the profiles from Survey-2 should have been added to the figure, but this leads to an unnecessary complexity.

\subsubsection{Survey-1,Transect-1 and Survey-2,Transect-2 (Fig.17a)}

1195

On the easternmost transect of the first survey, $\# 1$ and \#3, in the middle-northern side of the Strait, are violet while \#5, more to the south at greater depths $(415 \mathrm{~m})$ is blue; the $\# 5 \mathrm{~S}_{\max }\left(28.965 \mathrm{~kg} \cdot \mathrm{m}^{-3}\right)$ is the overall maximum of the experiment and the densest set of relatively homogeneous data is $65 \mathrm{~m}$ thick. Profile \#7 indicates that the top of the blue component was sampled at $320 \mathrm{~m}$ while $\# 9$, more to the south and down to $270 \mathrm{~m}$, did not evidence any significant amount of MW.

On the same transect 10 days after, first note (Fig.16) the specific location of \#801 that is in fact the northernmost profile; MWs are evidenced (not shown) there over relatively shallow depths of $\sim 200 \mathrm{~m}$. Profiles $\# 799,803$ and 805 , over depths of 275,280 and $330 \mathrm{~m}$ evidence the same component of the MO that is $30-\mathrm{m}$ thick at \#805. Because they are upstream from the central zone, all four profiles might be colored in orange with $\# 801$ on the top of the layer, \#799 and \#803 in its upper part, and \#805 the closest to the core. These profiles performed in succession clearly account for a relatively large spreading of this MO component there, and at least at that time. Indeed, \#805 is exactly at the position of \#1 where the MO component was, 10 days earlier, clearly violet. 
Ocean Sci. Discuss., https://doi.org/10.5194/os-2017-54

Manuscript under review for journal Ocean Sci.

Discussion started: 1 August 2017

(C) Author(s) 2017. CC BY 4.0 License.

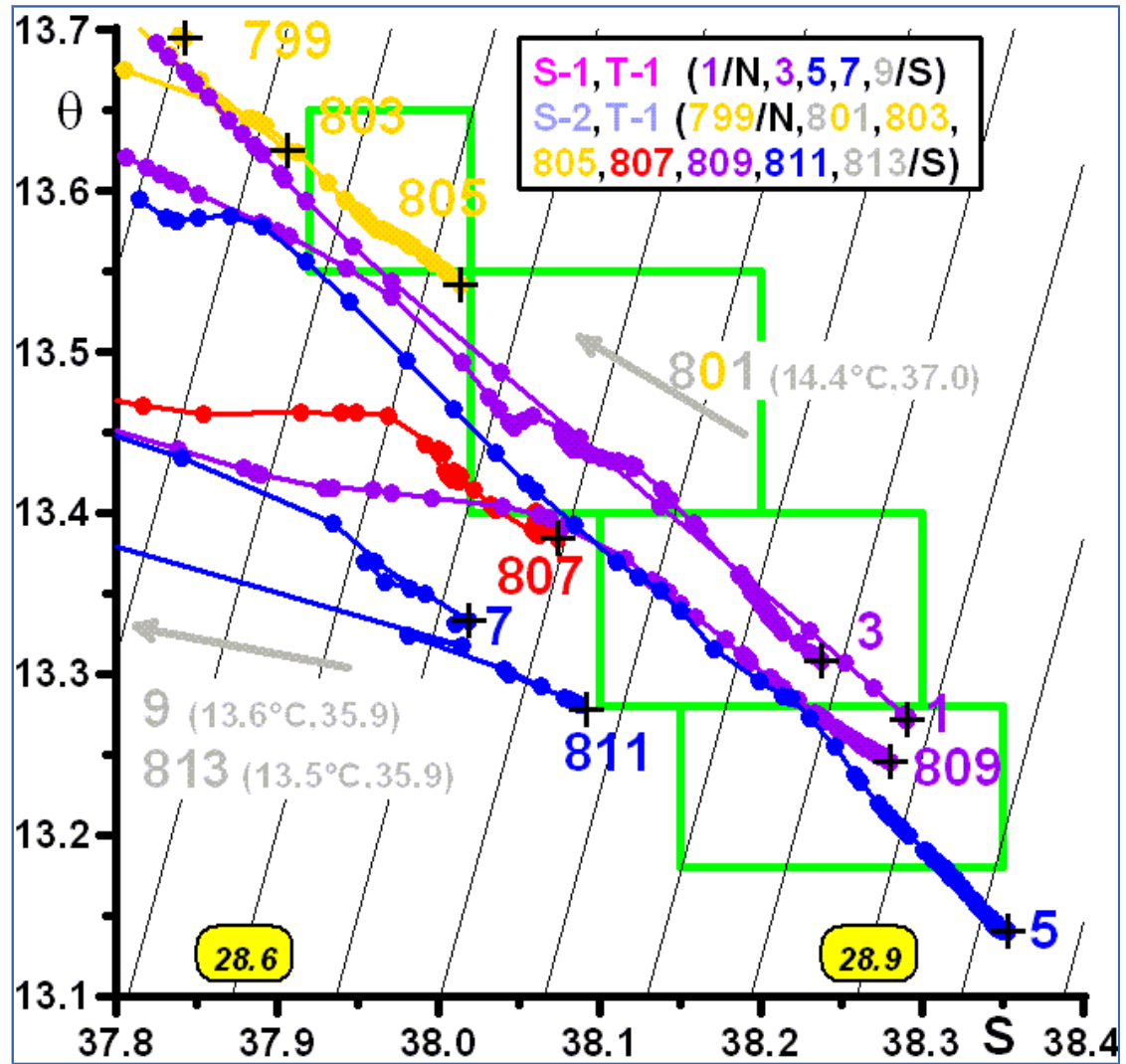

Figure 17a. As in Fig.3a for Survey-1, Transect-1 and Survey-2, Transect-1.

Similar changes are observed between \#807 and \#3 that are exactly at the same position and reach similar depths of 380 and $370 \mathrm{~m}$ with very different $\mathbf{S}_{\max }$; note that the $\# 807 \mathbf{S}_{\max }=28.70 \mathrm{~kg} \cdot \mathrm{m}^{-3}$ was observed, as a relatively homogeneous layer 10-20 m thick, at $320 \mathrm{~m}$ on \#3. Stratification and characteristics have thus markedly changed, which accounts for the red color we give to \#807. The same dramatic changes have been observed between $\# 809$ and \#5, both down to $415 \mathrm{~m}$ and exactly at the same place, with the $\# 809 \mathrm{~S}_{\max }=28.88 \mathrm{~kg} \cdot \mathrm{m}^{-3}$ observed at $345 \mathrm{~m}$ on $\# 5$, which accounts for the violet color given to \#809. Still for similar reasons, \#811 down to $315 \mathrm{~m}$ only sampled the top of the blue component, exactly as did \#7 at the same place and depth while, far to the south, \#813 did not evidence any MO at $250 \mathrm{~m}$. 
Ocean Sci. Discuss., https://doi.org/10.5194/os-2017-54

Manuscript under review for journal Ocean Sci.

Discussion started: 1 August 2017

(C) Author(s) 2017. CC BY 4.0 License.

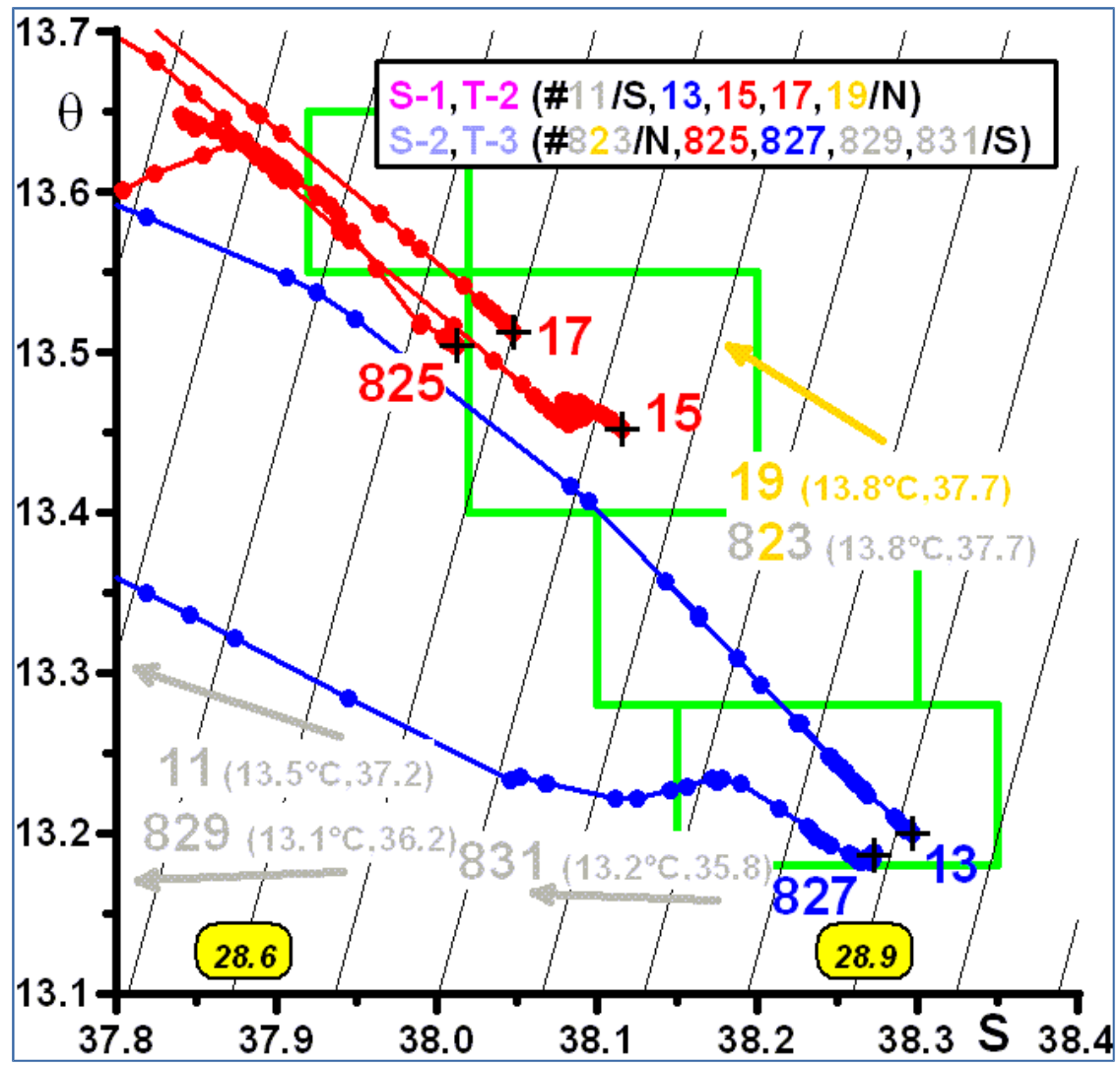

Figure 17b. As in Fig.3a for Survey-1, Transect-2 and Survey-2, Transect-3.

Both transects in Fig. 17b are performed at nearly similar locations $\sim 10$ days apart. The southernmost profiles (\#11 and \#829, both at the same location, and \#831) do not evidence any significant amount of MWs (at 340, 350 and $295 \mathrm{~m}$ ). Both \#13 and \#827, at the same location and just upstream from the along-MO transects and north-east point time series, which accounts for the significance of the green rectangles, display nearly the same blue component at $400 \mathrm{~m}$; note the marked changes in the mixing line characteristics due to the replacement, there and/or upstream, of SAW (\#13) by NACW (\#827).

More to the north, \#15 (360 m), 17 (305 m) and $825(355 \mathrm{~m})$ in between, clearly evidence the red component that has clearly moved or has markedly changed since $\# 825$ should have had a $\mathbf{S}_{\max }$ in between the other ones. Both \#19 (250 m, Fig.17e) and \#823 (300 m, not shown), at roughly similar locations, clearly evidence the orange water, as did profiles \#799 to \#805, which indicates that a relatively large section of the Strait was occupied by the same light orange component. 
Ocean Sci. Discuss., https://doi.org/10.5194/os-2017-54

Manuscript under review for journal Ocean Sci.

(C) Author(s) 2017. CC BY 4.0 License.

(c) (i)

3.5.3 Survey-1, Transect-3, together with Survey-2, Transect-2 and Survey-2, Transect-4 (Fig.17c,e)

1295 Note that the Transect-3 from the first survey is downstream from most of the central zone and just across the first along-MO transect that evidenced red and orange waters in its westernmost part (Fig.5, 6h). The Transect-2 from the second survey is almost far upstream the central zone while the Transect- 4 of that survey is across the southern part of that zone. Therefore, all three transects cannot, a priori, be compared.

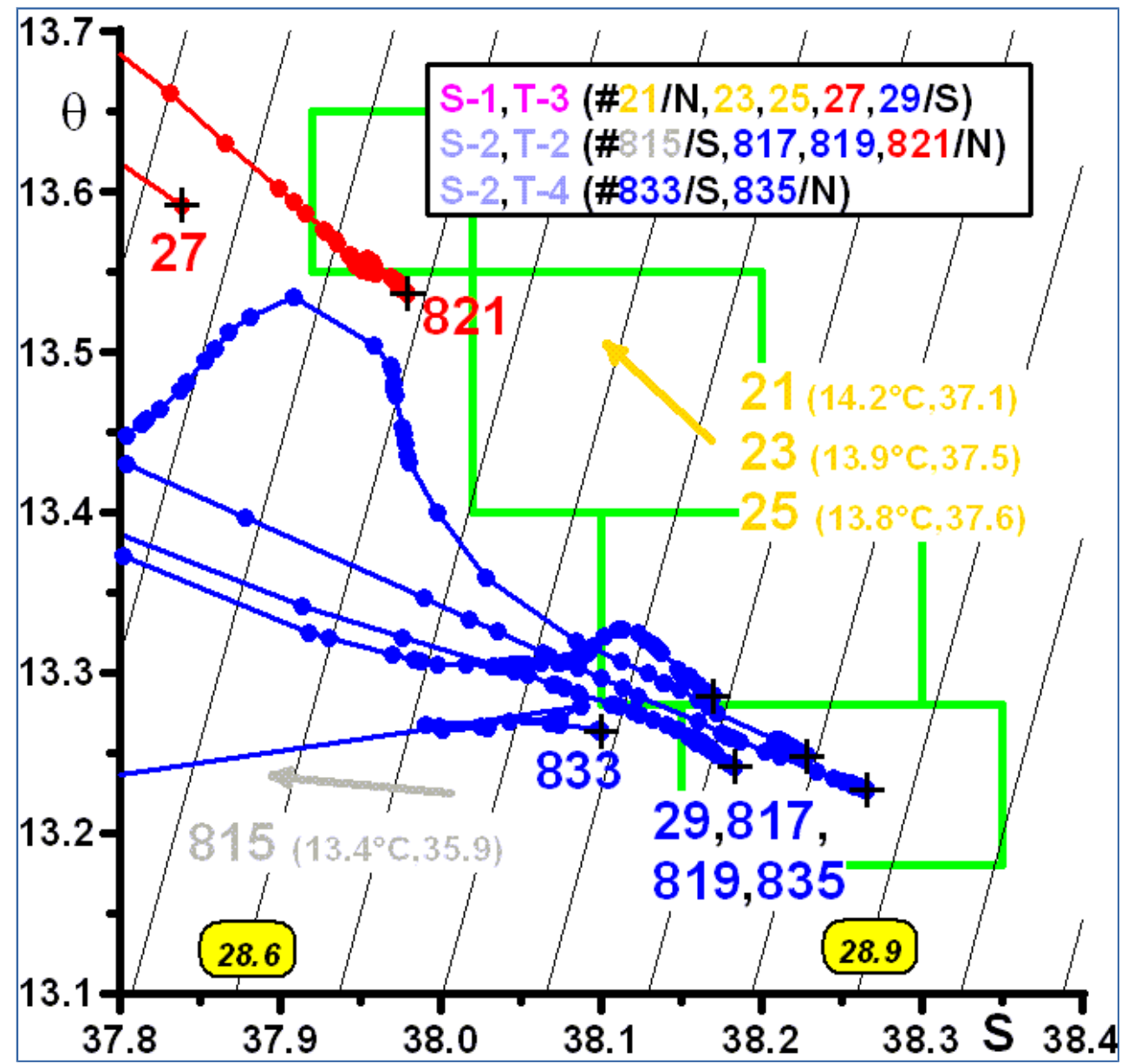

Figure 17c. As in Fig.3a for Survey-1, Transect-3 and Survey-2, Transect-2 and Transect-4.

Whatever the case, figure 17c shows that \#29 (480 m), \#817 (355 m),\#819 (420 m), \#833 (400 m), and \#835

(405 m), all clearly evidence the same blue component with nearly similar characteristics, which provides valuable information. Upstream from the central zone \#817 and \#819 indicate that the blue component is 
Ocean Sci. Discuss., https://doi.org/10.5194/os-2017-54

Manuscript under review for journal Ocean Sci.

Discussion started: 1 August 2017

(c) Author(s) 2017. CC BY 4.0 License.

evidenced all four components) and over a depth range from below $420 \mathrm{~m}$ to above $355 \mathrm{~m}$. In the central zone, and at the end of the MO-2009 experiment, hence just 1 day after the Leg 8 of the along-MO Transect-2 (Fig.8h) that evidenced some kind of invasion (as compared to the previous legs) of blue water, \#833 and \#835 confirm the very large spreading of that component in the deeper southern part of the Strait. Note that the slight

1310 difference in maximum depth between $\# 833$ and \#835 could account for the slight difference in $\mathbf{S}_{\max }$ they have, and that, even with a relatively slight difference in cross-Strait location, \#833 (resp. \#835) more to the south coherently indicates a mixing more with NACW (resp. SAW). Finally, the similarity of the \#29, 817, 819 and $835 \mathrm{~S}_{\max }$ accounts for a relatively reduced mixing from upstream to downstream across the studied area, at least of this densest component of the MO there. Note that \#815 (270 m) being very south and shallow did not sample any partially unmixed MW, as expected.

Profile \#821 (360 m) being very similar to and nearly upstream from \#825 (355 m) performed just $\sim 1 \mathrm{~h}$ after, the latter being similar to neighbor \#15 and \#17, all being red (Fig.17b) in the similar depth range, is clearly red. As indicated by Fig.17e, \#27 has a seemingly similar q-S diagram and it is along similar streamlines (Fig.16); so that, even if much deeper $(560 \mathrm{~m})$ in a kind of canyon, it is red too.

Interesting information is provided by \#21, 23 and 25 that are clearly orange (Fig.17e). Even though \#21 in the north did not evidence a marked orange layer, note that \#23 and \#25, as well as \#19, evidence relatively thick homogeneous layers of 51, 85 and $44 \mathrm{~m}$. We found especially interesting to note that these homogeneous layers at both \#23 and \#25 are associated with mixing lines having slopes that are markedly different and different from the overall slope of the SAW-orange MW mixing lines: each of both homogeneous layers kept the memory of previous mixing processes. 
Ocean Sci. Discuss., https://doi.org/10.5194/os-2017-54

Manuscript under review for journal Ocean Sci.

Discussion started: 1 August 2017

(c) Author(s) 2017. CC BY 4.0 License.

Discussions

\section{(c) (1)}

\subsubsection{Survey-1, Transect-4 and Transect-5 (Fig.17d,e)}

1340

1345

1350

1355

First note that both transects have been collected in succession and far downstream from the central zone at the beginning of the experiment. Profiles \#31, \#33 and \#37 during Transect-4 sampled three different components of the MO that, thanks to the associated depths $(470,455,470 \mathrm{~m})$ and to the coloring made upstream along nearby streamlines are, respectively, the blue, violet and red ones. Profile \#35 (400 m, Fig. 17e) did not sample any MW; even if it might be considered to be in the wake of two bathymetric bumps ( $<350$ and $<300 \mathrm{~m}$ ), hence somehow protected from the MO, \#35 definitively demonstrates the MO splitting at the Strait exit.

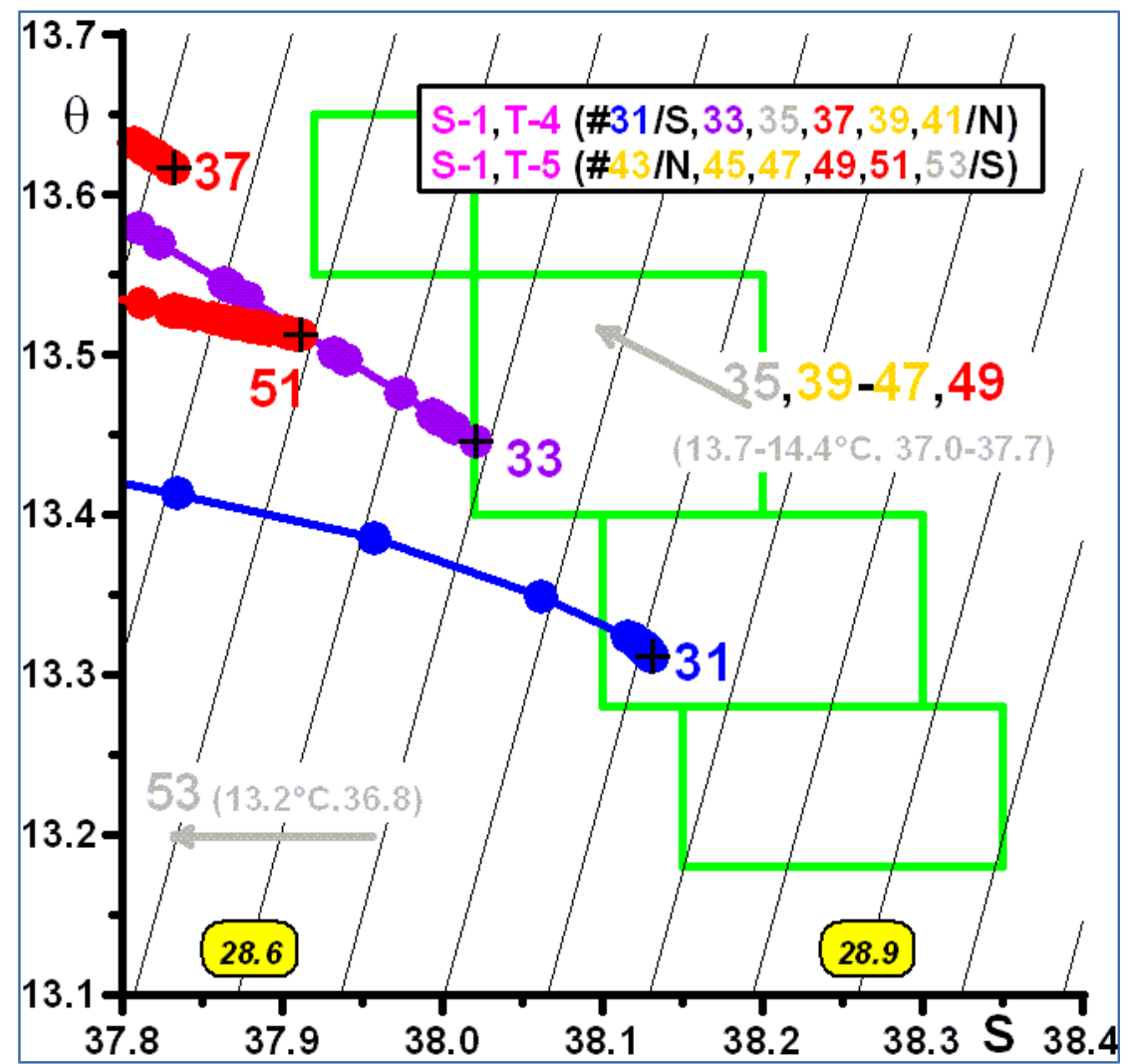

Figure 17d. As in Fig.3a for Survey-1, Transect-4 and Transect-5.

The westernmost Transect-5 did evidence, in the range of Fig. $17 \mathrm{~d}$, only one MW at \#51 (515 m) that, thanks to the mixing with NACW in the south and the still valid green rectangles, accounts for a red coloring which is consistent with the red coloring upstream at \#37 (470 m), \#15 (360 m), \#17 (305 m), \#825 (355 m) and \#807 $(380 \mathrm{~m})$. Even though this is clearly a very rough sampling of one of the MO components, its sinking from 350$360 \mathrm{~m}$ at $6^{\circ} 18^{\prime} \mathrm{W}(\# 15, \# 825)$ to $470 \mathrm{~m}$ at $6^{\circ} 26^{\prime} \mathrm{W}(\# 37)$ and to $515 \mathrm{~m}$ at $6^{\circ} 33^{\prime} \mathrm{W}$ (\#51) is realistic as well as its lifting up from $380 \mathrm{~m}$ at $6^{\circ} 13^{\prime} \mathrm{W}$ (\#807) that might be due to the constriction of the Strait section in the central zone surroundings. 
Ocean Sci. Discuss., https://doi.org/10.5194/os-2017-54

Manuscript under review for journal Ocean Sci.

Discussion started: 1 August 2017

(c) Author(s) 2017. CC BY 4.0 License.

As demonstrated by Fig.17e, the nearby \#49 is clearly red too and both are very different from the set \#39, 41, 43, 45 and 47 that are all clearly orange and all aligned along the same mixing line. The $S_{\max }$ of the orange profiles in Fig.17e provide interesting information that is related less to their own value, which could be considered as roughly decreasing downstream (as expected along any given streamline of the MO), than to their associated immersion. Indeed, along any given transect, the $\mathbf{S}_{\max }$ immersion is increasing southward: it is $338 \mathrm{~m}$ at \#21, $386 \mathrm{~m}$ at \#23, and $463 \mathrm{~m}$ at \#25; it is $352 \mathrm{~m}$ at \#41 and $409 \mathrm{~m}$ at \#39; it is $375 \mathrm{~m}$ at \#43, $426 \mathrm{~m}$ at \#45 and $452 \mathrm{~m}$ at $\# 45$; note that it is also $248 \mathrm{~m}$ at \#19 and $299 \mathrm{~m}$ at \#823 (10 days after). Assuming that roughly the same streamline concerns the northern part of the transects, the $S_{\max }$ immersion is increasing downstream: it is $248 \mathrm{~m}$ at \#19, $338 \mathrm{~m}$ at \#21, $352 \mathrm{~m}$ at \#41 and $375 \mathrm{~m}$ at \#43. At least the orange component of the MO is thus sinking down-stream while being inclined cross-stream, hence roughly following the continental slope. Note that this orange component is associated with $S_{\max }=28.33 \mathrm{~kg} \cdot \mathrm{m}^{-3}$ at \#19 and $=28.25 \mathrm{~kg} \cdot \mathrm{m}^{-3}$ at \#25 while being relatively homogeneous over large thicknesses of 44 and $85 \mathrm{~m}$, resp.. 
Ocean Sci. Discuss., https://doi.org/10.5194/os-2017-54

Manuscript under review for journal Ocean Sci.

Discussion started: 1 August 2017

(c) Author(s) 2017. CC BY 4.0 License.

\section{(c) (i)}

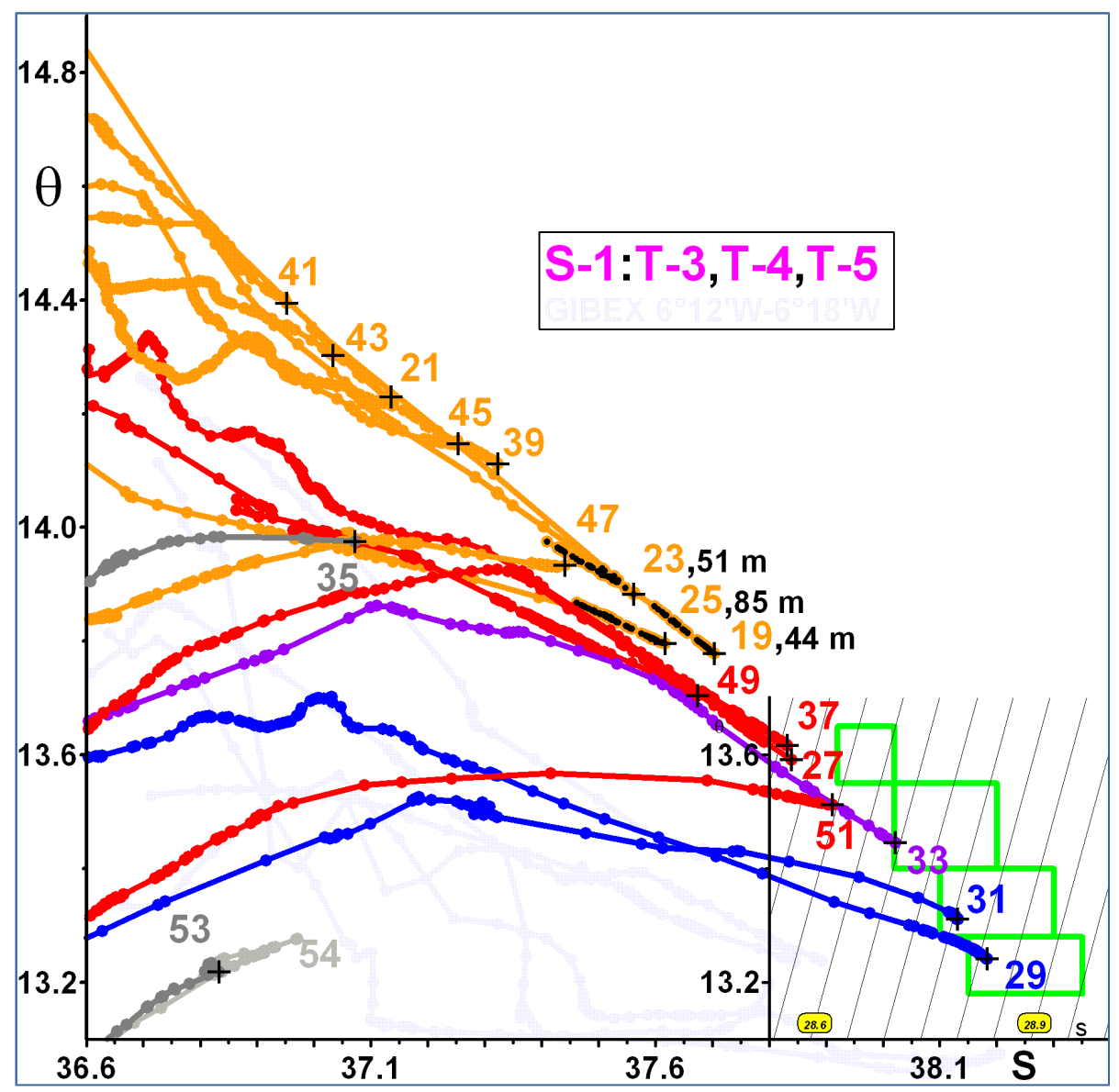

Figure 17e. As in Fig.3a for Survey-1, Transect-3, Transect-4 and Transect-5. GIBEX data at $\sim 6^{\circ} 15^{\prime} \mathrm{W} / 6.25^{\circ} \mathrm{W}$ in 1985-1986 are plotted in light and dark gray.

Profiles in the southern part of the transects upstream from the central zone that have been colored in gray could have been drawn in Fig.17e, displaying an intense mixing between NACW and the blue component that is not very informative. We just plotted $\# 53$ since, strangely and contrary to all other profiles, $\mathrm{S}_{\mathrm{q}}$ during the upcast (\#54) were significantly larger than at the end of the downcast (at $529 \mathrm{~m}$ ), reaching a maximum at $519 \mathrm{~m}$ and displaying numerous other instabilities, as expected during the cascading of each of the components of the MO. Both the violet and the blue components have been missed by the westernmost transect. 
Ocean Sci. Discuss., https://doi.org/10.5194/os-2017-54

Manuscript under review for journal Ocean Sci.

Discussion started: 1 August 2017

(c) Author(s) 2017. CC BY 4.0 License.

In the Parts 1 to 3 of our trilogy, we have presented different re-analyses of some data sets collected during the 1985-1986 Gibraltar Experiment (GIBEX), performed from the Alboran sub-basin in the western basin of the Mediterranean Sea all over the Strait of Gibraltar till its exit in the Atlantic Ocean (these specific terms being used, without any possible confusion, in all our papers since 2005), hence including there the domain sampled by the MO-2009 Experiment. Even though we deal herein only with data from MO-2009 that used a strategy much more efficient than the GIBEX strategy there, significant comparisons will be made below.

\subsection{The overall sampling strategy}

The MO-2009 strategy, that combined regional surveys, repeated tow-yo transects roughly in cross- and alongStrait directions, and yo-yo time series, has been of valuable interest for what concerns descriptive oceanography. During GIBEX, two yo-yo time series at $5^{\circ} 43^{\prime} \mathrm{W}$ and $6^{\circ} 05^{\prime} \mathrm{W}$ were performed but their interest might not have been suspected since they should have been more numerous and the object of published analyzes.

1405 Cross-Strait transects have been repeated, during each GIBEX campaign as well as during successive campaigns, but they were too coarse to provide definitive information, they did not extend across the whole MO (as well as most MO-2009 transects), and along-Strait transect were performed only occasionally. However, and at least for what concerns descriptive oceanography, considering the knowledge acquired during the numerous studies performed since decades in the Strait, furthermore we think having provided a significant improvement in our

1410 understanding of the MO heterogeneity, we show hereafter that we still lack, essentially, an adequate cross-Strait transect that, even if unique, would be performed, in the zone of the MO-2009 cross-Strait transect within one day or so.

\subsection{The regional surveys}

At the Strait exit, which is where checking the hypothetical effect of local bathymetric features in the splitting of the MO into a series of veins should be done, surveys at least similar to the two MO-2009 ones were, at least to our knowledge, surprisingly never performed before. Even if still relatively coarse, these surveys (Fig.18) have allowed verifying the juxtaposition side by side of four components of the MO all across the Strait. These

1420 components are very close to each others in the narrowest portion of the Strait, essentially upstream from the central zone but, as shown by \#35 and \#53 ( $\mathrm{S}_{\max } \sim 27.8 \mathrm{~kg} \cdot \mathrm{m}^{-3}$, Fig.16 and 17e) and even if the westernmost transect was not prolonged south enough to sample the blue and violet components, it seems that the densest and lightest sides of the MO were split in the west of the study area. 
Ocean Sci. Discuss., https://doi.org/10.5194/os-2017-54

Manuscript under review for journal Ocean Sci.

Discussion started: 1 August 2017

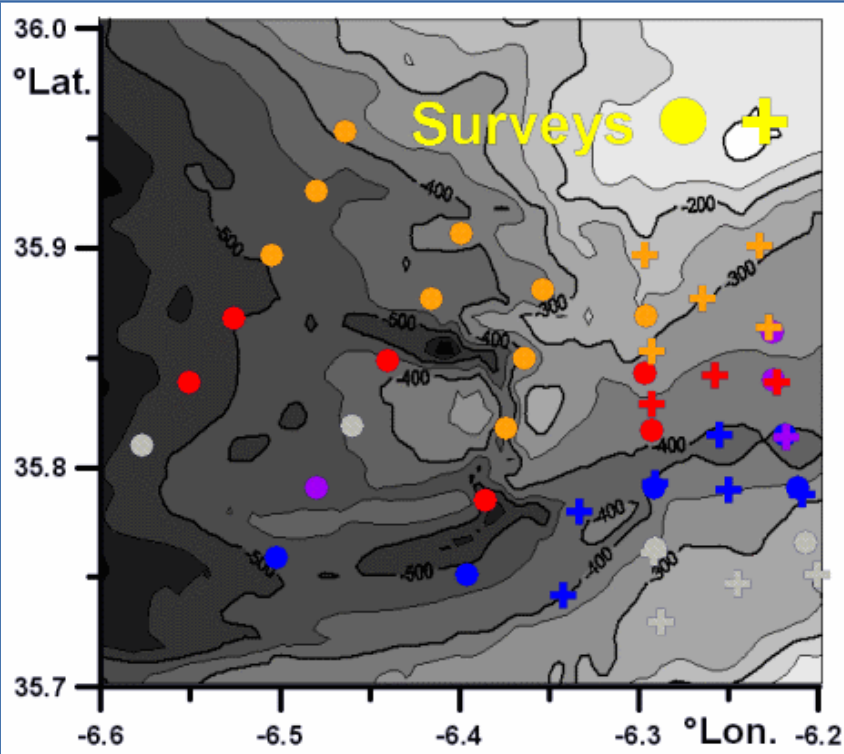

Figure 18. Data points are colored according to the results inferred from the $\theta$-S diagrams analysis, i.e. according to the color observed there on the bottom during the 1st and 2nd regional surveys (Survey-1 as circles, Survey-2 as crosses).

These surveys have evidenced a relatively large amount of orange water as well as its sinking all over the upper part of the northern continental slope. Such a light water was shown in Part 2 to have already sunk from 150-160 $\mathrm{m}$ at $5^{\circ} 50^{\prime} \mathrm{W}$ down to $\sim 320 \mathrm{~m}$ at $6^{\circ} 05^{\prime} \mathrm{W}$ (in 1985-1986), which is $\sim 70 \mathrm{~m}$ deeper than the depth where it was found in the narrowest part of the Strait exit in 2009 ( $\sim 250 \mathrm{~m}$ at $\# 19$, hence $\sim 6^{\circ} 18^{\prime} \mathrm{W}$, Fig. 17e). Depending on the MO flux and on the Strait width, it might be that some components could have been temporarily split and temporarily depressed (by $\sim 170 \mathrm{~m}$ ) within the Strait before re-joining all together and eventually having to overflow at the Strait exit before definitively splitting and sinking in the Ocean. The bathymetry is relatively complex at greater depths in the studied domain and, because MWs are constrained in a relatively narrow passage, systematically evidencing all of them with a $5-\mathrm{km}$ sampling is impossible.

We do think that it is such a coarse sampling that has prevented, up to now, from a correct understanding of the $\mathrm{MO}$ composition and structure. For instance, and just considering the frequent occurrence of the violet component during the two along-MO transects and the four time series, which were all chosen by chance where it often outflows, i.e. in the middle of the Strait, the fact that the violet component was never sampled during five out of seven north-south transects of the surveys (Fig.18) is very demonstrative: at least during the MO-2009 experiment, the violet component, even if frequently sampled in the central and deepest zone, hence the most frequently shown in the figures herein, was probably not the most important component of the MO. 
Ocean Sci. Discuss., https://doi.org/10.5194/os-2017-54

Manuscript under review for journal Ocean Sci.

Discussion started: 1 August 2017

(c) Author(s) 2017. CC BY 4.0 License.

Regional surveys are either relatively coarse or relatively biased, especially in a domain where the spatiotemporal variability is relatively large, so that, once they have allowed defining some general characteristics, what has been done herein, they are of limited interest and forthcoming studies must focus on specific aspects of the MO.

\subsection{The yo-yo time series}

Such a strategy has been shown, in Parts 1, 2 and 3, to be of tremendous interest, while having been located on the basis of, probably, more geographical than hydrodynamical arguments, and even if all of them lasted just for $\sim 1$ day. In Part 1, such a time series has clearly and objectively allowed differentiating, without any a priori about the Mediterranean Sea functioning, the three densest components of the MO at the Strait entrance and it has suggested the occurrence of two lighter ones, which is a classification, now partly supported by other studies that we previously made some years ago (Millot, 2009). In Part 2, another time series has allowed differentiating three types of MWs passing by, hence the MO meandering in the western side of the Strait, as well as establishing possible links with the upstream time series mentioned above.

In Part 3, the major interest of the time series has been to show that, most of the time, profiles were evolving in a continuous way, hence making reliable features that could have been considered as strange if considered isolated. They have allowed differentiating not only this or that component of the MO (e.g. Fig.10a) but even, when present, different types of this or that component (e.g. Fig.10b, Fig.13a,b). They have shown that, even at a place where only two components were observed most of the time (e.g. the 60 violet or blue profiles during the Central Point-2 series, Fig.11a,b), the two other components could be clearly sampled at least once (e.g. the orange and red profiles). They have provided significant information about the specific location of this or that component, mainly blue and sometimes violet at the north-east point (Fig.13, 14), violet or blue at the central point (Fig.10, 11) and red or violet at the southwestern point (Fig.15). Even more interesting for our purpose, they have allowed evidencing that these components were, at least sometimes, separated by relatively thin interface layers (e.g. 10b,c). Overall, they have shown that the MO was still meandering at the Strait exit.

Note that the yo-yo time series strategy is basically identical to ours when we initiated the HYDROCHANGES program (CIESM Group, 2002). Moored CTDs allow getting unbiased information during relatively long periods of time since a 1-y servicing has been shown (Millot, 2007, 2009) to be possible and sufficient, even in places such as the continental shelf of Morocco or the southern sill of Camarinal. Such CTDs could be easily and valuably moored at any given place in the narrowest part of the Strait, even if allowing the general monitoring of only one or two components of the MO in the long term with only the temporal sampling of the other components. Now, the accurate sampling of the relatively thin interface layers we have evidenced in between two components, which is an essential information for our purpose, could also be done with moored CTDs, even though both a relatively short time step and relatively long deployments would be necessary, which would imply 
Ocean Sci. Discuss., https://doi.org/10.5194/os-2017-54

Manuscript under review for journal Ocean Sci.

Discussion started: 1 August 2017

(c) Author(s) 2017. CC BY 4.0 License.

extended memories and enlarged batteries. Even though more complex, expensive and disturbed by intense currents, yo-yoing autonomous devices should also be deployed there.

\subsection{The along-MO transects}

1505

Consistently with what has been inferred from the time series that were located along these transects, they were clearly not along the $\mathrm{MO}$ current lines (misalignment of $\sim 10^{\circ}$ ). This has allowed evidencing mainly blue water in their northern part, which must be considered as the left-hand side of the MO and violet water in their southern part, which corresponds in fact to the middle of the MO, up to evidencing both the red and the orange waters

1510 (Fig.6h) when the transect was prolonged, even coarsely, till the right-hand side of the MO. Such a mean direction was already evidenced by direct current measurements (Nash et al., 2012) and can be easily specified with the available LADCP data.

In any event, the along-MO transects were located mainly in the left-hand side of the MO so that they revealed essentially either one (violet, Fig.5) or the other (blue, Fig.7) component located there, which is not an essential information; would have they been located mainly on the right-hand side, they would have revealed essentially the orange or the red component. Also, they were performed while progressing downstream, hence possibly sampling the same water (note the $\sim 2 \mathrm{~m} . \mathrm{s}^{-1}$ or $\sim 4$ knots maximum speeds, Fig. $12 \mathrm{~b}$ ) and certainly reducing the actual variability while, if performed upstream, they would have for sure sampled much different waters and increased the actual variability. Once general features in a study area have been specified, along-stream transects represent the most biased strategy, necessarily giving the worth estimation of the variability. However, these nearly along-MO transects were somehow equivalent to a cross-MO transect with a very short spatial sampling, which has allowed revealing and sampling relatively thin interface layers.

\subsection{The cross-MO transects}

We based all our analysis in Part 3 on four tow-yo legs performed in succession along the same transect with a relatively small 1-km sampling interval, in particular in associating the four MO components evidenced in such a way with some $\mathrm{q}$ and $\mathrm{S}$ ranges (specified as green rectangles in the figures) that have facilitated the data

1530 description without having any consequences on the results and understanding. That said, one or even two components were missed by three out of four legs (Fig.2c), and we had to merge together data collected $\sim 12 \mathrm{~h}$ apart. In addition, three legs did not reach the edges of the MO, which has prevented sampling, in particular, the orange water during Leg 1 and the blue water during Leg 3.

Overall, one can consider that, the MO being markedly heterogeneous and formed by a set of different components juxtaposed side by side on the horizontal, sampling it with vertical profiles has not been the most efficient strategy. Now that these general features have been established, definitive information about the structure of these components and their interface layers can be obtained in a definitive and efficient manner with 
Ocean Sci. Discuss., https://doi.org/10.5194/os-2017-54

Manuscript under review for journal Ocean Sci.

Discussion started: 1 August 2017

(c) Author(s) 2017. CC BY 4.0 License.

basic ideas and common instrumentation. Sampling must be as fine as possible and cover the whole MO, with transects in between isobaths of 200-250 m on the southern and northern slopes. It must be as rapid as possible, which implies, essentially, focusing on the MO itself, hence avoiding the unnecessary sampling of the AWs in the upper depths range. Bias must be avoided as much as possible, so that closest data must be collected in the shortest possible period of time, the problem to be addressed being of soundly putting together data collected in this or that part of the MO, not of comparing its left-hand side with its right-hand one. Along such transects (in the $\mathrm{x}$ direction and over depth $\mathrm{z}$ ), information must come, at a series of given $\mathrm{x}_{\mathrm{i}}$, from measurements over $\mathrm{z}$ of basic parameters as well as any other ones (chemical and radiological).

Within the $12 \mathrm{~h}$ needed to perform the four legs of the cross-MO transect, we claim that a single twofold transect would certainly provide much valuable and even definitive results about the MO structure. A first transect should be performed with a CTD continuously towed at 10-20 m above the bottom all across the Strait between the $\sim 250 \mathrm{~m}$ isobaths; this transect would evidence for sure all MO components present there as well as the thin interface layers. For such a transect, a necessary additional equipment must be a pinger, or any device allowing the definition in real time of the height of the CTD above the bottom so as to be sure about sampling, at a given altitude, a relatively dense part of each of the MO components. On the way back, and on the basis of the information collected just before, a two-yo transect should be performed still focusing on the MO itself, and even on specific portions of it. Ideally, for both the data analysis as well as for, eventually, focusing on this or that feature that would justify sampling it again, the CTD should be accurately 3-D positioned with a ship-mounted acoustic base and, obviously, lowering and rising of the CTD should be performed with a sampling interval as short as possible (few hundredths of $\mathrm{m}$ ), ship maneuverability permitting. 
Ocean Sci. Discuss., https://doi.org/10.5194/os-2017-54

Manuscript under review for journal Ocean Sci.
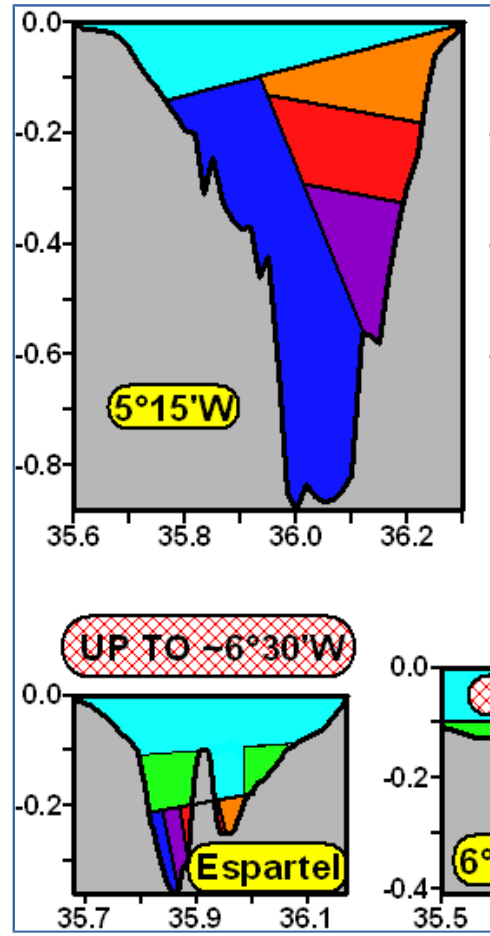
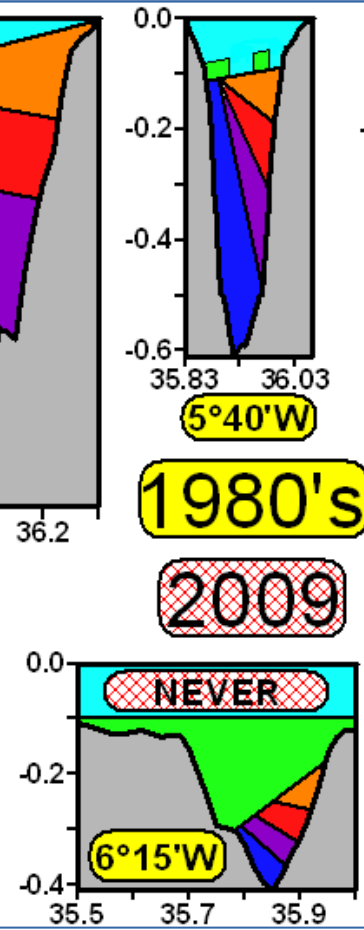
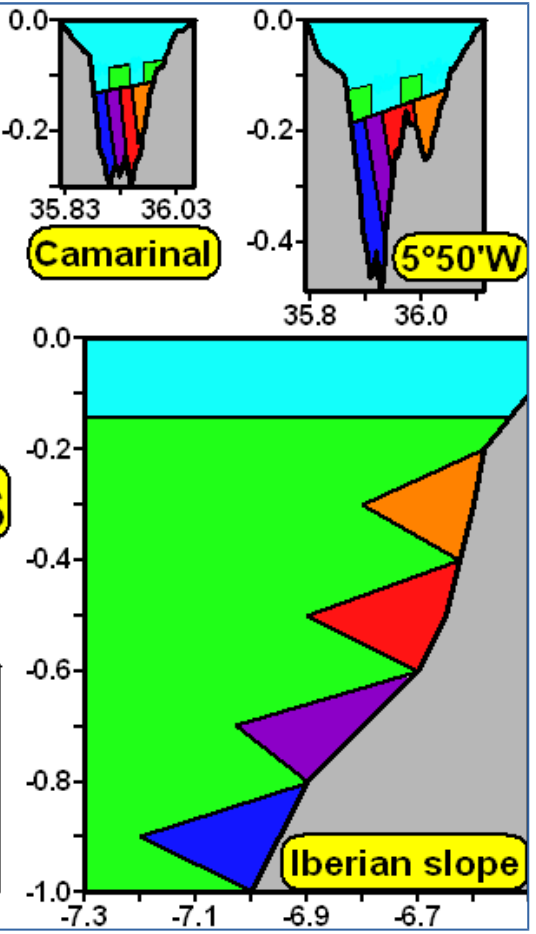

1565

(cyan) and NACW (as well as deeper ones, green), and of the MWs, initially three light circulating IWs (orange, red, violet) and one dense sluggish DW (blue), from the Alboran sub-basin $\left(5^{\circ} 15^{\prime} \mathrm{W}\right)$ through the Strait and along the Iberian slope. Colors used in our 2014a paper slightly differ from those used in Part 1: violet is used in this figure for an IW while it is used in Part 1 for a DW; and pink used in Part 1 for an IW (out of 5 MWs) is not used in this figure (only $4 \mathrm{MWs).} \mathrm{In} \mathrm{any} \mathrm{event,} \mathrm{it} \mathrm{is} \mathrm{not} \mathrm{the} \mathrm{purpose} \mathrm{of} \mathrm{this} \mathrm{trilogy} \mathrm{to} \mathrm{link} \mathrm{colors} \mathrm{and} \mathrm{MWs} \mathrm{even}$ though, in our mind only and in particular at the Strait exit, WIW, EIW, EDW and WDW could be orange, red, violet and blue, resp.. Note that major changes in such a schematization must be considered in the Strait western side and at the Strait exit between the 1980's and the late 2000's.

We have explained at the beginning of the Introduction why we never (since the mid 1980's at least) shared the hypothesis of a homogeneous MO, we started specifying our ideas about the Strait functioning in the diagrams about the circulation in the Sea we continuously improved (from Millot (1987) till Millot and Taupier-Letage (2005)), we published our first measurements in the Strait and our leading ideas in Millot et al. (2006) and, after a series of papers dedicated to the Strait, we synthesized our own understanding with a diagram (Fig.31 of Millot (2014a)) extrapolated here as Fig.19. 
Ocean Sci. Discuss., https://doi.org/10.5194/os-2017-54

Manuscript under review for journal Ocean Sci.

Discussion started: 1 August 2017

(c) Author(s) 2017. CC BY 4.0 License.

The Mediterranean Waters (MWs) formed in the north of this or that sub-basin of this or that basin of the Sea must exit the Sea through the Strait. In the western part of the Alboran $\left(5^{\circ} 15^{\prime} \mathrm{W}\right.$ to $5^{\circ} 40^{\prime} \mathrm{W}$ in Fig. 19), one must differentiate intermediate waters (IWs) that circulate along the European continental slope anticlockwise, due to the Coriolis effect, from deep waters (DWs) that are essentially trapped, hence circulating only sluggishly, in the western basin. Because IWs thus accumulate along the European slope before outflowing through the Strait, DWs are forced to overflow (not outflow, and no need for any suction effect for that) along the African slope, thus directly interacting there with the Atlantic Waters (AWs) that are inflowing over the African shelf and slope, also due to the Coriolis effect. The first direct consequence of such a tremendous role played by the Coriolis effect (at least in our own understanding) is that even the lightest of the IWs mix less intensively with the AWs than the densest of the DWs do.

At the Strait entrance (e.g. $\left.5^{\circ} 43^{\prime} \mathrm{W}\right)$ that is slightly but significantly east from the Camarinal sills $\left(5^{\circ} 45^{\prime} \mathrm{W}\right)$ and their intense mixing processes, the stratification of the MWs is somehow intermediate between those proposed for $5^{\circ} 40^{\prime} \mathrm{W}$ and Camarinal in Fig.19. It is still mainly horizontal and slightly vertical, with DWs (resp. IWs) being found more in the south (resp. north), but the specificity there is that this stratification has dramatically increased, as compared to most of the Alboran even at $5^{\circ} 40^{\prime} \mathrm{W}$. We have shown in Part 1 numerous amazing examples of the mixing processes that concern all the MWs down to several $100 \mathrm{~s} \mathrm{~m}$ and that clearly account for the transformation of $\mathbf{S}_{\mathrm{q}}$ profiles that are relatively smooth in most of the Sea into markedly stepped ones in the western Alboran $\left(5^{\circ} 40^{\prime} \mathrm{W}\right)$ and at the Strait entrance $\left(5^{\circ} 43^{\prime} \mathrm{W}\right)$.

Even though we do lack adequate simulations of the changes that the MO layering is encountering in the Camarinal surroundings, essentially due to the Coriolis effect we think, we still rely on the schematization we proposed for Camarinal in Fig.19. There, the section offered to the MO reduces, so that the velocities of the IWs must intensify to maintain the fluxes, which lead them to deepen, up to occupying the whole northern part of the Strait, hence rejecting the DWs in the whole southern part of it. The MWs that are superimposed at the Strait entrance thus come to be juxtaposed side by side as soon as Camarinal, with a stratification in density that has dramatically and rapidly evolved from vertical to horizontal. That said, and having shown with just a plot of 49 $\mathbf{S}_{\max }$ values collected in the mid-1980's (Fig.4, Part 1) that the MWs at the Strait entrance could be separated in a

1610 set of four-five relatively homogeneous and mostly superimposed layers, it is clear that each of these swung layers then mix independently and directly with the specific AW inflowing over them, hence leading to q-S diagrams being almost straight mixing lines within the Strait itself downstream to, at least in the late 2000's, the Strait exit.

1615 Now, while they progress along the Strait (Camarinal to Espartel in Fig.19), the MWs mix with AWs that are less and less mixed together and, especially in the western side of the Strait (Fig.3, 4), the North Atlantic Central Water (NACW) can be more and more clearly identified at $\sim 300 \mathrm{~m}$ along the African slope, still due to the Coriolis effect, and separated from the much widely distributed and seasonally variable Surface Atlantic Water (SAW). A direct consequence illustrated in Part 2 and by all q-S diagrams herein is that the densest (resp. 
Ocean Sci. Discuss., https://doi.org/10.5194/os-2017-54

Manuscript under review for journal Ocean Sci.

Discussion started: 1 August 2017

(c) Author(s) 2017. CC BY 4.0 License.

lightest) MWs tend to mix more with the relatively dense (resp. light) NACW (resp. SAW). Therefore, and necessarily, the mixing of a set of MWs, characterized by some original DsM at the Strait entrance, with this specific set and location of AWs within the Strait, will lead the MO to be characterized by some final DsO>DsM at the Strait exit, when the MO enters the Ocean.

In its western part (Espartel and $6^{\circ} 15^{\prime} \mathrm{W}$ in Fig.19), the Strait widens, the IWs slacken and are less efficient in pushing away the DWs; furthermore the latter now tend to accelerate due to gravity and are thus submitted to an increased Coriolis effect, all MWs tends to accumulate, one above the other, along the northern continental slope. This is the situation schematized for $6^{\circ} 15^{\prime} \mathrm{W}$ in the $1980^{\prime}$ s that was not observed yet at $6^{\circ} 30^{\prime} \mathrm{W}$ in 2009 . Downstream, after the MO has split into veins clearly superimposed (as schematized along the Iberian slope in Fig.19), the lightest (resp. densest) of them will sink through, circulate within and thus mix with relatively light (resp. dense) oceanic waters.

\subsection{The density range of the MO}

At the Strait entrance, the largest densities are encountered in the south and they are often associated there with $100-200-\mathrm{m}$ homogeneous layers; as shown by the yo-yo time series at $5^{\circ} 43^{\prime} \mathrm{W}$, the blue water was associated in the mid-1980's with $\mathbf{S}_{\max }>29.095 \mathrm{~kg} . \mathrm{m}^{-3}$. The lowest densities are encountered in the north sometimes associated with thick layers ( $>80 \mathrm{~m}, \# 5$ of the $5^{\circ} 40^{\prime} \mathrm{W}$ transect); at these times, the orange water was commonly characterized by $\mathbf{S}_{\max }=29.02 \mathrm{~kg} \cdot \mathrm{m}^{-3}$, which makes a DsM of $\sim 0.075 \mathrm{~kg} \cdot \mathrm{m}^{-3}$.

Now, in the western part of the Strait and at the Strait exit during e.g. the first regional survey of the MO-2009 experiment, the densest blue component was found at \#5 (Transect-1) with $\mathbf{S}_{\max }=28.96 \mathrm{~kg} \cdot \mathrm{m}^{-3}$ while the $\mathbf{S}_{\max }$ associated with the lightest orange component was $28.33 \mathrm{~kg} . \mathrm{m}^{-3}$ at \#19 (Transect-2) and $28.26 \mathrm{~kg} . \mathrm{m}^{-3}$ at \#25 (Transect-3), which makes a DsO of $\sim 0.7 \mathrm{~kg} \cdot \mathrm{m}^{-3}$.

Even though the data sets at the entrance and the exit of the Strait are not simultaneous and we are unable to follow the evolution along the Strait of the lightest and densest components of the MO, the MO-2009 demonstrates that the MO is characterized by a very large density range there. Such a $0.7 \mathrm{~kg} . \mathrm{m}^{-3}$ range is even larger that the $0.55 \mathrm{~kg} . \mathrm{m}^{-3}$ range evidenced, from data in the early 2000's, for the veins in the Cape St Vincent surroundings according to Ambar et al. (2008). Furthermore we have evidenced that at least the lightest (orange) component starts to be split as soon as Camarinal sills and all components at the Strait exit could be separated by interface layers while continuously spreading from left to right (as shown for the blue component), it is clear that the vertical layering observed at the entrance (over a relatively small $\mathrm{S}_{\mathrm{q}}$ range) has swung at the exit (over a relatively large $S_{q}$ range) into a horizontal layering that will naturally lead to the formation of independent veins cascading and then spreading in the Ocean at their own levels of equilibrium, without any necessity for any kind of truncation by bathymetric features. 
Ocean Sci. Discuss., https://doi.org/10.5194/os-2017-54

Manuscript under review for journal Ocean Sci.

Discussion started: 1 August 2017

(c) Author(s) 2017. CC BY 4.0 License.

\subsection{The 1980 's vs. 2009 overall characteristics}

1660

That said, all q-S diagrams from the MO-2009 experiment (till $\sim 6^{\circ} 30^{\prime} \mathrm{W}$ ) are, at the level of the MO (essentially for $\mathrm{S}>37.8$, Fig.17e), straight mixing lines between a given MW and a given AW, which is in fact observed all along the Strait upstream, as soon as $5^{\circ} 50^{\prime} \mathrm{W}$ that is just west of the Camarinal sills. According to tour own analysis of the GIBEX data (Millot, 2014a), such a situation of MWs juxtaposed side by side corresponds to the schematization we proposed for $5^{\circ} 50^{\prime} \mathrm{W}$ till Espartel $\left(5^{\circ} 58.5^{\prime} \mathrm{W}\right.$, Fig. 19). Downstream, but still in the western side of the Strait near $6^{\circ} 15^{\prime} \mathrm{W}\left(6^{\circ} 12^{\prime} \mathrm{W}-6^{\circ} 18^{\prime} \mathrm{W}\right.$, light gray profiles in Fig. 17e), the 1985-1986 GIBEX q-S diagrams at the MO level were no more straight, as they were since Camarinal, but sinuous. We hypothesized that, because the Strait is more and more widening there, the lightest components less and less constrain the densest ones in the southern side of the Strait; the latter, still due to the Coriolis effect, are then progressively forced to move toward the middle of the Strait and then on its northern side: we thus proposed for $6^{\circ} 15^{\prime} \mathrm{W}$ a schematization that evidences the natural re-superimposition on the MO components.

Now, $6^{\circ} 15^{\prime} \mathrm{W}\left(6.25^{\circ} \mathrm{W}\right.$ in Fig. 18) is clearly in the east of the MO-2009 studied area where, in 2009 and from $6^{\circ} 12^{\prime} \mathrm{W}$ till $6^{\circ} 30^{\prime} \mathrm{W}$, all q-S diagrams were still straight mixing lines at the MO level. Note that the q-S GIBEX diagrams in Fig. $17 \mathrm{e}$ were collected at $6^{\circ} 12^{\prime} \mathrm{W}$ and should thus be compared with the q-S MO-2009 diagrams at the same longitude $\left(6^{\circ} 20^{\prime} \mathrm{W}\right.$ in Fig. 18) that are shown in Fig. 17a: 2009 diagrams (\#1-7 and \#803-811) are much more straight than in 1985-1986. It is clear that the MO was markedly split on the vertical at and downstream from $6^{\circ} 15^{\prime} \mathrm{W}$ in the $1980^{\prime}$ s while it was not split yet on the vertical at $\sim 6^{\circ} 30^{\prime} \mathrm{W}$ in 2009 . It might be that the MO hydrological changes we evidenced at the Strait entrance (Millot et al., 2006) between the mid-1980' and the early 2000 's, probably associated with dynamical changes there, have had dramatic hydrological and dynamical consequences in the western side of the Strait and at the Strait exit.

Some of the main data sets analyzed in Parts 1 (GIBEX-5 $5^{\circ} 43^{\prime} \mathrm{W}$, HYDROCHANGES-5 $5^{\circ} 45^{\prime} \mathrm{W}$ and $\left.5^{\circ} 58.5^{\prime} \mathrm{W}\right), 2$ (GIBEX- $6^{\circ} 05^{\prime} \mathrm{W}$ ) and 3 (MO-2009, GIBEX- $6^{\circ} 15^{\prime} \mathrm{W}$ ) are represented all together in Fig.20. Comparisons between GIBEX $-5^{\circ} 43^{\prime} \mathrm{W}$ and $\mathrm{HC}-5^{\circ} 45^{\prime} \mathrm{W}$ illustrate the dramatic changes evidenced by Millot et al. (2006) at the Strait entrance between the mid-1980's and the mid-2000's. Comparisons between GIBEX-6 ${ }^{\circ} 15^{\prime} \mathrm{W}$ and MO-2009 show that these changes have been maybe more dramatic at the Strait exit. In any event, the three sets of GIBEX plots (vertical CTD profiles) and the two sets of HYDROCHANGES plots (CTD time series) clearly show that the marked horizontal heterogeneity of the MO we have evidenced herein at the Strait exit is perfectly consistent with the horizontal heterogeneity of the MO within the Strait as well as with the vertical heterogeneity at the Strait entrance and in the westernmost part of the Mediterranean Sea. 
Ocean Sci. Discuss., https://doi.org/10.5194/os-2017-54

Manuscript under review for journal Ocean Sci.

Discussion started: 1 August 2017

(C) Author(s) 2017. CC BY 4.0 License.

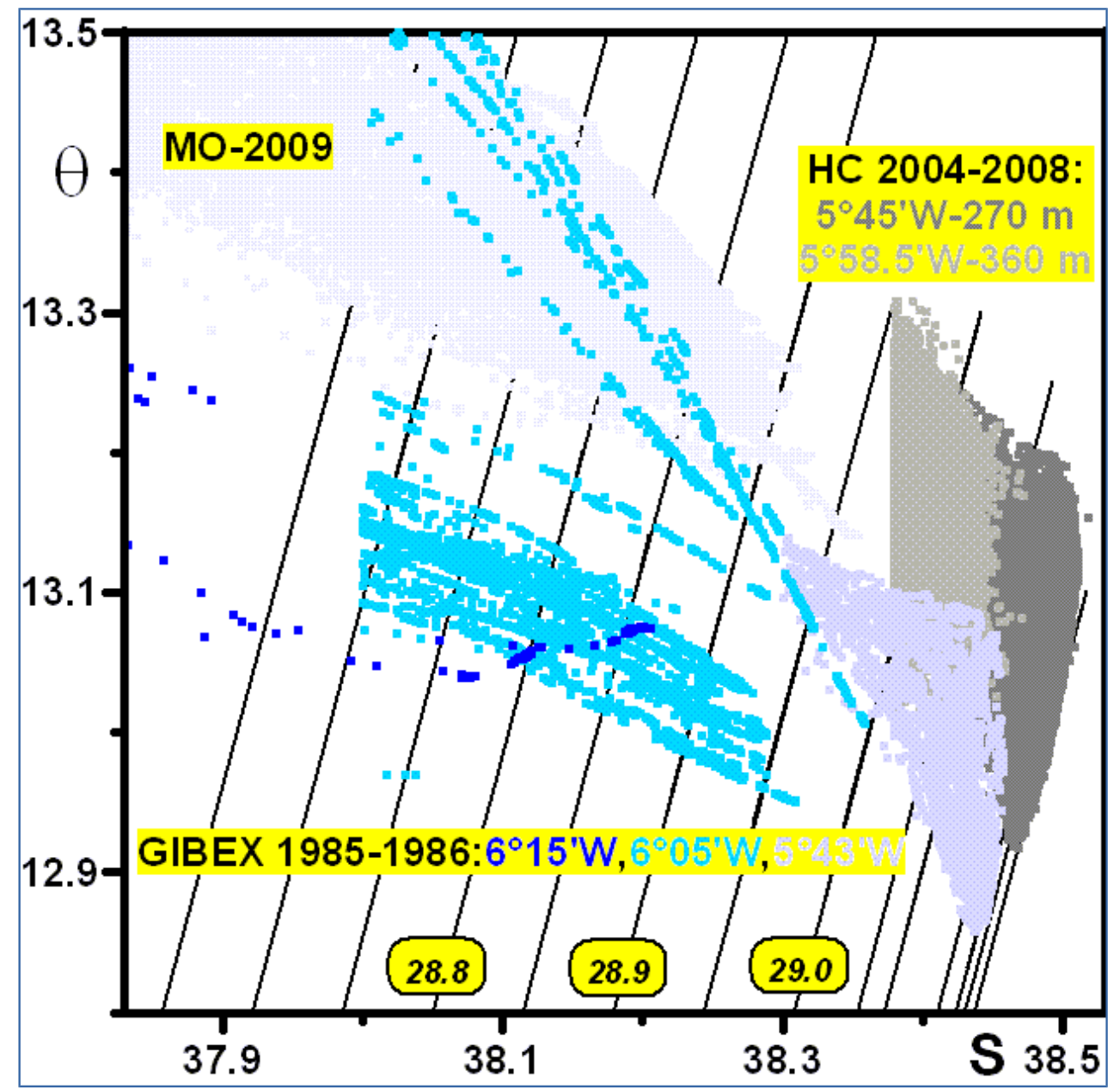

Figure 20. Some of the 1985-1986 GIBEX data sets are plotted in light blue (the yo-yo time series at $5^{\circ} 43^{\prime} \mathrm{W}$, truncated for $\mathrm{S}<38.3$ ), medium blue (the yo-yo time series at $6^{\circ} 05^{\prime} \mathrm{W}$, truncated for $\mathrm{S}<38.0$ ) and dark blue (between $6^{\circ} 12^{\prime} \mathrm{W}$ and $6^{\circ} 18^{\prime} \mathrm{W}$ ). The 2004-2008 HYDROCHANGES time series truncated for $\mathrm{S}<38.38$ are

plotted in dark gray $\left(5^{\circ} 45^{\prime} \mathrm{W}\right.$, Camarinal southern sill $)$ and medium gray $\left(5^{\circ} 58.5^{\prime} \mathrm{W}\right.$, Espartel southern sill). All MO-2009 data are plotted in light gray.

We thus just need adequate numerical simulations explaining i) why stratification increases just at the Strait entrance, as compared to the whole Sea and most of the Alboran sub-basin in particular, possibly due to the isopycnals slope (as schematized in Fig.19) and ii) why stratification of the MWs swing from vertical to horizontal when the lightest of them outflow through the Strait in the north, due to the Coriolis effect, and lead the densest to overflow in the south. 
Ocean Sci. Discuss., https://doi.org/10.5194/os-2017-54

Manuscript under review for journal Ocean Sci.

Discussion started: 1 August 2017

(c) Author(s) 2017. CC BY 4.0 License.

\section{Conclusion}

In Part 1, we have first argued for the fact that GIBEX CTD profiles collected within the Strait in the mid-1980's (data available via MEDAR Group (2002)), and in particular at $6^{\circ} 05^{\prime} \mathrm{W}$ in its western side, display straight mixing lines that are not converging while evidencing near the bottom markedly different $\mathrm{q}-\mathrm{S}-\mathrm{S}_{\mathrm{q}}$ sets. This allowed us to definitively demonstrate that the MO has always been markedly heterogeneous, there and upstream, thus contradicting what has been hypothesized by most (not all, e.g. Howe et al., 1974) studies that have considered the whole Strait, and is still hypothesized in actual studies about the Strait entrance (e.g. Naranjo et al. (2015) and Garcia-Lafuente et al. (2017)).

Having finally demonstrated what we had always hypothesized since our schematic diagrams of the circulation within the Sea improved from Millot (1987) to Millot and Taupier-Letage (2005), and have tried supporting in a series of papers dedicated to the Strait, from Millot et al.(2006) to Millot (2014a), we have stopped the reanalysis of the MO-2009 data set we were doing and have looked for additional data sets available upstream. We found an extremely valuable GIBEX 1-day yo-yo time series at the Strait entrance $\left(5^{\circ} 43^{\prime} \mathrm{W}\right.$, i.e. significantly upstream from the Camarinal sills at $5^{\circ} 45^{\prime} \mathrm{W}$ ) that has seemingly never been analyzed previously. In a fully objective way, this yo-yo time series of 49 profiles allows demonstrating that five layers of relatively homogeneous Mediterranean Waters (MWs) can be identified at the Strait entrance and over depths of $\sim 300 \mathrm{~m}$ or even more. Even though we personally think being able to identify each of these MWs, and with the major aim of being as objective as possible, furthermore considering what we said in Millot (2013,2014b), we decided to mainly deal with colored waters and no more with water names. One major result from Part 1 is that these five MWs at the Strait entrance are essentially superimposed and slightly inclined (the densest more to the south) as we have always hypothesized. But another major result that we did not foreseen is that these MWs are more layered than anywhere else in the Sea, and that these profiles provide amazing examples of the tremendous instabilities and mixing processes that are occurring within each of the layers.

In Part 2, we have first re-analyzed all GIBEX transects collected during five campaigns at both $5^{\circ} 50^{\prime} \mathrm{W}$ and $6^{\circ} 05^{\prime} \mathrm{W}$ that we previously analyzed, now focusing on the lowest part of the profiles. Even though very coarse and not long enough, all transects evidence, close to the bottom, different and more or less homogeneous q-S-S $q$ sets that confirm the marked heterogeneity of the MO, there on the horizontal with the densest (resp. lightest) MWs on its left-hand (resp. right-hand) side, that is complexified by the tremendous variability of the Atlantic Waters (AWs) already evidenced by Millot (2008). We also showed that the lightest MW can be easily identified along the European continental slope over depths of $\sim 150 \mathrm{~m}$ at $5^{\circ} 50^{\prime} \mathrm{W}$ down to $\sim 320 \mathrm{~m}$ at $6^{\circ} 05^{\prime} \mathrm{W}$, clearly demonstrating that the lightest component of the $\mathrm{MO}$ has been split as soon as the Camarinal sills, sinking by as much as $\sim 170 \mathrm{~m}$ within the Strait. These transects are too coarse for evidencing all MWs, be they five or four, so that we have generally avoided dealing with colors there. $6^{\circ} 05^{\prime} \mathrm{W}$ that clearly shows the succession of three different q-S-S $\mathrm{q}$ sets evidencing a significant meandering of 
Ocean Sci. Discuss., https://doi.org/10.5194/os-2017-54

Manuscript under review for journal Ocean Sci.

Discussion started: 1 August 2017

(c) Author(s) 2017. CC BY 4.0 License.

the MO. Following Millot (2014a), we have tried establishing relationships between the data sets at $6^{\circ} 05^{\prime} \mathrm{W}$ and $5^{\circ} 43^{\prime} \mathrm{W}$ and have found sound arguments confirming the reliability of the mixing line slopes: a classification based on characteristics inferred upstream could be even more significant than the classification from local characteristics.

In Part 3, we have analyzed the CTD profiles from the MO-2009 Experiment kindly made available to us with an approach as objective as possible. From a cross-MO tow-yo transect composed of four legs performed with a relatively small sampling interval of $\sim 1 \mathrm{~km}$, we first show that four MO components can be identified, still with the lightest (resp. densest) component on the right- (resp. left-) hand side of the MO. We colored them, for convenience without any scientific implication, according to the location of the q-S-S $\mathrm{s}_{\max }$ sets in a q-S diagram wit respect to four rectangular zones. We then analyzed the two along-MO transects, the five yo-yo time series and the two regional surveys performed between $6^{\circ} 12^{\prime} \mathrm{W}$ and $6^{\circ} 30^{\prime} \mathrm{W}$ (all data plotted in Fig.20) in a way that,

1755 even if not initially dedicated to descriptive oceanography, appears relatively efficient in this respect.

We have first demonstrated that the four components were retrieved during the whole experiment (adequate sampling permitting), continuously meandering more or less intensively but sometimes tremendously, and that even strange profiles considered alone (as collected with a coarse sampling) were in fact in continuity with neighbors. As we previously noticed (e.g. Millot, 2014a), the densest MO component clearly flows, in the western side of the Strait along the southern continental slope, progressively moving towards the middle of the Strait and finally along the northern continental slope at the Strait exit. The lightest MO component is, as expected, found over the upper part of the northern continental slope, but with an amount that is much larger than we personally expected ... and that nobody else (except Howe et al. (1974), Gascard and Richez (1985) and

1765 us) has even been expecting within the Strait itself. In any event, the regional surveys have allowed following the sinking over the slope from the western side of the Strait to the Strait exit of, at least, this lightest component. Last but not least, we demonstrate from some sets of CTD data that the MO components are separated, at the Strait exit at least, by relatively thin interface layers that are markedly more AWs than MWs.

Even though our demonstrations are undoubtedly reliable, we still lack of a data set that could be entirely plotted in a simple way to definitely illustrate the MO heterogeneity at the Strait exit ... as everywhere all along the Strait. This is why we recommend performing, with a single CTD first towed at some tens $\mathrm{m}$ above the bottom once all across the Strait, then tow-yoed with a sampling interval as small as possible (few hundredths of m, ship maneuverability permitting) to sample the sole MO down to the bottom once all across the Strait back. Such measurements that will provide definitive information about the MO structure could be performed within just half a day or so, hence easily repeated at least during a couple of days; would the CTD be accurately positioned with a ship-mounted acoustic base, sampling of specific features such as the interface layers could be made in a way as efficient as possible. One could also think deploying autonomous profiling devices or much cheaper and simple autonomous CTDs moored close to the bottom (as in the HYDROCHANGES program) with enlarged batteries and extended memories to allow a relatively short sampling interval. 
Ocean Sci. Discuss., https://doi.org/10.5194/os-2017-54

Manuscript under review for journal Ocean Sci.

Discussion started: 1 August 2017

(c) Author(s) 2017. CC BY 4.0 License.

As for the numerical simulations required to provide a definitive understanding of the MO heterogeneity, one should first address the problem of the layering at the Strait entrance: are isopycnals slopes of a few \% able to layer a continuously stratified set of waters? Numerical simulations are also required to address the role of the Coriolis effect in swinging the stratification of the given set of MWs from vertical, in the Sea, to horizontal in the Strait where individual mixing with a set of AWs should be made possible. At the Strait exit, the reverse problem should be addressed in clearly specifying the role of the bathymetry, though determinant in all previous works while we consider it only plays a minor role, as compared to that of the sole Coriolis effect, for what concerns the splitting of a series of MO components juxtaposed side by side till the Strait exit into a series of superimposed veins along the Iberian continental slope as schematized in Fig.19.

Data availability. Free and easy access of the GIBEX data to everybody via the four MEDAR/MEDATLAS CD's. HYDROCHANGE data available upon request. MO-2009 data are property of J.L. Pelegri.

Team list. C. Millot is retired and works alone. M. Emelianov belongs to a team but essentially intervened alone.

Authors contributions. M. Emelianov participated in the MO-2009 experiment, he introduced C. Millot to J.L. Pelegri, he prepared .xls files that C. Millot could process and he made the ODV plots.

Competing Interests. The authors declare they have no conflict of interest.

Acknowledgments. We warmly and sincerely thank Prof. J.L. Pelegri, the leader of the team of the Institut de Ciènces del Mar from Barcelona (Spain) who conducted the MO-2009 experiment, for having made the CTD data available to us without any request, Dr. Ballabrera-Poy and M. Gasser for their help in some data files processing and $\mathrm{H}$. Peters for having provided us with the LADCP data. C. Millot did not receive any specific grant from funding agencies in the public, commercial, or not-for-profit sectors. M. Emelianov was supported by the Spanish Ministerio de Ciencia e Innovación, grants CTM2008-06438-C02-01, CTM2008-03422-E/MAR and CTM2011-30010-C02-01-MAR.

\section{References}

Ambar, I., Serra, N., Neves, F., and Ferreira, T.: Observations of the Mediterranean Undercurrent and eddies in the Gulf of Cadiz during 2001. J. Mar. Sys., 71, 195-220, doi:10.1016/j.jmarsys.2007.07.003, 2008.

Baringer, M., and Price, J.: Mixing and spreading of the Mediterranean Outflow. J. Phys. Oceanogr. 27, 1654$1677,1997 \mathrm{a}$.

1815 Baringer, M., and Price, J.: Momentum and energy balance of the Mediterranean Outflow. J. Phys. Oceanogr., 27, 1678-1692, 1997b.

Béthoux, J. P., Gentili, B., Raunet, J., and Tailliez, D.: Warming trend in the western Mediterranean deep water, Nature, 347, 660-662, 1990.

CIESM group: Mediterranean Water Masses acronyms. Round table session of the $36^{\text {th }}$ CIESM Congress, Monte 
Ocean Sci. Discuss., https://doi.org/10.5194/os-2017-54

Manuscript under review for journal Ocean Sci.

Discussion started: 1 August 2017

(c) Author(s) 2017. CC BY 4.0 License.

CIESM group: Tracking long term hydrological change in the Mediterranean Sea. Workshop Series $n^{\circ} 16$ edited by C. Millot and F. Briand, 134 p, 2002.

Garcia-Lafuente, J., Naranjo, C., Sammartino, S., Sanchez-Garrido, J., and Delgado, J.: The Mediterranean outflow in the Strait of Gibraltar and its connection with upstream conditions in the Alboran Sea, Ocean Sci., 13, 195-207. doi:10.5194/os-13-195-2017, 2017.

Gascard, J.C., and Richez, C.: Water masses and circulation in the western Alboran Sea and in the Straits of Gibraltar. Prog. Oceanogr. 15: 157-216, 1985.

Gasser, M., Pelegrí, J.L., Nash, J.D., Peters, H., and García-Lafuente, J.: Topographic control on the nascent Mediterranean outflow. Geo Mar. Lett., 31, 301-314. doi:10.1007/s00367-011-0255-x, 2011.

1830 Gasser, M., Pelegri, J.L., Emelianov, M., Bruno, M., Chioua, J., Garcia, E., Nash, J.D., Pastor, M., Peters, H., Rodriguez-Santana, A., and Salvador, J., 2017. Tracking the Mediterranean outflow in the Gulf of Cadiz. Prog. Oceanogr., in press, http://dx.doi.org/10.1016/j.pocean.2017.05.015..

Howe, M., Abdullah, M., and Deetea, S.: An interpretation of the double T-S maxima in the Mediterranean outflow using chemical tracers. J. Mar. Res., 32, 3, 377-383, 1974.

MEDAR group: MEDATLAS/2002 database. Mediterranean and Black Sea database of temperature salinity and bio-chemical parameters. Climatological Atlas. IFREMER Edition (4 CDroms), 2002.

Millot, C.: Circulation in the Western Mediterranean Sea. Oceanol. Acta, 10, 2, 143-149, 1987.

Millot, C.: Interannual salinification of the Mediterranean inflow. Geophysical Research Letters, 34, L21069, doi:10.1029/2007/GL031179, 2007.

1840 Millot, C.: Short-term variability of the Mediterranean in- and out-flows. Geophys. Res. Let., 35, L15603. doi:10.1029/2008/GL033762, 2008.

Millot, C.: Another description of the Mediterranean Sea outflow. Progr. Oceanogr., vol. 82, iss. 2, 101-124. doi:10.1016/j.pocean.2009.04.016, 2009.

Millot, C.: Levantine Intermediate Water characteristics: an astounding general misunderstanding! Scientia

1845 Marina 77(2), 217-232. doi:10.3989/scimar.03518.13A, 2013.

Millot, C.: The Mediterranean Sea in- and out-flows' heterogeneities. Progr. Oceanogr., 120, 254-278.

doi.org/10.1016/j.pocean.2013.09.007, 2014a.

Millot, C.: Levantine Intermediate Water characteristics: an astounding general misunderstanding! (addendum). Scientia Marina 78(2), 165-171. doi:10.3989/scimar.04045.30H, 2014b.

1850 Millot, C. and Briand, F.: Executive summary. In "Tracking long term hydrological change in the Mediterranean Sea", 7-14 (CIESM Workshop Series n 16), http://www.ciesm.org/online/monographs/Monaco02.html, 2002.

Millot, C., and Taupier-Letage, I.: Circulation in the Mediterranean Sea, in The Handbook of Environmental Chemistry, Vol.5: Water Pollution, Part K, pp. 29-66, Springer-Verlag, Berlin-Heidelberg, doi: 10.1007/b107143, 2005.

1855 Millot, C., Candela, J., Fuda, J.L., and Tber, Y.: Large warming and salinification of the Mediterranean outflow due to changes in its composition. Deep-Sea Res., 53/4, 656-666. doi:10.1016/j.dsr.2005.12.017, 2006.

Millot, C., and Garcia-Lafuente, J.: The seasonal and fortnightly variability of the Mediterranean outflow. Ocean Sciences, 7, 1-8, doi:10.5194/os-7-1-2011, 2011. 
Ocean Sci. Discuss., https://doi.org/10.5194/os-2017-54

Manuscript under review for journal Ocean Sci.

Discussion started: 1 August 2017

(c) Author(s) 2017. CC BY 4.0 License.

Ocean Science

Discussions

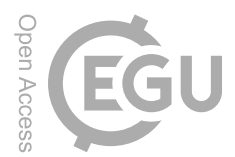

(c) (i)

Naranjo, C., Sammartino, S., Garcia-Lafuente, J., Bellanco, M., and Taupier-Letage, I.: Mediterranean waters

1860 along and across the Strait of Gibraltar, characterization and zonal modification. Deep-Sea Res., I, 105, 41-52. http://dx.doi.org/10.1016/j.dsr.2015.08.003, 2015.

Nash, J., Peters, H., Kelly, S., Pelegri, J., Emelianov, M., and Gasser, M.: Turbulence and high-frequency

variability in a deep gravity current outflow. Geophys. Res. Let., 39, L18611. doi:10.1029/2012GL052899, 2012.

Schlitzer, R.: Ocean Data View, http://odv.awi.de, 2014.

1865 